\title{
Social organisation and mating system of the fosa (Cryptoprocta ferox)
}

\author{
Dissertation \\ zur Erlangung des mathematisch-naturwissenschaftlichen Doktorgrades \\ „Doctor rerum naturalium“ \\ der Georg-August-Universität Göttingen
}

vorgelegt von

Mia-Lana Lührs

aus

Gehrden 
Referent: Prof. Dr. Peter M. Kappeler

Korreferent: Prof. Dr. Eckhard W. Heymann

Tag der mündlichen Prüfung: 16. Juli 2012 
To my home Hamelspringe.

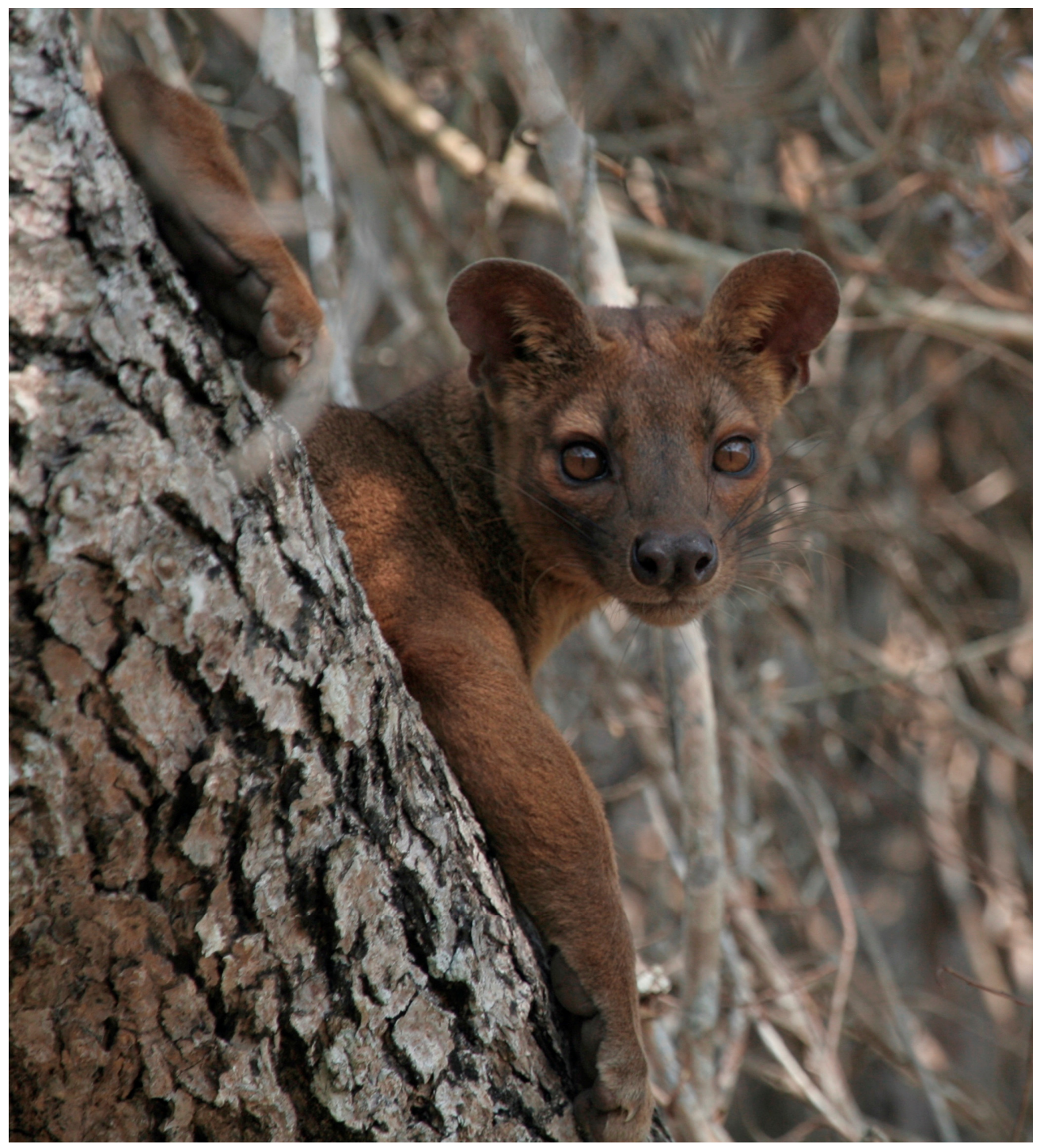





\section{CONTENTS}

GENERAL INTRODUCTION

\section{CHAPTER 1}

Simultaneous GPS-tracking reveals male associations in a solitary carnivore with Peter M. Kappeler

Under review in Behavioral Ecology and Sociobiology

\section{CHAPTER 2}

An unusual case of cooperative hunting in a solitary carnivore with Melanie Dammhahn Journal of Ethology (2010) 28: 379-383

\section{CHAPTER 3}

Strength in numbers: males in a carnivore grow bigger when they associate and hunt cooperatively

with Melanie Dammhahn and Peter M. Kappeler

Revised manuscript for publication in Behavioral Ecology

\section{CHAPTER 4}

Polyandry in treetops: how male competition and female choice interact to determine an unusual mating system in a carnivore with Peter M. Kappeler

GenERAL DisCussion

REFERENCES

APPENDIX

ACKNOWLEDGMENTS 



\section{General Introduction}

The study of social systems is one of the most insightful fields of behavioural biology because it offers the opportunity to investigate the interaction of a species' ecology, life-history, space-use and reproductive strategies as a whole and thereby meets a behavioural biologist's innate interest in understanding the diversity of nature. In particular, studying species that evolved unique solutions to evolutionary problems, which appear to contradict predictions of classical theory, is instructive because it allows putting current theory to a test and stimulates the development of new hypotheses. Madagascar's largest extant carnivore, the fosa (Cryptoprocta ferox), represents one such case where indications of facultative male sociality and excessive promiscuous mating on traditional trees lacked detailed investigation of their socio-ecological determinants and challenged hypotheses about the incentives of polyandry. In this thesis, I therefore studied the social organisation and mating system of this species in detail and aimed to contribute to the understanding of a unique mammalian social system. In the following, I will briefly describe basic entities and diversity of social systems, focussing on mammals and carnivorans in particular, and derive specific questions of this thesis.

\section{Social organisation: the basic element of social systems}

According to Kappeler \& van Schaik (2002), social systems comprise three different elements: social organisation, mating system and social structure. These three categories require adequate distinction because they can be shaped by distinct selective forces despite reciprocal interaction. In the following, I will focus on the two elements, which were of interest in this study of a solitary species: the social organisation and the mating system. The 'social organisation' of a species refers to size, spatiotemporal cohesion and sex ratio of a social unit (Kappeler \& van Schaik 2002), i.e. those individuals that regularly interact with each other (Struhsaker 1969). Traditionally, three types of social organisation are being distinguished: solitary, pair-living and group-living. Whereas solitary individuals do not synchronise their activity with conspecifics, gregarious individuals do so with either one partner of the opposite sex (pair-living) or with several individuals of variable sexual composition (group-living).

The social organisation of a species is primarily shaped by ecological factors such as the distribution of food resources and predation risk, with females representing the basal unit of the society (Crook \& Gartlan 1966; Emlen \& Oring 1977; Terborgh \& Janson 1986). Since females and males differ in their potential reproductive rates due to differential investment in reproduction (Trivers 1972; Clutton-Brock \& Parker 1992), their spatiotemporal distribution is determined by different selective pressures. Whereas females can increase their reproductive success exclusively by investment in offspring survival, males can maximise their reproductive rates by fertilisation of more ova, i.e. access to more females (Bateman 1948; Trivers 1972). As a result, females are assumed to respond in their degree of sociality to the distribution of risks and resources, while males secondarily respond to the spatial and temporal distribution of receptive females. This interaction of ecological factors and reproductive strategies has been summarised in the socio-ecological model (Crook \& Gartlan 1966; Crook 1970; Bradbury \& Vehrencamp 1976; Emlen \& Oring 1977; Macdonald 1983; Terborgh \& Janson 1986). In species, where a dispersed spatial and temporal distribution of food 
resources does not promote female sociality because food cannot be shared by more than one female and their offspring, males are predicted to live solitarily as well. Alternatively, female gregariousness may be promoted where food resources are predictable and clumped in space and time and can be shared within a group or where group-living is beneficial to reduce predation risk (e.g., van Schaik 1983). When females form groups, males either singly join female groups ('harem groups') or form multi-male-multi-female groups.

Members of the mammalian order Carnivora are well-suited to study social systems because they representatively reflect the diversity of mammalian social organisation in type, frequency and intra-specific flexibility. In carnivores, all types of social organisation are represented, with solitary organisation being the most frequent pattern (80-95\% of species: Bekoff et al. 1984; Gittleman 1984). Among the terrestrial carnivores (infra-order Fissipedia), 7 out of 13 extant families have independently evolved group-living from a presumably solitary or socially flexible ancestor (reviewed in Dalerum 2007). In accordance with the general mammalian pattern, pair-living is the least common form of social organisation and is predominantly found among the canids (Kleiman \& Eisenberg 1973) where it has been attributed to obligate biparental care (Kleiman 1977). Whereas canids represent the only invariably gregarious carnivore family, all other families show a high proportion of solitary species. This is due to the fact that the vast majority of carnivore species includes meat (live prey or carcasses) in their diet, a dispersed and unpredictable resource, which may impede profitable sharing and therefore rarely promotes sociality (McNab 1963; Gittleman \& Harvey 1982; Gompper \& Gittleman 1991; Carbone et al. 2007). Accordingly, the exclusively carnivorous ('hypercarnivorous') felid family has the highest proportion of solitary species among the Carnivora. In group-living canids as well as in lions (Panthera leo), cheetahs (Acinonyx jubatus) and spotted hyaenas (Crocuta crocuta), constraints of a hypercarnivorous diet on sociality have been overcome by the evolution of cooperative hunting as a means to broaden the prey spectrum, thereby increasing prey size and thus the amount of food to be shared (Schaller 1972; Kleiman \& Eisenberg 1973; Kruuk 1975; Caro 1994; Creel \& Creel 1995). Because an increase of per capita food intake in comparison to individual hunting of smaller prey remains to be demonstrated, however, cooperative hunting is seen to date as a consequence of sociality rather than its initial driving force (Packer \& Ruttan 1988; Caro 1989; Packer et al. 1990; Fryxell et al. 2007).

The predominantly solitary lifestyle of carnivores is by no means equal to asociality, however, because social tolerance among individuals can be high at rich food patches and both sexes tolerate the formation of spatial groups when food is abundant (e.g., Dalerum et al. 2006). Accordingly, males may form spatial groups where females aggregate (e.g. in raccoons (Procyon lotor): Gehrt \& Fritzell 1998). Furthermore, some carnivore species show extraordinary intra-specific variation in the degree of sociality in response to variation in food availability. For example, in a member of the canid family, the red fox (Vulpes vulpes; reviewed in Cavallini 1996), and in a member of the mustelid family, the Eurasian badger (Meles meles; Woodroffe \& Macdonald 1993; da Silva et al. 1993), individuals may live as solitary foragers or associate in pairs or groups depending on local food availability. Their flexible responses to resource distribution qualify carnivores as a suitable model taxon to test predictions of socio-ecological theory. In fact, several new hypotheses have been developed based on the study of carnivores, for example the resource dispersion hypothesis - a variant of the socioecological model, which posits that group formation is based on resource dispersion and richness regardless of benefits of sociality per se (Macdonald 1983; Carr \& Macdonald 1986; Johnson et al. 2002). 
In addition to their social flexibility, their ecological role qualifies carnivores as an interesting taxon to study aspects of socio-ecological theory. In contrast to species from other mammalian orders, only few carnivore species experience predation pressure as adults (e.g., small-bodied weasels and mongooses) because the majority of species can be found on the highest trophic level of food webs where they often act as top predators (e.g., Hairston et al. 1960). Hence, the top-down factor 'predation' can largely be excluded as a key determinant of sociality in carnivores. On the other hand, acquiring food resources at the a highest trophic level results in large range sizes, low population densities, predominantly nocturnal activity and an elusive life-style, particularly in solitary carnivores. These aspects render studies of solitary carnivores difficult and might explain why empirical research on factors determining and limiting sociality has largely focussed on group-living species (e.g., African lions (Panthera leo): Van Orsdol et al. 1985; Packer et al. 1990; Spong 2002; hyaenas (Crocuta crocuta and Hyaena brunnea): Kruuk 1972; Frank 1986a; Mills 1990; Hofer \& East 1993; Boydston et al. 2005; Smith et al. 2008; wild dogs (Lycaon pictus): Frame et al. 1979; Creel \& Creel 2002; meerkats (Suricata suricatta): Doolan \& Macdonald 1996; Clutton-Brock et al. 2001). Due to their prevalence among mammals and their potential social flexibility, solitary species are of special interest, however, in the study of determinants of social systems. In the present thesis, I therefore provide detailed information on the social behaviour of a solitary carnivore and further aim to unravel its interaction with the species' mating system.

\section{Mating systems and sex-specific reproductive strategies}

The 'mating system' represents another substantial element of a social system, which is partly predetermined by a species' social organisation. Mating systems describe reproductive interactions between individuals, whereby two levels need to be distinguished: the 'social' mating system characterising mating couples and the 'genetic' mating system as the actual reproductive outcome of mating behaviour (Kappeler \& van Schaik 2002). The diversity of mating systems in mammals is stunning, ranging from rare monogamy to frequent polygynandry or promiscuity (Clutton-Brock 1989). This variability of mating systems is shaped by sex-specific reproductive strategies and their interaction with environmental conditions (Emlen \& Oring 1977; Clutton-Brock 1989).

Divergent reproductive strategies result from the difference in potential reproductive rates between males and females. In mammals, female investment in their offspring is high due to gestation and lactation, whereas males provide parental care only in a minority of species (CluttonBrock et al. 1989; Clutton-Brock 1991). While females bear the costs of offspring care, males are confronted with higher variance in reproductive success because their higher reproductive rates lead to a male bias in operational sex ratio (Emlen \& Oring 1977). Whereas males thus compete with each other for a limited number of reproductive opportunities and aim to increase the number of mates, females were selected to restrict the set of mates to the minimum which provides highest benefits for their fitness (Darwin 1871; Trivers 1972; Emlen \& Oring 1977; Andersson 1994). Whether males compete with each other directly ('contest competition') or indirectly ('scramble competition') for monopoly over females depends on the distribution of females in space and time and hence their monopolisation potential (Emlen \& Oring 1977; Andersson 1994). Where females are spatially clumped and asynchronously cycling, males directly compete via contest and morphological traits related to fighting ability are being promoted. As a result, species with a strong skew in male reproductive success exhibit sexual dimorphism with males being superior to females (Darwin 1871; 
Andersson 1994). By contrast, constraints on male monopolisation potential lead to male scramble competition favouring mate search or sperm competitive abilities (Schwagmeyer \& Woontner 1985, 1986; Birkhead 1995). Monopolisation of female home ranges in species where females are solitary and dispersed is thereby equivalent to the defence of a female group and favours male contest competitive abilities. In search for the highest quality mate, females may actively enhance male-male competition ('indirect female choice'; Wiley \& Poston 1996) to acquire beneficial competitive traits for their male offspring and linked preference for superior males in female offspring (Fisher 1930). Female choice and male-male competition can operate both before and after copulation. Postcopulatory sexual selection operates in species where females mate with multiple males (polyandry) leading to sperm competition between ejaculates of different males for the fertilisation of the ova (e.g., Parker 1970; Ginsberg \& Huck 1989; Møller \& Birkhead 1989; Gomendio \& Roldan 1993; Gomendio et al. 1998; Stockley 2004) or providing an arena for cryptic female choice among sperm of different quality (Birkhead \& Møller 1993; Eberhard 1996, 2009; Birkhead \& Pizzari 2002).

Whereas males aim to monopolise females, female interests may diverge in that they either prefer to choose a different mate or seek copulations with several males (polyandry) leading to conflict between the sexes over maximisation of their reproductive success (reviewed in Chapman et al. 2003). Even though females cannot reproduce at higher rates by mating multiply, polyandry has been shown to yield a number of benefits related to female fitness. Potential benefits include increased fertility and fecundity, fertilisation assurance, reduced male harassment, infanticide avoidance, and indirect genetic benefits related to mate quality, heterozygosity and compatibility (e.g., Hunter et al. 1993; Yasui 1998; Jennions \& Petrie 2000; Zeh \& Zeh 2001; Hosken \& Stockley 2003; Simmons 2005; Slatyer et al. 2012a). Females of many species have been shown to seek polyandrous matings leading to a conflict of interest between the sexes over female remating rates (Parker 1979; Chapman et al. 2003). In mammals, penile spines, elongated penis bones (bacula) and male harassment have been hypothesised to be selected under sexual conflict (Dixson 1987; Smuts \& Smuts 1993; Stockley 2002). In accordance with this assumption, penile spines are most frequently found in species with female polyandrous mating (Dixson 1987). A female's opportunity to mate multiply and to enhance male-male competition thereby largely depends on her access to multiple mates, which in turn is determined by the species' spatial and temporal distribution, i.e. its social organisation.

Since the majority of species of the Carnivora has a solitary social organisation, the prevailing mating system in this order is scramble competition polygyny (Sandell 1989), which is characterised by scramble competition between males for location of dispersed females rather than contest competition for access to those females. Males in these systems are limited in their access to females by their dispersed distribution and face difficulties locating and defending large numbers of receptive females. Similarly, females are restricted in the set of mates to choose from, and resistance to any male bears a high risk of fertilisation failure. Females in solitary species therefore evolved a number of adaptations to assure fertilisation including seasonal polyoestrus (e.g., Moreira et al. 2001; Concannon et al. 2009), induced ovulation (e.g., Llewellyn \& Enders 1954; Mead 1981; Mead et al. 1993; Larivière \& Ferguson 2003), conspicuous scent-marking (e.g., Macdonald 1980; Gorman \& Trowbridge 1989) and vocal signalling (e.g., Rieger \& Peters 1981; Kleiman \& Peters 1990; de Oliveira 1998) and, as a distinct adaptation in ursids and mustelids, delayed implantation and superfetation (Thom et al. 2004; Yamaguchi et al. 2004, 2006). Most of these adaptations potentially give rise to sexual conflict by increasing a female's chances to mate multiply and are thus fascinating subjects for 4 
the study of sexual selection. Despite the ubiquity of solitary species and their diversity in reproductive strategies, both empirical and theoretical research on carnivore mating systems has been largely focussed on group-living species (e.g., African lions (Panthera leo): Bygott et al. 1979; Packer \& Pusey 1982, 1983; Davies \& Boersma 1984; hyaenas (Crocuta crocuta and Hyaena brunnea): Kruuk 1972; Mills 1982; Frank 1986b; Owens \& Owens 1996; Engh et al. 2002; East et al. 2003; wild dogs (Lycaon pictus): Frame et al. 1979; Creel \& Creel 2002; Spiering et al. 2010; meerkats (Suricata suricatta): Clutton-Brock et al. 2006). Due to the practical difficulties of studying the secretive mating behaviour of far-ranging species with low population density, information on mating systems of solitary carnivores is mostly restricted on the genetic aspects of the mating system (e.g., black bears (Ursus americanus): Schenk \& Kovacs 1995; brown bears (U. arctos): Bellemain et al. 2006a,b).

The interaction of sex-specific reproductive strategies to form the observed diversity of social systems has been of major interest for behavioural ecologists ever since the establishment of the discipline. Recurrent focus has thereby been put on the refinement of socio-ecological models, the function of female polyandry, forms and consequences of sexual conflict and the resolution of the lek paradox (e.g., Kotiaho et al. 2008; Bonduriansky \& Chenoweth 2009; Port et al. 2011; Collet et al. 2012; Slatyer et al. 2012a). I studied a carnivore species that combines a set of morphological and behavioural traits that relate to several of these central topics in behavioural ecology. This species underwent parallel evolution in the isolation of an island environment, evolved both a rare form of social organisation and a unique mammalian mating system and combines otherwise antagonistic traits such as low population density and male contest competition, sexual dimorphism with superior males and female dominance, as well as penile spines, an elongated baculum (Dickie 2005) and extraordinary polyandry. Many of these aspects had only been anecdotally described before or were based on very small sample sizes. The main aim of this thesis was therefore to investigate two major components of the species' social system, its social organisation and the mating system as well as the interaction of both in order to elucidate determinants of sociality and sex-specific mating strategies.

\section{Study species}

The fosa (Cryptoprocta ferox Bennett, 1833) is a medium-sized (6-10 kg), forest-dwelling carnivore endemic to Madagascar. Genetic analyses revealed that all Malagasy carnivorans form a monophyletic sister group to the African mongooses (Herpestidae), which split from the latter about 25 million years ago with the colonisation of Madagascar (Veron \& Catzeflis 1993; Yoder et al. 2003). Malagasy carnivorans are therefore classified today as the family of Madagascar mongooses (Eupleridae). The fosa is the most basal species in the family and exhibits a set of morphological and behavioural traits that historically led to repeated taxonomic misclassification (reviewed in Köhncke \& Leonhardt 1986; Veron \& Catzeflis 1993). After extinction of its larger congener, Cryptoprocta spelea (Goodman et al. 2004), fosas represent the largest extant carnivore species in Madagascar and ecologically act as top predators. Their diet is exclusively carnivorous (hypercarnivorous) and comprises all extant lemur species, tenrecs (Tenrecidae), other mammals, birds, reptiles and occasionally amphibians and invertebrates (Albignac 1973; Rasoloarison et al. 1995; Dollar et al. 2007; Hawkins \& Racey 2008; Chapters 2 and 3). Seasonal variation in diet can be high because tenrecs, a main prey type, hibernate during austral winter (Gould \& Eisenberg 1966). Fosas are 
assumed to be distributed all over Madagascar (Albignac 1973; Hawkins 2003) and therefore inhabit a wide variety of forest types of different climatic conditions and varying degree of seasonality. In Kirindy Forest/CNFEREF, a dry deciduous forest in central western Madagascar, where I studied fosas, seasonality is pronounced, with a dry season with little or no rainfall from April to October and a wet season with high precipitation from November to March (Sorg \& Rohner 1996).

Due to their hypercarnivorous diet, fosas are predicted to show a solitary social organisation, but early anecdotes indicated the occurrence of male associations. Hawkins (1998) studied the species' social organisation by radio-tracking and confirmed that females are most likely territorial and that, in accordance with predictions for solitary carnivores (Sandell 1989), larger male ranges overlap with the ranges of multiple females but that individuals of either sex do not interact socially. Moreover, Hawkins \& Racey (2005) reported that the population density of fosas in Kirindy was lower than expected for a carnivore of their size (Carbone \& Gittleman 2002). Hawkins (1998) also documented two cases of males defending each other in the context of trapping. In this thesis, I therefore aimed to unravel (1) whether male associations exist in fosas, (2) if so, how abundant this phenomenon is, (3) how stable associations are in space and time, and (4) which factors determine male association formation. In contrast to Hawkins (1998), I was able to benefit from modern technology in the form of GPS-tracking and to work with a larger sample size of individuals. A detailed investigation of the fosa's social organisation by simultaneous GPS-tracking and dynamic interaction tests is presented in Chapter 1.

The results of this systematic investigation indeed confirmed the existence of stable male associations in fosas along with a strictly solitary subset of males. The co-occurrence of both types of social organisation raised the question concerning proximate mechanism and ultimate function of male association in this species. A first indication of the interplay of sociality and cooperation in food acquisition is provided in Chapter 2, where I describe a singular observation of cooperative hunting by three males in detail and summarise further anecdotal evidence for the universal nature of this behaviour. A systematic investigation of function and consequences of male association and cooperative hunting for male morphology and mating success is presented in Chapter 3.

A potentially even more instructive aspect of fosa behaviour is its unusual mating habits. First described by Albignac (1970), fosas meet at 'traditional' trees for the purpose of mating. One to three oestrous females may occupy a tree sequentially or simultaneously and do so for about a week during the annual mating season in October/November (Hawkins \& Racey 2009, Chapter 4). Presumably due to the spatial predictability and the duration of female mating activity, a large number of males accumulate at a mating tree. Females mate multiply with multiple males (polyandry) and copulations are often prolonged and highly vocal. Hawkins (1998) classified the mating system of the fosa as a new form combining elements of scramble competition polygyny and a lek. In contrast to scramble competition polygyny as it is found in solitary species, contest competition supposedly plays a major role as a determinant of a male's mating success as indicated both by frequent fights at mating sites and sexual dimorphism in body size and mass (Albignac 1970, 1973; Hawkins \& Racey 2009; Chapter 4). Prolonged and repeated copulations further render sperm competition a likely component of male-male scramble competition. Males in this species thus compete at three major levels: mate/tree location, access to the oestrous female and sperm competition after copulation. Mechanisms and determinants of (pre-copulatory) male-male competition were therefore one major focus in the present study of the species' mating system. 
From the females' perspective, mating at predetermined locations, mating on top of a tree and an exceptional investment in polyandrous mating raised questions about the ultimate function of this unusual system for female fitness. In contrast to Hawkins (1998), I was able to observe several females continuously and in detail over the course of their mating activity and inferred form and putative function of male and female mating strategies in Chapter 4.

Finally, I will discuss the social organisation and the mating system of fosas in the light of socio-ecological theory and I will hypothesise about the driving selective forces shaping this unique mammalian social system against the background of Madagascar's evolutionary history, geography and seasonality. Furthermore, I provide an outlook for future directions in the study of social systems. 


\title{
Chapter 1
}

\section{Simultaneous GPS-tracking reveals male associations in a solitary carnivore}

Mia-Lana Lührs \& Peter M. Kappeler

\begin{abstract}
According to socio-ecological theory, the distribution of males and their degree of sociality are primarily a response to female distribution. In hypercarnivorous species, females have large spatial requirements to meet their nutritional needs and food competition among females is intense. As a result, females are solitary and territorial, and solitary males compete for dispersed females. Yet, anecdotal evidence has accumulated suggesting that facultative male sociality may be more common in solitary carnivores than previously thought. We studied spatial interactions among fosas (Cryptoprocta ferox, Eupleridae), Madagascar's largest carnivore, using simultaneous GPS-tracking of 13 fosas in Kirindy Forest, Madagascar, to determine patterns of sex-specific spatial distribution and degree of sociality. Dynamic interaction tests revealed that females were truly solitary and analysis of home range overlap indicated female territoriality. Nonetheless, a subset of males was found to be associated in stable dyads that were characterised by extensive range overlap and frequent close proximity. Interestingly, solitary and associated males coexisted in the study population, raising questions concerning constraints and flexibility of social tolerance in hypercarnivores. We argue that permanent association among female fosas is constrained by limited food availability whereas male dyadic sociality is presumably promoted by intra-sexual competition. The persistence of solitary males may reflect limited social tolerance among unfamiliar individuals in carnivores.
\end{abstract}

Under review in Behavioral Ecology and Sociobiology 


\section{Introduction}

According to socio-ecological theory, a species' social organisation is determined by the spatial and temporal distribution of risks and resources (Crook and Gartlan 1966; Crook 1970; Bradbury and Vehrencamp 1976; Emlen \& Oring 1977; Macdonald 1983; Terborgh \& Janson 1986). Since female fitness is limited by access to food resources, and male fitness is mainly determined by access to receptive females (Williams 1966; Trivers 1972; Clutton-Brock \& Parker 1992), female social organisation is assumed to represent the primary response to ecological factors, whereas male social organisation is thought to be a response to female distribution (Altmann 1990) and therefore only secondarily affected by ecological factors. Even though socio-ecological models were developed with a focus on group-living species, their main principles could be shown to be also applicable to solitary and pair-living species (Schülke 2003; Dammhahn \& Kappeler 2009).

An explicit socio-ecological model is represented by the resource dispersion hypothesis (RDH; Macdonald 1983; Carr \& Macdonald 1986; Johnson et al. 2002), which asserts that territory size is determined by resource dispersion, whereas group size of the territory holders is determined by resource abundance and richness. This model makes general predictions about the potential to tolerate conspecifics in a territory, irrespective of other factors affecting sociality, such as costs and benefits of group-living (reviewed in Krause \& Ruxton 2002). The RDH has been tested in a number of carnivores (e.g., badgers: da Silva et al. 1993; Johnson et al. 2001; foxes: Geffen et al. 1992; Baker et al. 2000), but also in rodents (Herrera \& Macdonald 1989) and birds (Davies et al. 1995), and, despite the complexity of factors influencing sociality, enjoyed general support.

Suitable model species to illuminate determinants of social organisation can be found in the mammalian order Carnivora because the number of decisive factors, such as top-down control (predation), intra-guild competition, or food resource diversity may be reduced. In top predators feeding exclusively on meat (live prey or carcasses), so-called hypercarnivorous species, this reduction of confounding factors is maximised, unless intra-guild competition is intense or intra-guild predation is common, as in many continental African large carnivores (Creel \& Creel 1996; Durant 1998; Caro \& Stoner 2003). Since meat is a resource that is unpredictable both in space and time, spatial requirement to meet a sufficiently large food supply increases with the proportion of meat in the diet (McNab 1963; Gittleman \& Harvey 1982; Gompper \& Gittleman 1991). Females of hypercarnivores and omnivores therefore often inhabit large territories and rarely exhibit gregarious tendencies; the most prominent exception being hypercarnivorous lions and spotted hyaenas (Kruuk 1972; Schaller 1972; Bertram 1975). As a result, most carnivores live solitarily ( $\geq 85 \%$; Bekoff et al. 1984; Gittleman 1984).

Since male spatial distribution is not only determined by food resources, but also by the distribution of females (Macdonald 1983), solitary carnivore males usually inhabit large home ranges that overlap with those of several females (Sandell 1989). However, in some species of terrestrial Carnivora, males exhibit tendencies to associate with other males, even when females are solitary. Such male associations appear to serve joint defence of a larger territory, entailing access to more females (Macdonald 1983), e.g. in cheetahs (Caro 1994) and different species of solitary mongooses (Rood \& Waser 1978; Cavallini \& Nel 1990; Waser et al. 1994; Hays \& Conant 2003; Rathbun \& Cowley 2008). In other species, males may form temporary groups in response to short-term female aggregation, e.g. in racoons (Gehrt \& Fritzell 1998), or groups with little social interaction, e.g. in 
striped hyaenas (Wagner et al. 2008) or slender mongooses (Waser et al. 1994), to form coalitions against other males.

Do these cases of male association in species with solitary females contradict socio-ecological theory? Not necessarily. If male sociality allows for defence of and access to more females and food resource needs can be compensated by larger territory or even benefits of group-living, such as cooperative hunting, male coalitions do represent a response to female distribution. In cheetahs, fitness costs of reproductive competition among allies are compensated by indirect fitness benefits because associates are most often littermates (Caro \& Collins 1986). In mongooses with solitary females, evidence for male associations is so far only anecdotal because solitary carnivores are difficult to study. Information about relatedness of associates as well as composition, stability and incentives of male associations in these species is therefore lacking.

Recently, GPS-tracking methods have added a helpful tool for studying enigmatic carnivore species (e.g., Soisalo \& Cavalcanti 2006; Bandeira de Melo et al. 2007; Barlow et al. 2011). In the present study, we used this technology to investigate the social organisation (sensu Kappeler \& van Schaik 2002) of a top predator endemic to Madagascar, the fosa (Cryptoprocta ferox), in which male associations have been observed anecdotally (Lührs \& Dammhahn 2010). Fosas are the largest members of Madagascar's mongooses (Eupleridae) weighing up to $11 \mathrm{~kg}$. They are hypercarnivorous, hunting lemurs and other mammals, birds, reptiles, amphibians and occasionally invertebrates (Rasoloarison et al. 1995; Hawkins \& Racey 2008; Lührs \& Dammhahn 2010). Since the extinction of their larger congener $C$. spelea (Goodman et al. 2004) fosas act as top predators in the ecosystem and neither face intra-guild predation risk nor resource competition. In fact, sympatric carnivores (smaller Madagascar mongooses and introduced Viverricula indica and Felis sylvestris) represent potential prey species. Confounding factors influencing the species' social organisation are therefore limited to intra-specific dynamics. The first study on the fosa's social organisation using radiotelemetry indicated a solitary life-style, large ranges and accordingly low population density in accordance with its carnivorous diet (Hawkins 1998; Hawkins \& Racey 2005). Limitations of radiotracking, such as the dependence on a dense and expansive road system, posed problems on sample size, however, and likely led to underestimation of the species' range sizes. Furthermore, true interactions, and thus the degree of sociality among individuals, could not be assessed, and the details of male associations remain obscure.

We therefore studied fosas using simultaneous GPS-tracking of males and females to determine the species' spatial organisation and to evaluate the degree of sociality. Based on the fosa's hypercarnivorous diet, we predicted females to be solitary and territorial, i.e. to retain an exclusive home range area with stable arithmetic means (referred to as the 'territory'), and not to socially interact with conspecifics, but instead to avoid activity centres of overlapping males. With respect to male social organisation, we aimed to describe spatial dynamics of male association and to evaluate differences between solitary and associated males. For this purpose, we compared differences in ranging behaviour during and outside the mating season, frequency of social interaction, home range area, overlap and spatial stability of home range means. If male association in fosas serves joint defence of a territory, associated and solitary males should not differ in home range size according to the $\mathrm{RDH}$, but ranges of associated males should overlap to a lesser extent with ranges of other males. Male sociality would then serve exclusively to mitigate access to females within the territory. Alternatively, associated males may not defend a territory but increase overlap 
with females by range extension. According to the RDH, in this case associated males should not differ from solitary males with respect to intrasexual range overlap. Male sociality would then likely serve other purposes, such as coalitional support or cooperative hunting.

\section{Methods}

\section{GPS-tracking}

Spatial data presented here were obtained via GPS-tracking of 13 wild fosas (9 males, 4 females)

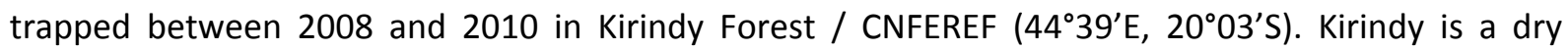
deciduous forest with pronounced seasonality. The local dry season with little to no rainfall spans half a year from May to October, while the wet season from November until April is characterised by high humidity and frequent rainfall (Sorg \& Rohner 1996; Kappeler \& Fichtel 2012). Fosas were trapped annually during the dry season with 10 live-traps $(42 \times 15 \times 20$ cin. bobcat trap, Tomahawk, USA) along transects shifted weekly over a $9 \mathrm{~km}^{2}$ area in the forest centre. Traps were set along roads, paths or rivers, which the animals were known to use, and were controlled every two hours during the day and twice at night. Trapped animals were briefly anaesthetised, measured and equipped with GPS-tags in individually designed collars (150-200 g, e-obs $\mathrm{GmbH}$, Germany). Only adult individuals were equipped with collars which made up less than $5 \%$ of the individuals' body mass (Gannon \& Sikes 2007). After recovery from anaesthesia, animals were released the site of capture and effort to re-trap animals after depletion of the collars' battery was maximised. None of the individuals that were re-trapped to remove the GPS collar exhibited injuries or significant weight loss. Since trappability was highest towards the end of the dry season, most tracking data were obtained from September onwards. GPS-tags logged positions once per hour on the hour, with occasional drop out values (about 40\%), presumably due to atmospheric disturbance, high forest density or weak batteries. Average horizontal accuracy of locations was $\pm 12 \mathrm{~m}$. GPS data were downloaded via remote download stations located at water-holes or via hand-held remote devices.

\section{Static spatial data analyses}

In order to evaluate spatial distribution of male and female fosas, individual GPS locations were used to calculate two types of home range estimates (minimum convex polygons (MCPs; Mohr 1947) and kernel home ranges (Worton 1989), as well as to determine spatial stability of these ranges (stability of the arithmetic mean, i.e. the mean of the home range area) and their use (stability of the weighted mean, i.e. the mean of positions). For calculation of home range estimates, spatial autocorrelation was not corrected for in order to conserve biological meaning (De Solla et al. 1999). Since the minimum tracking frequency was one location per hour, fosas were potentially able to cross their entire range within this period (based on observed maximum hourly travel distances) we considered spatial data points to be statistically independent (Swihart \& Slade 1985).

Exploratory data analysis revealed that the removal of outliers led to loss of biological meaning and only little reduction of MCP home range size. We therefore chose $100 \%$ MCPs as appropriate means to quantify maximum space cover and potential overlap among individuals. In order to avoid overestimates of home range size, use and overlap associated with MCPs (Swihart \& 
Slade 1997), we additionally determined kernel estimates between 50 and $90 \%$ probability density (Börger et al. 2006). Since $90 \%$ kernel home range areas exceeded areas of $100 \%$ MCPs and thereby created even more false overlap than MCPs, we provide $90 \%$ kernel areas only as a reference and based our analyses exclusively on MCPs and 50\% kernels. The combination of MCPs, $50 \%$ kernels and shifts in home range means were used to estimate static interaction between individuals as a proxy for the degree of territoriality and sociality. For site fidelity and true territoriality, we assume the arithmetic mean of a range to be stable as an indication for the individual being 'trapped' within a given space, whereas weighted means, i.e. preferably used regions within this stable range, may vary. Home range areas were calculated in $R$ ( $R$ Development Core Team 2011) using the package 'adehabitatHR' (Calenge 2006). Weighted home range means were determined in ArcView 3.3 (ESRI, California, USA) using the 'weighted means' extension (Jenness 2004).

All spatial analyses were performed month-wise to create comparable, temporally overlapping units among different individuals. Where individuals could not be tracked over the whole course of a calendar month, positions were added from either preceding or subsequent months to achieve comparable sample size (see Table 1 for exact tracking periods).

\section{Dynamic spatial data analysis}

Since static interaction between individuals is insufficient to quantify the degree of sociality, we further used dynamic spatial data analysis to examine direct interaction between simultaneously tracked individuals. Simultaneous positions were obtained for a total of 36 dyads (three femalefemale (F-F), 17 male-female (M-F) and 16 male-male (M-M) dyads) based on nine males and four females (see Table 2 for details). Only those positions were considered for interaction tests where both individuals could be located. Dyadic analyses were performed over the entire period of simultaneous tracking (4-6 weeks), except for two dyads that could be tracked long enough to create separate data sets for two months.

In order to determine whether two individuals associate, avoid each other or simply move randomly in relation to each other, we performed Doncaster's model of dynamic interaction (Doncaster 1990). This test compares $n$ observed inter-individual distances with expected ones calculated from all $n^{2}$ distances possible within the given set of spatial points (i.e. within an $n \times n$ matrix). A critical distance assuming awareness of each other's presence can then be taken to compare observed cumulative probability of occurrence of two individuals within the critical distance with expected probabilities using a chi-square test. Since fosas had been observed not to necessarily notice conspecifics at distances above $50 \mathrm{~m}$, we chose $50 \mathrm{~m}$ as the critical distance. As this is a rather short distance for a carnivore of this size, any interaction effects found within $50 \mathrm{~m}$ can be assumed to be conservative and well suited to evaluate true sociality. We compared observed probabilities with expected values with a $4 \times 4$ contingency table containing counts below and above $50 \mathrm{~m}$, respectively, and evaluated whether two individuals could be located within $50 \mathrm{~m}$ more often or less often than expected by chance based on the distribution of given locations.

In order to detect inter-individual dynamics beyond the critical distance, we additionally evaluated minimum distances as well as average distances between individuals of a dyad. We divided minimum distances by dyadic average distance and divided observed distances by expected 
distances calculated for Doncaster's model to account for effects of differences in home range overlap. All calculations associated with spatial data were performed in R. Graphical presentation of spatial data was produced in ArcView 3.3 ('Animal Movement' extension; Hooge \& Eichenlaub 2000) and colour-adapted in Adobe Illustrator. Statistical graphs were produced in Statistica 10 and colouradapted in Adobe Illustrator.

Since relatedness among individuals contains crucial information in the study of social organisation, we additionally provide information on dyadic relatedness from an earlier study based on 16 microsatellite markers applied to a total of 33 fosas (see Chapter $\mathbf{3}$ for details). Relatedness coefficients for dyads focussed on here are provided in Table 2.

\section{Statistical analyses}

Since home range areas were gamma-distributed, we used a generalised linear mixed-effects model (GLMM) based on a gamma-distribution to determine whether the variance in monthly home range sizes was best explained by sex, social organisation (solitary vs. associated), ecological season (dry vs. wet) or reproductive season (mating season vs. non-mating season). Equivalent analyses were performed for monthly arithmetic and weighted mean shifts using linear mixed-effects models (LMMs). Dry season was assigned to the months May to October; wet season to November until January within the tracking period. October and November represented the mating season because mating activity peaked in November during all years, but males started long-distance excursions in search for mating trees in October.

Due to inflated type I error rates of stepwise model selection procedures (Mundry \& Nunn 2009), we retained all those predictor variables in our mixed models, which were of potential biological significance for the response variable. Models differed only in response variables and the fixed factors sex and social organisation, which were alternated depending on the question addressed. Seasons were included in every model and an animal's identity was included as a random factor throughout. Variables and residuals were tested for normal distribution using a Shapiro-Wilk test (Shapiro \& Wilk 1965). Arithmetic mean shifts were log-transformed to fit a normal distribution. Since shifts in weighted means were correlated with home range size, only fitted residuals were taken for analyses of weighted mean shifts. $P$-values for LMMs were calculated from 1000 Monte Carlo simulations and significance level was accepted at $P \leq 0.05$. All statistical analyses were performed in $\mathrm{R}$.

\section{Results}

Home range size, overlap and shifts

Static home range analysis revealed that males consistently used larger MCP ranges than females (GLMM: $t_{11}=-9.43, P<0.001$; Fig. 1; Appendix I, Table A1, Fig. A1). Whereas female range size appeared to remain stable over the course of the study period (Table 1; Fig. 1; Appendix I, Fig. A1), male range sizes tended to vary with reproductive season (LMM: $t=1.76, P=0.091, n=9$; Fig. 1; Appendix I, Table A2). Male ranges increased by a factor of $1.4 \pm 0.6$ SD during the mating season 
and decreased to their previous size in December (Fig. 1). Neither male nor female range sizes were affected by ecological season (GLMM: $t_{30}=-0.72, P=0.475$; Appendix I, Fig. A1).

Table 1 Overview of spatial data obtained for females (F1-F4) and males (M1-M9).

\begin{tabular}{|c|c|c|c|c|c|c|c|c|c|c|c|}
\hline ID & Year & Month & $\underset{\text { positions }}{\mathbf{N}}$ & $\begin{array}{l}\text { Tracking } \\
\text { started }\end{array}$ & $\begin{array}{c}\text { Tracking } \\
\text { ended }\end{array}$ & $\begin{array}{l}\text { N days } \\
\text { tracked }\end{array}$ & $\begin{array}{l}\text { MCP } \\
\text { area } \\
\text { (ha) }\end{array}$ & $\begin{array}{c}50 \% \\
\text { kernel } \\
\text { area (ha) } \\
\end{array}$ & $\begin{array}{c}90 \% \\
\text { kernel } \\
\text { area (ha) } \\
\end{array}$ & $\begin{array}{c}\text { Arithmetic } \\
\text { mean shift } \\
(\mathrm{m})\end{array}$ & $\begin{array}{c}\text { Weighted } \\
\text { mean shift } \\
(\mathrm{m})\end{array}$ \\
\hline F1 & 2008 & Sep & 252 & 17.09.2008 & 30.09 .2008 & 14 & 1203.2 & 273.3 & 1213.8 & - & - \\
\hline $\mathrm{F} 1$ & 2008 & Oct & 569 & 01.10 .2008 & 31.10 .2008 & 31 & 1881.3 & 479.7 & 1722.2 & 833.1 & 1049.4 \\
\hline $\mathrm{F} 1$ & 2008 & Nov & 489 & 01.11 .2008 & 30.11 .2008 & 30 & 1173.7 & 337.1 & 1216.2 & 902.6 & 1039.1 \\
\hline $\mathrm{F} 1$ & 2008 & Dec & 500 & 01.12 .2008 & 28.12 .2008 & 28 & 1127.1 & 507.4 & 1486.4 & 500.6 & 1118.7 \\
\hline $\mathrm{F} 1$ & 2009 & June & 298 & 10.06.2009 & 30.06 .2009 & 21 & 1971.8 & 173.1 & 1469.1 & - & - \\
\hline $\mathrm{F} 1$ & 2009 & July & 497 & 01.07.2009 & 31.07.2009 & 31 & 2024.0 & 590.9 & 2014.5 & 377.7 & 1901.0 \\
\hline $\mathrm{F} 1$ & 2009 & Aug & 431 & 01.08.2009 & 31.08 .2009 & 31 & 2157.7 & 571.2 & 2007.1 & 361.9 & 281.9 \\
\hline F1 & 2009 & Sep & 282 & 01.09.2009 & 30.09 .2009 & 30 & 2285.5 & 398.1 & 1980.8 & 292.4 & 939.6 \\
\hline $\mathrm{F} 1$ & 2009 & Oct & 296 & 01.10 .2009 & 31.10 .2009 & 31 & 2209.9 & 544.4 & 2177.4 & 256.5 & 652.0 \\
\hline $\mathrm{F} 1$ & 2009 & Nov & 74 & 01.11.2009 & 22.11.2009 & 22 & 1853.2 & 400.8 & 1375.6 & 412.0 & 695.0 \\
\hline F2 & 2009 & Sep & 294 & 12.09.2009 & 30.09 .2009 & 19 & 1389.6 & 459.1 & 1435.0 & - & - \\
\hline $\mathrm{F} 2$ & 2009 & Oct & 280 & 01.10.2009 & 21.10.2009 & 21 & 1342.5 & 589.8 & 1687.1 & 116.8 & 288.3 \\
\hline F3 & 2009 & Oct & 399 & 04.10.2009 & 04.11 .2009 & 31 & 1391.6 & 486.6 & 1409.3 & - & - \\
\hline F3 & 2010 & Aug & 317 & 13.08 .2010 & 31.08 .2010 & 19 & 1732.6 & 529.3 & 1643.0 & - & - \\
\hline F3 & 2010 & Sep & 250 & 01.09 .2010 & 16.09 .2010 & 16 & 2526.4 & 488.4 & 1960.8 & 432.8 & 616.6 \\
\hline $\mathrm{F} 4$ & 2010 & Nov & 430 & 01.11 .2010 & 30.11 .2010 & 30 & 2129.6 & 740.4 & 2307.5 & - & - \\
\hline M1 & 2008 & Sep & 166 & 21.09 .2008 & 30.09 .2008 & 10 & 3477.1 & 266.6 & 2163.2 & - & - \\
\hline M1 & 2008 & Oct & 488 & 01.10 .2008 & 31.10 .2008 & 31 & 7739.4 & 2239.0 & 6908.8 & 1650.8 & 2664.4 \\
\hline M1 & 2008 & Nov & 536 & 01.11 .2008 & 02.12 .2008 & 32 & 6815.8 & 1561.8 & 6049.8 & 1494.0 & 3090.2 \\
\hline M2 & 2009 & Sep & 180 & 16.09.2009 & 30.09.2009 & 15 & 3675.7 & 139.2 & 1409.3 & 1682.2 & 666.2 \\
\hline $\mathrm{M} 2$ & 2009 & Oct & 297 & 01.10.2009 & 31.10 .2009 & 31 & 7618.7 & 858.5 & 6602.3 & 1326.3 & 829.9 \\
\hline M3 & 2009 & May & 152 & 21.05.2009 & 31.05 .2009 & 11 & 4606.6 & 1919.5 & 6488.9 & - & - \\
\hline M3 & 2009 & June & 251 & 01.06.2009 & 19.06.2009 & 19 & 8456.6 & 2886.4 & 8627.0 & 1347.4 & 1885.0 \\
\hline M3 & 2009 & Sept & 145 & 20.09.2009 & 30.09 .2009 & 11 & 4404.6 & 1714.7 & 5921.0 & 2013.2 & 760.7 \\
\hline M3 & 2009 & Oct & 321 & 01.10.2009 & 24.10.2009 & 24 & 5488.4 & 2538.8 & 7394.2 & 133.5 & 1787.4 \\
\hline M4 & 2009 & May & 165 & 21.05.2009 & 31.05 .2009 & 11 & 4578.7 & 1764.9 & 5895.6 & - & - \\
\hline M4 & 2009 & June & 197 & 01.06.2009 & 17.06.2009 & 17 & 8065.4 & 2793.7 & 8295.2 & 1690.4 & 1467.7 \\
\hline M4 & 2009 & Sep & 150 & 19.09.2009 & 30.09 .2009 & 12 & 4841.9 & 1950.6 & 6877.3 & 2222.5 & 1634.8 \\
\hline M4 & 2009 & Oct & 317 & 01.10 .2009 & 25.10 .2009 & 25 & 5567.5 & 2771.7 & 7596.5 & 333.0 & 2267.3 \\
\hline M4 & 2010 & Sep & 503 & 02.09 .2010 & 30.09 .2010 & 29 & 5278.4 & 1844.4 & 5782.8 & - & - \\
\hline M4 & 2010 & Oct & 176 & 01.10 .2010 & 14.10 .2010 & 14 & 6552.4 & 3860.8 & 10156.4 & 1009.9 & 1540.9 \\
\hline M5 & 2009 & Oct & 425 & 01.10 .2009 & 31.10 .2009 & 31 & 4244.7 & 718.4 & 3140.4 & - & - \\
\hline M6 & 2010 & Oct & 239 & 15.10 .2010 & 31.10 .2010 & 17 & 4233.6 & 1025.4 & 4031.9 & - & - \\
\hline M6 & 2010 & Nov & 367 & 01.11 .2010 & 30.11 .2010 & 30 & 8961.4 & 2182.0 & 8882.2 & 3649.4 & 3973.8 \\
\hline M6 & 2010 & Dec & 353 & 01.12 .2010 & 31.12 .2010 & 31 & 8385.7 & 3040.3 & 9253.2 & 2935.2 & 194.1 \\
\hline M6 & 2011 & Jan & 143 & 01.01 .2011 & 19.01.2010 & 19 & 6736.3 & 2909.4 & 9029.3 & 2007.0 & 1098.8 \\
\hline M7 & 2010 & Oct & 248 & 15.10 .2010 & 31.10 .2010 & 17 & 6774.1 & 2142.6 & 7771.2 & - & - \\
\hline M7 & 2010 & Nov & 163 & 01.11 .2010 & 20.11 .2010 & 20 & 6080.6 & 2937.9 & 9157.8 & 2277.1 & 2760.5 \\
\hline M8 & 2010 & Sep & 486 & 01.09 .2010 & 30.09 .2010 & 30 & 3589.3 & 996.6 & 3349.5 & - & - \\
\hline M8 & 2010 & Oct & 485 & 01.10 .2010 & 31.10 .2010 & 31 & 3301.1 & 754.4 & 2604.3 & 278.9 & 811.4 \\
\hline M8 & 2010 & Nov & 462 & 01.11 .2010 & 30.11 .2010 & 30 & 4211.4 & 1283.5 & 3969.6 & 1205.8 & 188.2 \\
\hline M8 & 2010 & Dec & 424 & 01.12 .2010 & 31.12 .2010 & 31 & 2089.4 & 628.9 & 2007.2 & 699.2 & 237.8 \\
\hline M8 & 2011 & Jan & 266 & 01.01.2011 & 24.01 .2011 & 24 & 1876.2 & 678.2 & 2084.2 & 830.3 & 353.2 \\
\hline M9 & 2010 & Oct & 355 & 09.10 .2010 & 31.10 .2010 & 23 & 2183.3 & 851.0 & 2333.7 & - & - \\
\hline M9 & 2010 & Nov & 420 & 01.11.2010 & 30.11 .2010 & 30 & 4212.5 & 975.4 & 3300.6 & 1155.3 & 816.0 \\
\hline
\end{tabular}


The distribution of home ranges in space differed between males and females in accordance with size differences (Appendix I, Fig. A1). Whereas female ranges appeared not to overlap with those of unrelated individuals of the same sex (see Table 2 for information on relatedness), male monthly MCP ranges overlapped extensively both with those of females ( $23 \pm 12 \% \mathrm{SD}$ ) but also with those of other males ( $48 \pm 15 \%$ SD). More so, a subset of males shared ranges by 81 to $98 \%$ (M1-M2, M3-M4, M6-M7; Table 2). In females, high MCP overlap (58\% and 93\%) could only be found for a mother-daughter-dyad (F1-F3; Table 2). Yet, overlap in 50\% kernels was generally low for femalefemale $(<9 \%)$ and male-female dyads (19 $\pm 14 \%$ SD). Among male-male dyads, there was high variability, ranging from 0 to $100 \%$ overlap ( $40 \pm 11 \%$ SD), with the same subset of six males (M1-M2, M3-M4, M6-M7) showing highest overlap (50-100\%; Table 2).

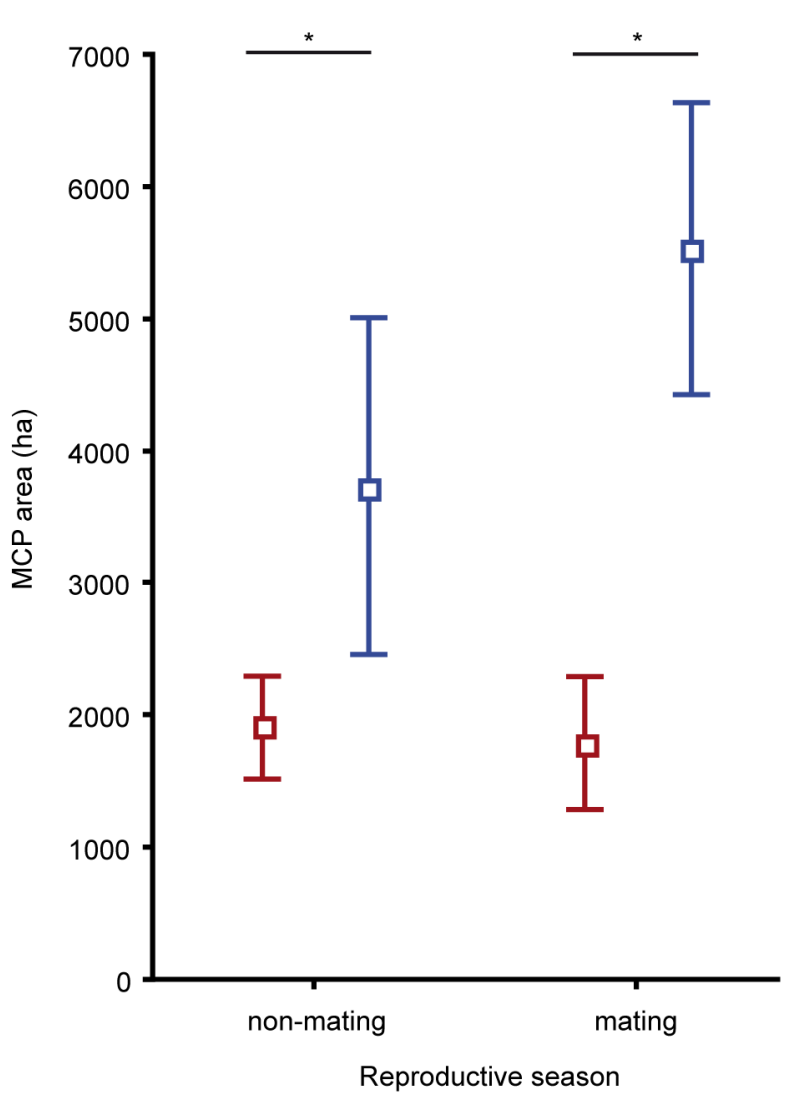

Fig. $1 \mathrm{MCP}$ home range areas of males (blue) and females (red) per reproductive season. Plotted are means (squares) and $95 \%$ confidence intervals (whiskers). Statistical differences are indicated as '*' for $P<0.05$ from a GLMM (see Appendix I, Table A1).

Arithmetic and weighted means of male ranges shifted from month to month by on average $1522 \pm 700 \mathrm{~m} \mathrm{SD}$ and $1429 \pm 799 \mathrm{~m} \mathrm{SD}$, respectively. In contrast, female ranges shifted only in their weighted means by $838 \pm 476 \mathrm{~m} \mathrm{SD}$, whereas average shifts in arithmetic means were negligible (499 $\pm 404 \mathrm{~m} \mathrm{SD}$; Table 1). As a result, males and females differed in arithmetic mean shifts (LMM: $t=-$ 3.02, $P=0.006, n=11$; Appendix I, Table A3), but not in weighted shifts (LMM: $t=0.23, P=0.823, n$ = 11; Fig. 2; Appendix I, Table A4), when range size was controlled for. Weighted mean shifts were neither affected by ecological season (LMM: $t=-0.30, P=0.765, n=11$ ), nor by reproductive season $(t=1.30, P=0.205, n=11$; Appendix I, Table A4). Arithmetic mean shifts remained unaffected by reproductive season (LMM: $t=-1.48, P=0.152, n=11$ ), but tended to increase towards the wet season ( $t=2.05, P=0.051, n=11$; Appendix I, Table A3), possibly as a result of enduring shifts by males beyond the mating season. 
Table 2 Overview of spatial data obtained from dyadic comparisons. Statistically supported deviations from Doncaster's (1990) dynamic interaction test (DIA) for a critical distance of $\leq 50 \mathrm{~m}$ are marked in bold.

\begin{tabular}{|c|c|c|c|c|c|c|c|c|c|c|c|c|c|c|c|c|c|c|c|c|c|c|c|c|c|}
\hline Year & ID1 & ID2 & Dyad & $\begin{array}{c}\mathbf{N} \\
\text { positions } \\
\end{array}$ & $\begin{array}{l}\mathrm{N} \text { days } \\
\text { tracked }\end{array}$ & Month & $\begin{array}{c}\text { MCP } \\
\text { area ID1 } \\
\text { (ha) } \\
\end{array}$ & $\begin{array}{l}\text { MCP } \\
\text { area ID2 } \\
\text { (ha) } \\
\end{array}$ & $\begin{array}{c}\text { MCP } \\
\text { overlap } \\
\text { ID1 (\%) } \\
\end{array}$ & $\begin{array}{l}\text { MCP } \\
\text { overlap } \\
\text { ID2 }(\%)\end{array}$ & $\begin{array}{c}\text { Overlap } \\
\text { MCP area } \\
\text { (ha) } \\
\end{array}$ & $\begin{array}{c}50 \% \\
\text { kernel } \\
\text { area ID1 } \\
\text { (ha) } \\
\end{array}$ & $\begin{array}{c}50 \% \\
\text { kernel } \\
\text { area ID2 } \\
\text { (ha) } \\
\end{array}$ & $\begin{array}{l}\text { Kernel } \\
\text { overlap } \\
\text { ID1 (\%) }\end{array}$ & $\begin{array}{l}\text { Kernel } \\
\text { overlap } \\
\text { ID2 } \% \text { ) }\end{array}$ & $\begin{array}{c}50 \% \\
\text { kernel } \\
\text { overlap } \\
\text { (\%) } \\
\end{array}$ & $\begin{array}{c}\text { Tracked } \\
<50 \mathrm{~m} \\
(\%)\end{array}$ & $\begin{array}{c}\text { DIA-test: } \\
\chi^{2} \\
\end{array}$ & $P$ & $\begin{array}{c}\text { Average } \\
\text { inter- } \\
\text { individual } \\
\text { distance }(\mathrm{m}) \\
\end{array}$ & $\begin{array}{c}\text { Average } \\
\text { distance } \\
\text { expected } \\
\text { (m) } \\
\end{array}$ & $\begin{array}{l}\text { Distance } \\
\text { observed/ } \\
\text { expected }\end{array}$ & $\begin{array}{c}\text { Minimum } \\
\text { distance } \\
\text { observed } \\
(\mathrm{m}) \\
\end{array}$ & $\begin{array}{c}\text { Minimum } \\
\text { distance } \\
\text { observed/ } \\
\text { average }\end{array}$ & $\begin{array}{l}\text { Relatedness } \\
\text { coefficient } r \\
\text { (TrioML) }\end{array}$ \\
\hline 2009 & $\mathrm{~F} 1$ & $\mathrm{~F} 2$ & F-F & 335 & 40 & Oct & 2209.9 & 1342.4 & 1.5 & 2.4 & 32.8 & 544.4 & 589.8 & 0.0 & 0.0 & 0.0 & 0 & & & 3744.0 & 3770.0 & 1.0 & 727.3 & 0.2 & 0.00 \\
\hline 2009 & F1 & F3 & F-F & 235 & 37 & Oct & 2209.9 & 1391.6 & 58.5 & 92.8 & 1291.8 & 544.4 & 486.6 & 7.1 & 8.3 & 7.7 & 0 & 0.09 & 0.760 & 2642.8 & 2498.0 & 1.1 & 494.1 & 0.2 & 0.69 \\
\hline 2009 & F2 & F3 & F-F & 161 & 18 & Oct & 1342.4 & 1391.6 & 8.7 & 8.4 & 116.7 & 589.8 & 486.6 & 0.0 & 0.0 & 0.0 & 0 & 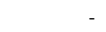 & - & 4013.1 & 4031.8 & 1.0 & 996.0 & 0.2 & 0.05 \\
\hline 2008 & F1 & M1 & $M-F$ & 1092 & 30 & Oct & 1997.3 & 7739.4 & 78.4 & 20.2 & 1566.6 & 544.4 & 2239.0 & 64.3 & 15.5 & 39.9 & 0 & 0.77 & 0.381 & 4043.9 & 3939.1 & 1.0 & 259.8 & 0.1 & 0.00 \\
\hline 2008 & $\mathrm{~F} 1$ & M1 & $M-F$ & 944 & 28 & Nov & 1242.2 & 7292.4 & 84.1 & 14.3 & 1044.7 & 400.8 & 1561.8 & 27.3 & 7.1 & 17.2 & 0 & 0.03 & 0.861 & 4603.7 & 4522.6 & 1.0 & 548.1 & 0.1 & . \\
\hline 2009 & F1 & M1 & $M-F$ & 320 & 32 & June & 1971.8 & 1082.9 & 26.2 & 47.6 & 515.9 & 173.1 & 189.2 & 10.0 & 10.0 & 10.0 & 0 & 10.89 & $<0.001$ & 2670.6 & 2575.3 & 1.0 & 157.0 & 0.1 & \\
\hline 2009 & $\mathrm{~F} 1$ & M2 & $M-F$ & 406 & 43 & July & 2024.0 & 1652.0 & 44.4 & 54.3 & 897.8 & 590.9 & 103.2 & 0.0 & 0.0 & 0.0 & 0 & 3.15 & 0.076 & 2614.8 & 2545.0 & 1.0 & 111.4 & 0.0 & 0.00 \\
\hline 2009 & F1 & M2 & $M-F$ & 275 & 46 & Oct & 2209.9 & 7618.7 & 62.3 & 18.1 & 1376.8 & 544.4 & 858.5 & 14.3 & 9.1 & 11.7 & 0 & 0.02 & 0.904 & 3517.2 & 3456.1 & 1.0 & 546.3 & 0.2 & \\
\hline 2009 & $\mathrm{~F} 1$ & M3 & $M-F$ & 274 & 35 & Oct & 2209.9 & 5488.4 & 29.8 & 12.0 & 659.2 & 544.4 & 2538.8 & 14.3 & 3.0 & 8.7 & 0 & 0.05 & 0.828 & 5052.4 & 5019.2 & 1.0 & 344.7 & 0.1 & 0.17 \\
\hline 2009 & F1 & M4 & $M-F$ & 284 & 37 & Oct & 2209.9 & 5567.5 & 30.2 & 12.0 & 668.0 & 544.4 & 2771.7 & 71.4 & 13.9 & 42.7 & 0 & 0.05 & 0.824 & 4921.4 & 4914.7 & 1.0 & 462.7 & 0.1 & 0.06 \\
\hline 2009 & $\mathrm{~F} 1$ & M5 & $M-F$ & 287 & 36 & Oct & 2209.9 & 4244.7 & 86.8 & 45.2 & 1919.2 & 544.4 & 718.4 & 71.4 & 55.6 & 63.5 & 0 & 0.20 & 0.653 & 2545.5 & 2479.1 & 1.0 & 101.1 & 0.0 & 0.00 \\
\hline 2009 & $\mathrm{~F} 2$ & M2 & $M-F$ & 305 & 36 & Oct & 1342.4 & 7618.7 & 100.0 & 17.6 & 1342.4 & 589.8 & 858.5 & 26.7 & 18.2 & 22.4 & 0 & 0.29 & 0.593 & 2574.8 & 2579.1 & 1.0 & 133.4 & 0.1 & 0.05 \\
\hline 2009 & $\mathrm{~F} 2$ & M3 & $M-F$ & 329 & 31 & Oct & 1342.4 & 5488.4 & 35.1 & 8.6 & 470.9 & 589.8 & 2538.8 & 0.0 & 0.0 & 0.0 & 0 & 0.02 & 0.893 & 5518.7 & 5469.0 & 1.0 & 426.6 & 0.1 & 0.06 \\
\hline 2009 & $\mathrm{~F} 2$ & M4 & $M-F$ & 312 & 32 & Oct & 1342.4 & 5567.5 & 35.1 & 8.5 & 471.2 & 589.8 & 2771.7 & 0.0 & 0.0 & 0.0 & 0 & 0.05 & 0.815 & 5111.5 & 5145.4 & 1.0 & 420.4 & 0.1 & 0.05 \\
\hline 2009 & F3 & M2 & $M-F$ & 195 & 30 & Oct & 1391.6 & 7618.7 & 75.3 & 13.8 & 1047.6 & 486.6 & 858.5 & 25.0 & 13.6 & 19.3 & 0 & 0.03 & 0.873 & 3866.6 & 3869.3 & 1.0 & 409.3 & 0.1 & 0.00 \\
\hline 2009 & F3 & M3 & $M-F$ & 194 & 21 & Oct & 1391.6 & 5488.4 & 19.2 & 4.9 & 267.7 & 486.6 & 2538.8 & 0.0 & 0.0 & 0.0 & 0 & & & 7286.1 & 7301.7 & 1.0 & 1109.0 & 0.2 & 0.20 \\
\hline 2009 & F3 & M4 & $M-F$ & 204 & 22 & Oct & 1391.6 & 5567.5 & 19.6 & 4.9 & 272.3 & 486.6 & 2771.7 & 8.3 & 1.4 & 4.9 & 0 & 0.02 & 0.889 & 6977.0 & 6974.2 & 1.0 & 1134.0 & 0.2 & 0.00 \\
\hline 2010 & F3 & M4 & $M-F$ & 187 & 15 & Sep & 2526.4 & 5278.4 & 25.9 & 12.4 & 653.3 & 488.4 & 1844.4 & 83.3 & 21.7 & 52.5 & 0 & 0.06 & 0.800 & 3812.7 & 3878.1 & 1.0 & 202.2 & 0.1 & \\
\hline 2009 & F3 & M5 & $M-F$ & 281 & 32 & Oct & 1391.6 & 4244.7 & 76.3 & 25.0 & 1062.3 & 486.6 & 718.4 & 0.0 & 0.0 & 0.0 & 0 & 0.04 & 0.836 & 3495.7 & 3486.2 & 1.0 & 309.1 & 0.1 & 0.00 \\
\hline 2010 & F3 & M8 & $M-F$ & 209 & 18 & Sep & 2526.4 & 3589.3 & 52.4 & 36.9 & 1323.7 & 488.4 & 996.6 & 29.2 & 14.0 & 21.6 & 0 & 0.01 & 0.922 & 3314.4 & 3266.9 & 1.0 & 281.3 & 0.1 & 0.01 \\
\hline 2010 & $\mathrm{~F} 4$ & M6 & M-F & 298 & 36 & Nov & 2129.6 & 8961.4 & 100.0 & 23.8 & 2129.6 & 740.4 & 2182.0 & 80.0 & 26.7 & 53.3 & 3.4 & 58.11 & $<0.001$ & 4319.7 & 4128.4 & 1.0 & 2.1 & 0.0 & 0.00 \\
\hline 2010 & F4 & M7 & $M-F$ & 134 & 25 & Nov & 2129.6 & 6080.6 & 88.3 & 30.9 & 1880.3 & 740.4 & 2937.9 & 85.0 & 21.3 & 53.1 & 7.5 & 71.65 & $<0.001$ & 4328.2 & 4066.0 & 1.1 & 5.2 & 0.0 & 0.19 \\
\hline 2010 & F4 & M8 & $M-F$ & 358 & 35 & Nov & 2129.6 & 4211.4 & 81.5 & 41.2 & 1735.1 & 740.4 & 1283.5 & 35.0 & 20.0 & 27.5 & 0.3 & 2.98 & 0.084 & 3115.6 & 2990.1 & 1.0 & 4.2 & 0.0 & 0.00 \\
\hline 2010 & F4 & M9 & $M-F$ & 346 & 35 & Nov & 2129.6 & 4212.5 & 12.9 & 6.5 & 273.9 & 740.4 & 975.4 & 0.0 & 0.0 & 0.0 & 0 & 0.11 & 0.744 & 4522.7 & 4650.7 & 1.0 & 113.4 & 0.0 & 0.00 \\
\hline 2009 & M1 & M2 & $M-M^{1}$ & 271 & 24 & June & 1082.9 & 711.3 & 65.6 & 99.9 & 710.9 & 189.2 & 86.9 & 50.0 & 100.0 & 75.0 & 43.2 & 416.33 & $<0.001$ & 420.3 & 1488.8 & 0.3 & 0.4 & 0.0 & 0.72 \\
\hline 2009 & M1 & M3 & $M-M$ & 291 & 30 & June & 1082.9 & 8456.6 & 67.6 & 8.7 & 731.8 & 189.2 & 2886.4 & 20.0 & 1.2 & 10.6 & 0 & - & - & 5200.3 & 5203.2 & 1.0 & 374.0 & 0.1 & 0.01 \\
\hline 2009 & M1 & M4 & $M-M$ & 262 & 27 & June & 1082.9 & 8065.4 & 60.0 & 8.1 & 649.5 & 189.2 & 2793.7 & 20.0 & 1.3 & 10.6 & 0 & - & - & 5059.2 & 5067.7 & 1.0 & 291.0 & 0.1 & 0.00 \\
\hline 2009 & M2 & M3 & $M-M$ & 273 & 34 & Oct & 7618.7 & 5488.4 & 31.6 & 43.9 & 2411.0 & 858.5 & 2538.8 & 0.0 & 0.0 & 0.0 & 0.4 & 0.75 & 0.388 & 6359.9 & 6247.5 & 1.0 & 44.0 & 0.0 & 0.05 \\
\hline 2009 & M2 & M4 & $M-M$ & 281 & 37 & Oct & 7618.7 & 5567.5 & 31.9 & 43.7 & 2433.3 & 858.5 & 2771.7 & 9.1 & 2.8 & 5.9 & 0.4 & 0.16 & 0.689 & 5870.7 & 5776.9 & 1.0 & 23.8 & 0.0 & 0.00 \\
\hline 2009 & M2 & M5 & $M-M$ & 284 & 42 & Oct & 7618.7 & 4244.7 & 15.4 & 27.7 & 1175.5 & 858.5 & 718.4 & 0.0 & 0.0 & 0.0 & 0 & 0.01 & 0.918 & 4766.4 & 4809.3 & 1.0 & 815.4 & 0.2 & 0.00 \\
\hline 2009 & M3 & M4 & $M-M^{2}$ & 241 & 27 & June & 8456.6 & 8065.4 & 93.3 & 97.8 & 7890.4 & 2886.4 & 2793.7 & 83.6 & 86.3 & 84.9 & 92.9 & 18360.91 & $<0.001$ & 20.6 & 4242.1 & 0.0 & 1.2 & 0.0 & 0.00 \\
\hline 2009 & M3 & M4 & $M-M^{2}$ & 347 & 35 & Oct & 5488.4 & 5567.5 & 99.1 & 97.6 & 5436.5 & 2538.8 & 2771.7 & 89.4 & 81.9 & 85.7 & 85.3 & 43281.21 & $<0.001$ & 206.7 & 4438.4 & 0.0 & 0.2 & 0.0 & 0.00 \\
\hline 2009 & M3 & M5 & $M-M$ & 319 & 33 & Oct & 5488.4 & 4244.7 & 15.3 & 19.8 & 840.9 & 2538.8 & 718.4 & 3.0 & 11.1 & 7.1 & 0 & 0.07 & 0.798 & 5258.8 & 5201.6 & 1.0 & 368.8 & 0.1 & 0.02 \\
\hline 2009 & M4 & M5 & $M-M$ & 310 & 34 & Oct & 5567.5 & 4244.7 & 15.3 & 20.0 & 851.0 & 2771.7 & 718.4 & 11.1 & 44.4 & 27.8 & 0 & 0.30 & 0.586 & 5194.8 & 5141.3 & 1.0 & 220.6 & 0.0 & 0.11 \\
\hline 2010 & M4 & M8 & $M-M$ & 515 & 43 & Sep & 5278.4 & 3589.3 & 8.3 & 12.2 & 439.6 & 1844.4 & 996.6 & 16.3 & 30.0 & 23.2 & 0 & 0.01 & 0.914 & 5435.1 & 5322.4 & 1.0 & 470.9 & 0.1 & 0.00 \\
\hline 2010 & M6 & M7 & $M-M^{3}$ & 267 & 37 & Nov & 8961.4 & 6080.6 & 65.3 & 96.2 & 5851.8 & 2182.0 & 2937.9 & 93.3 & 70.0 & 81.7 & 20.6 & 2212.21 & $<0.001$ & 2302.9 & 4920.5 & 0.5 & 2.3 & 0.0 & 0.52 \\
\hline 2010 & M6 & M8 & $M-M$ & 393 & 41 & Nov & 8961.4 & 4211.4 & 41.5 & 88.4 & 3722.0 & 2182.0 & 1283.5 & 55.0 & 94.3 & 74.6 & 0 & 0.66 & 0.417 & 3857.8 & 3783.3 & 1.0 & 53.2 & 0.0 & 0.13 \\
\hline 2010 & M6 & M8 & $M-M$ & 348 & 55 & Dec & 6909.4 & 2089.4 & 29.6 & 97.8 & 2044.3 & 3040.3 & 628.9 & 13.0 & 64.3 & 38.7 & 0 & 0.06 & 0.815 & 4336.1 & 4315.4 & 1.0 & 489.9 & 0.1 & \\
\hline 2010 & M6 & M9 & $M-M$ & 488 & 51 & Nov & 8961.4 & 4212.5 & 17.7 & 37.6 & 1585.7 & 2182.0 & 975.4 & 23.3 & 53.8 & 38.6 & 3.5 & 68.57 & $<0.001$ & 4791.1 & 4849.2 & 1.0 & 3.1 & 0.0 & 0.00 \\
\hline 2010 & M7 & M8 & $M-M$ & 279 & 37 & Nov & 6080.6 & 4211.4 & 57.8 & 83.4 & 3512.2 & 2937.9 & 1283.5 & 40.0 & 91.4 & 65.7 & 0.4 & 2.65 & 0.103 & 4203.1 & 4269.0 & 1.0 & 2.7 & 0.0 & 0.01 \\
\hline 2010 & M7 & M9 & $M-M$ & 287 & 37 & Nov & 6080.6 & 4212.5 & 17.0 & 24.5 & 1033.8 & 2937.9 & 975.4 & 17.5 & 53.8 & 35.7 & 0.7 & 8.80 & 0.003 & 5644.5 & 5546.7 & 1.0 & 34.0 & 0.0 & 0.00 \\
\hline 2010 & M8 & M9 & $M-M$ & 302 & 27 & Oct & 3301.1 & 2183.3 & 21.4 & 32.3 & 705.2 & 754.4 & 851.0 & 10.5 & 9.1 & 9.8 & 0 & 0.06 & 0.802 & 3627.8 & 3592.9 & 1.0 & 125.9 & 0.0 & 0.20 \\
\hline 2010 & M8 & M9 & $M-M$ & 321 & 32 & Nov & 4211.4 & 4212.5 & 35.3 & 35.3 & 1488.6 & 1283.5 & 975.4 & 31.4 & 42.3 & 36.9 & 0.3 & 0.01 & 0.933 & 2958.4 & 3689.9 & 0.8 & 45.6 & 0.0 & \\
\hline
\end{tabular}

${ }^{a}$ Triadic likelihood estimator TrioML based on 16 microsatellite markers applied to a population of 33 individuals (see Chapter 3 for details). Close relatedness $(r>0.5)$ is marked in bold. 


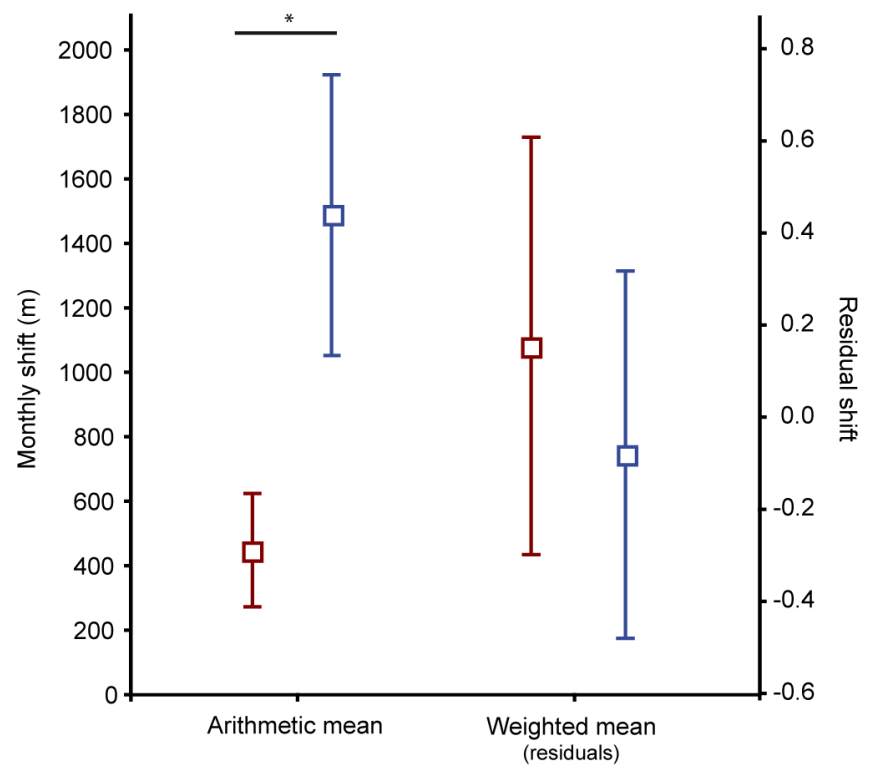

Fig. 2 Monthly MCP home range shifts of arithmetic means (left) and weighted means (right) for males (blue) and females (red). Plotted are means (squares) and 95\% confidence intervals (whiskers). Weighted means were controlled for difference in absolute home range size and only residuals were plotted. Statistical differences are indicated as '*' for $P<0.05$ from LMMs (see Appendix I, Tables A3 and A4).

\section{Dyadic interaction}

We could neither find a relationship between home range size and the probability of two individuals to overlap, nor between the probability of two individuals being tracked within $50 \mathrm{~m}$ (binomial regression: $P>0.05$ ). Male-male dyads were, however, found more often within $50 \mathrm{~m}$ than malefemale dyads $(z=-2.70, P=0.007, n=30)$.

Doncaster's dynamic interaction test revealed that the only non-exclusive female-female dyad interacted randomly $\chi^{2}{ }_{1}=0.094, P=0.760$ ) despite $76 \%$ of MCP overlap (Table 2). Females generally avoided conspecifics at a higher contact radius than the critical distance of $50 \mathrm{~m}$ (Table 2). A comparison of observed inter-individual distances with those predicted by the model revealed that female-female dyads maintained larger distances than expected, and they differed in this respect from all other dyads (Mann-Whitney $U$ test: $Z=2.81, P=0.005, n=36$; Appendix I, Fig. A2). Moreover, females maintained higher minimum distances to conspecifics of either sex than males ( $Z$ $=2.06, P=0.038, n=53$ ), with highest separations to other females, when related to observed average distances (Table 2).

Male-male dyads showed dyadic variability in accordance with variability in extent of kernel overlap. Whereas 13 male-male dyads exhibited random interaction $\left(\chi_{1}^{2} \leq 2.65, P \geq 0.103\right.$; Table 2; Appendix I, Fig. A3), the three male dyads with exceptionally high kernel overlap showed high attraction $\left(X_{1}^{2} \geq 416.33, P<0.001\right)$ and were found within $50 \mathrm{~m}$ at $21 \%, 43 \%$ and $88 \%$, respectively, of the positions tracked (Table 2). Figure 3 shows the respective deviation of observed inter-individual distances from expected values for the three dyads. Accordingly, they showed lower average interindividual distances than expected and differed in this respect from all other dyads (Mann-Whitney $U$ test: $Z=2.81, P=0.005, n=36$; Table 2). Since these males could be shown to be gregarious with stable social interaction partners, we refer to them as 'associated males' as opposed to 'solitary males'. The association M6-M7 was found in close proximity to M9 more often than expected $\left(\chi_{1}^{2} \geq\right.$ 
8.80, $P<0.003$; Table 2). This may, however, represent an artefact of temporary close proximity at a mating site where males aggregated without true social interaction.

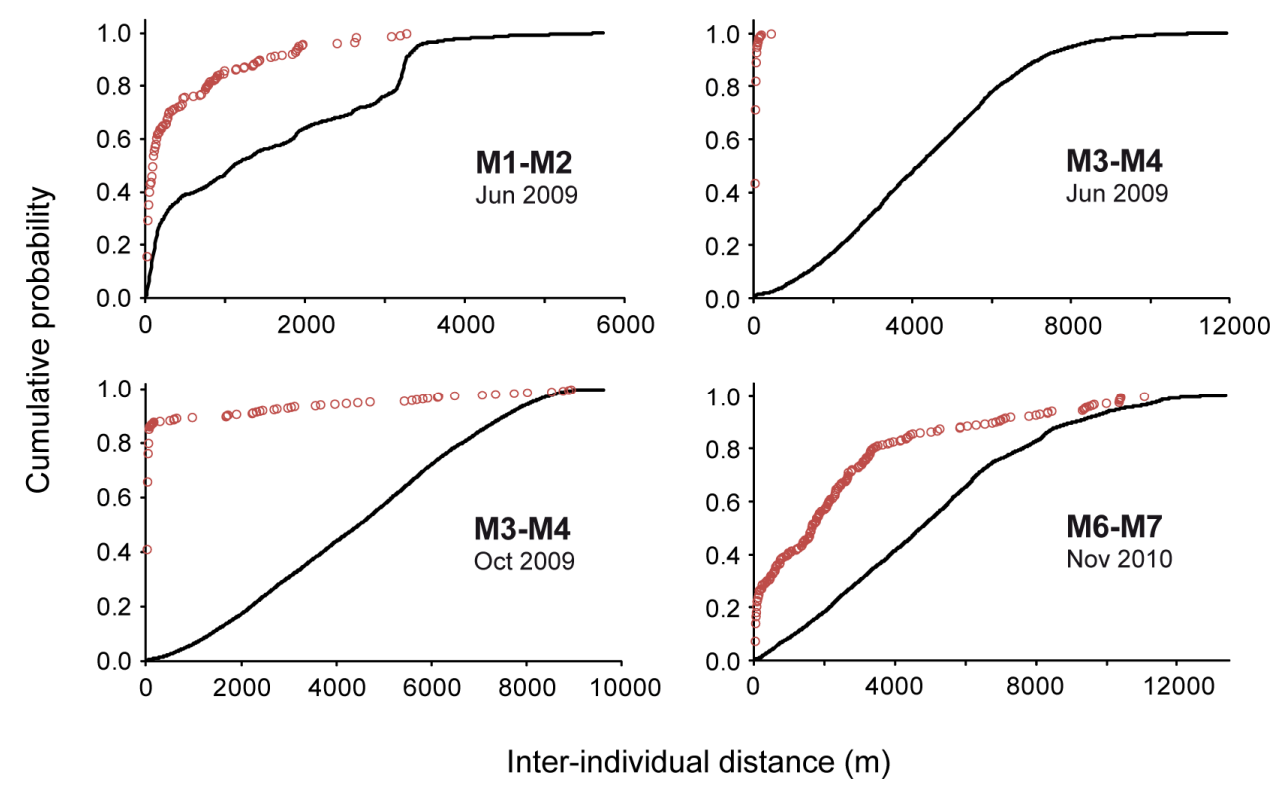

Fig. 3 Cumulative probabilities of observed (red circles) and expected (black line) inter-individual distances for three simultaneously tracked male-male dyads which were classified as 'associated'. Expected values were calculated according to Doncaster (1990) from all possible $n^{2}$ distances between $n$ positions of both individuals. As opposed to solitary males (cf. Appendix I, Fig. A3), associated males can be recognised by large deviation of observed proximity from random expectation.

Male-female dyads interacted randomly $\left(\chi^{2}{ }_{1} \leq 3.42, P \geq 0.076\right.$; Table 2$)$, except for one male association (M6-M7) being found close to female F4 more often than expected $\left(\chi^{2}{ }_{1} \geq 58.11, P<0.001\right.$; Table 2; Appendix I, Fig. A4). This attraction was mainly driven by close proximity during the mating season and was therefore probably related to sexual activity. Only one male-female dyad (M1-F1) actively avoided each other at the critical distance $\left(\chi_{1}^{2}=10.89, P<0.001\right)$. This dyad, however, could not be shown to avoid each other in comparisons of observed and expected average distances (Table 2). MCP overlap between these two individuals was relatively low (36.9\%) and interaction assessment may therefore be less reliable.

\section{Differences between solitary and associated males}

In comparison to solitary males and females, associated males inhabited larger MCP ranges (LMM: $t$ $=5.35, P<0.001, n=9$; Appendix I, Table A2). Differences in range overlap could not be globally evaluated because two dyads of associates ranged far outside of the study area, where information about the number of resident males and females was unavailable. The only associated dyad within the main study area did not show signs of territorial defence, however. Individual-based comparison revealed that associated males overlapped with ranges of non-associated males by $30.2 \pm 17.4 \%$ SD, which was comparable to solitary males' overlap with other males (31.5 $\pm 12.7 \%$ SD; Table 2$)$. 
Absolute $50 \%$ kernel areas overlapping with females did not differ between associated and solitary males (Mann-Whitney $U$ test: $Z=-0.75, P=0.456, n=9$ ), nor did overlap with non-associated males $(Z=1.10, P=0.272, n=13)$. A difference emerged, however, in kernel overlap of male associations among each other when compared to other male-male dyads, with different associations obviously avoiding each other's kernel areas (Mann-Whitney $U$ test: $Z=-2.03, P=0.042, n=20$; Table 2). This could not be confirmed for inter-individual distances, where factors of observed distances between opponent associated males were comparable to other non-associated male-male dyads $(Z=0.42, P=$ $0.671, n=12$ ).

\section{Discussion}

As predicted, we found no indication for female sociality, but indications for female territoriality. Furthermore, males expanded their ranges towards the mating season and shifted their ranges in space, whereas those of females remained stable in space and time. Male associations were characterised by extensive dyadic overlap and frequent close proximity. In contrast to solitary males, associated males inhabited larger ranges and therefore potentially overlapped with more females, even though we were unable to quantify the latter. There were no indications for male territoriality suggesting that male association serves purposes other than territorial defence. We therefore conclude that female fosas are truly solitary whereas males can either live solitarily or permanently associated with other males. Such intra-specific social variability is a rare phenomenon among mammals that we discuss in more detail below.

The observed pattern of female social organisation fits general predictions for a hypercarnivorous species, where females cannot afford to compete with other females for a scarce food resource. Female fosas seem to be truly solitary with clear indications of territoriality, which is in line with previous studies (Hawkins \& Racey 2005). Although the present sample size only permits preliminary conclusions, we found an unrelated female dyad to have exclusive ranges and both range borders (as reflected in arithmetic mean) and range sizes and locations were stable in space and time for four females. The only exception was found for a mother-daughter dyad (F1-F3), which shared a common territory but still avoided social contact, as indicated by their exclusive $50 \%$ kernels, random pattern of dynamic interaction and an average inter-individual distance of $2.6 \mathrm{~km}$. Interestingly, we found no indication for an effect of a second female's presence on territory size. This is generally predicted by the resource dispersion hypothesis ( $R D H)$ if resource richness is high enough to allow tolerance of conspecifics at low cost. Relatedness may reduce the costs of tolerance in this case (Lindström 1986), especially when both females preferentially use different areas within their territory and thereby reduce scramble competition for food. The stability of female territory size across seasons and years suggests in line with the RDH that territory size is adapted to resource dispersion and to the minimum territory size needed to sustain its inhabitant (and potential dependent offspring) during lean periods such as the dry season.

In contrast, ranging patterns observed in male fosas were only partly consistent with general patterns found in other carnivorous and polygynous species. Males had larger ranges than females because they compete not only for food but more so for females and therefore additionally expanded their ranges during the mating season. Since the fosa's mating system is characterised by seasonal aggregation at specific mating trees (Hawkins \& Racey 2009; Chapter 4), it may be more 20 
important for males to keep track of the locations of mating trees than to defend female territories year-round. Males are therefore more likely to benefit from seasonal expansion of their range in combination with a search for mating trees than from maximising exclusive overlap with females in general. This is a clear distinction of this system from other solitary carnivores, where female territoriality promotes year-round male monopoly and resident males gain benefits in mating success (Sandell 1989).

The most striking result of this study concerns facultative male sociality. As revealed by Doncaster's dynamic interaction test, some males associated with stable partners, even though the degree of cohesion varied extensively. Associated males' ranges overlapped much more than those of any other dyad, and clearly deviated in their interaction pattern from random expectation, whereas non-associated male dyads did not. This aspect of male social organisation appears to contradict the general hypercarnivore pattern, because some males associate despite a disperse distribution of females. The coexistence of two male tactics of sociality in fosas may be explained by one of the following scenarios: life-long association of male litter-mates, male bachelor groups, population density effects, or constraints on group formation by solitary males.

Male associations in fosas may represent a convergent behavioural adaptation to associations of litter-mates in cheetahs. Similarities between these two species can be found for association size, which in both cases corresponds to a maximum litter-size of three offspring, the proportion of associated males in a population, as would be expected if litter sex ratio was a crucial determinant (about 60\%; Caro \& Collins 1986), and the apparent temporal stability of association composition. If males were socially flexible and coalition formation was temporal, the observed association would have changed in composition over the course of our study. A switch in association partners has never been observed in fosas, however. Anecdotal observations indicate instead that two males that lost their partners due to fatalities never paired up with another male.

In contrast to cheetahs, associated fosa males did not defend an exclusive territory, although they seemed to maintain site fidelity within larger ranges and therefore potentially gained access to more females than solitary males. We cannot exclude the possibility that non-exclusivity of male ranges in fosas is a consequence of high male density. We did find, however, another meaningful difference between fosas and cheetahs. In an earlier study (Chapter 3), we investigated genetic relationships and found that two out of five male associations consisted of non-relatives (see Table 2 for relatedness of associates referred to in this study). Kinship alone is therefore insufficient to explain male associations in this species. Evident similarities between cheetah associations and fosas are therefore limited to range size and composition, and alternative explanations such as bachelor male groups need to be considered.

Groups of bachelor males have been reported from a number of group-living ungulates (e.g., Jarman 1974; Feist \& McCullough 1975; Klingel 1975; Clutton-Brock et al. 1982), primates (e.g., Pusey \& Packer 1987) and other taxa. These associations of not necessarily related males provide benefits of group-living to their members without a cost of shared reproduction because bachelor males rarely gain access to females before they achieve territory-holding positions. These groups often consist of young males lacking physical strength to compete with older males for access to females. Associated fosa males are unlikely to represent an example of bachelor groups. First, females are solitary and far-ranging and can therefore not be monopolised by single males. Males therefore 
compete with each other temporarily for mating opportunities, rather than for exclusive territories to gain access to females. Male associations seem to be stable year-round and are therefore unlikely to form in order to challenge other males temporarily. Second, there is no indication for an age difference between solitary and associated males (Chapter $\mathbf{3}$ ). Sociality is therefore unlikely to represent an age-dependent phenomenon in this species.

Since male distribution is determined by female distribution, male sociality would be predicted under high female density and a female-biased sex ratio. Our trapping data and female territoriality suggest, however, that male density in Kirindy Forest is three times as high as female density. Female density is therefore unlikely to promote male sociality in this case. On the other hand, a male bias within the population may facilitate the formation of associations, with lower costs of shared reproduction even among unrelated coalition members, compared to single males trying to compete independently with all other males in the population. Under these circumstances, male associations may alternatively be explained by high intra-sexual competition due to male-biased sex ratio.

These effects of mate competition are insufficient to explain why only a subset of males formed coalitions, however. The persistence of solitary males, in combination with the observed stability in composition of associations, indicates a constraint in social tolerance for males in general. While male litter-mates may easily associate due to familiarity, unrelated associates may rely on either familiarity or a sensitive developmental phase of social tolerance to ally. As mentioned earlier, associates do not differ in age from solitary males and more so, members of a given association appear to be of similar age. Furthermore, the youngest unrelated association is subadult and likely reached independence only recently (Chapter 3). It may thus be this phase of early independence where males may either form associations or stay alone for the rest of their life. Escalated intrasexual competition in combination with temporally limited social tolerance may thus explain the coexistence of solitary and associated males in our study population.

What remains to be clarified, however, is why females seem to be socially intolerant, whereas some males tolerate associations even with unrelated males. Recent research on wolverines (Dalerum 2005; Dalerum et al. 2006) suggested that solitary carnivore species may potentially be much more socially tolerant than previously assumed (cf. Kleiman \& Eisenberg 1973). In fact, carnivores show high social flexibility in grouping tendencies when resource availability increases (e.g., red foxes: reviewed in Cavallini 1996; badgers: reviewed in Woodroffe \& Macdonald 1993; da Silva et al. 1993). In accordance with the RDH, carnivore group size is therefore likely limited by resource productivity alone, suggesting that a change in resource patch richness would promote sociality even in otherwise strictly solitary species (such as the wolverine). In fosas, group size appears to be limited to three individuals because larger associations have never been observed. In fact, associations of three individuals have a strong skew in body condition with one individual being poorly developed. If the biggest prey type (a $3 \mathrm{~kg}$ lemur of the genus Propithecus) or the highest density prey (Tenrecidae) in Kirindy Forest do not permit association of more than two individuals, females with dependent offspring cannot afford tolerance of other individuals. Food competition and potential reproductive suppression (da Silva et al. 1994; Dalerum et al. 2006) may therefore explain why fosa females are socially intolerant. 
We conclude that limited food resource availability most likely constrains permanent association in female fosas, while male dyadic sociality appears to be promoted by high intra-sexual competition. Mechanisms involved in association formation are likely to explain why sociality is limited to a subset of males but remain to be illuminated. Further research will be required to investigate the phenomenon of facultative male sociality in solitary carnivores in more detail in order to understand whether factors constraining female sociality and promoting male sociality are equivalent. 


\title{
Chapter 2
}

\section{An unusual case of cooperative hunting in a solitary carnivore}

Mia-Lana Lührs \& Melanie Dammhahn

\begin{abstract}
Cooperative hunting has been documented for several group-living carnivores and had been invoked to be either the cause or the consequence of sociality. We report the first detailed observation of cooperative hunting for a solitary species, the Malagasy fosa (Cryptoprocta ferox). We observed a 45minutes-hunt of a 3-kg arboreal primate by three male fosas with changing roles among the hunters and subsequent share of prey. We hypothesise that social hunting in fosas could have either evolved to take down recently extinct larger lemur prey or could be a by-product of male sociality which is beneficial for other reasons.
\end{abstract}

Journal of Ethology (2010) 28: 379-383 


\section{Introduction}

The vast majority of carnivores are solitary (80-95\%: Bekoff et al. 1984) and are therefore found to hunt alone. Combined action of several individuals to take down and share prey has been described for several group-living carnivores, e.g. lions (Schaller 1972; Packer et al. 1990), wild dogs (Estes \& Goddard 1967; Creel \& Creel 1995), wolves (Mech 1970), and hyaenas (Kruuk 1972, 1975; Mills 1990). Indeed, cooperative hunting has been suggested to be closely linked to the social organisation of a species either by being the cause of sociality (Creel \& Creel 1995) or by being its consequence (Packer \& Ruttan 1988). It has been suggested that cooperative hunting may favour sociality when prey is too large or too difficult to be taken down by a single individual (Schaller 1972; Kruuk 1975; Creel \& Creel 1995). Similarly, sociality may offer the possibility to hunt socially, thereby extending the range of prey species secondarily (Schaller 1972). So far, cooperative hunting of non-gregarious carnivores has been described only once anecdotally for the solitary Canadian lynx (Lynx canadensis; Barash 1971). Therefore, whether and why solitarily ranging and foraging individuals associate to hunt together remains unclear. Here, we report the first detailed observation of an unusual case of cooperative hunting in an otherwise solitary carnivore, the fosa.

The fosa (Cryptoprocta ferox) is the largest extant member of the Madagascar mongooses (Eupleridae). It is restricted to Madagascar and potentially widespread on the island but threatened by habitat loss. Males $(\leq 12 \mathrm{~kg}$ ) are heavier than females $(<9 \mathrm{~kg})$. Fosas are adapted to arboreal locomotion by short muscular limbs and a long tail. Nevertheless, in the dry deciduous forests of western Madagascar, they are frequently found on the ground and climb up trees only for hunting or mating. Fosas are exclusively carnivorous, feeding on a variety of vertebrates, but mostly lemurs and tenrecs (Hawkins \& Racey 2008; Chapter 3). Their social organisation has been classified as solitary because individuals are usually encountered alone (Hawkins \& Racey 2005). However, a number of anecdotal reports of social hunting have accumulated over the past 16 years from Kirindy Forest/CNFEREF and Andasibe-Mantadia National Park (Table 1). These hunting events typically included two individuals and were directed towards the highly agile sifakas (genus Propithecus, Primates).

Table 1 Anecdotal reports of socially hunting fosas in Kirindy Forest/CNFEREF and Mantadia National Park.

\begin{tabular}{clccll}
\hline Location & Observer & No. individuals & Sex composition & Prey & Outcome \\
\hline Mantadia & N. Garbutt, J. Powzyk & 2 & F, M & Propithecus diadema & failed \\
Mantadia & N. Garbutt & 2 & unknown & P. diadema & unknown \\
Kirindy & M.S. Razafindrasamba & 2 & F, M & P. verreauxi & catch $^{\text {Ka }}$ \\
Kirindy & Tourist guide & 2 & M, M & P. verreauxi & catch $^{\text {a }}$ \\
Kirindy & C. Rakotondrasoa & 2 & M, M & P. verreauxi & failed (disturbed)
\end{tabular}

$F$ female, $M$ male, ${ }^{a}$ no direct observation of the hunt but of two males feeding on a carcass

\section{Material and Methods}

This observation was made coincidentally on $29^{\text {th }}$ September 2007 during the course of a study on fosa behavioural ecology in Kirindy Forest/CNFEREF, a dry deciduous forest in central western 
Madagascar. This forest is characterised by pronounced seasonality. During a long dry season (May October) little or no rain falls and fosas suffer from water scarcity, low food availability and lack of cover. In the dry season, fosas exert considerable predation pressure on lemurs ( $>50 \%$ of their diet) with a clear preference for larger species (Rasoloarison et al. 1995; Hawkins \& Racey 2008). The largest extant lemur in Kirindy Forest/CNFEREF is the Verreaux's sifaka (Propithecus verreauxi). Sifakas are arboreal vertical clingers and leapers, weigh up to $3.5 \mathrm{~kg}$ and live in mixed-sex groups of 4 adult individuals on average (Kappeler \& Schäffler 2008). The following observation was made from wooden shelters, usually used as housing for researchers, at the field station of the German Primate Center, which is located in Kirindy Forest/CNFEREF. The shelters are distributed in the forest around the central camp site and will be named with letters according to their sequence of occurrence during the course of the hunt.

\section{Results}

We were attracted to the situation by three male fosas passing by the camp site in single file and subsequent terrestrial predator alarm calls uttered by a group of sifakas (Fichtel \& Kappeler 2002). One observer (MLL) followed the fosas and could observe the complete course of the hunt from a distance of about 5-30 m. When the observer arrived at shelter A (Fig. 1; 16:20), one sifaka had been isolated from its group.
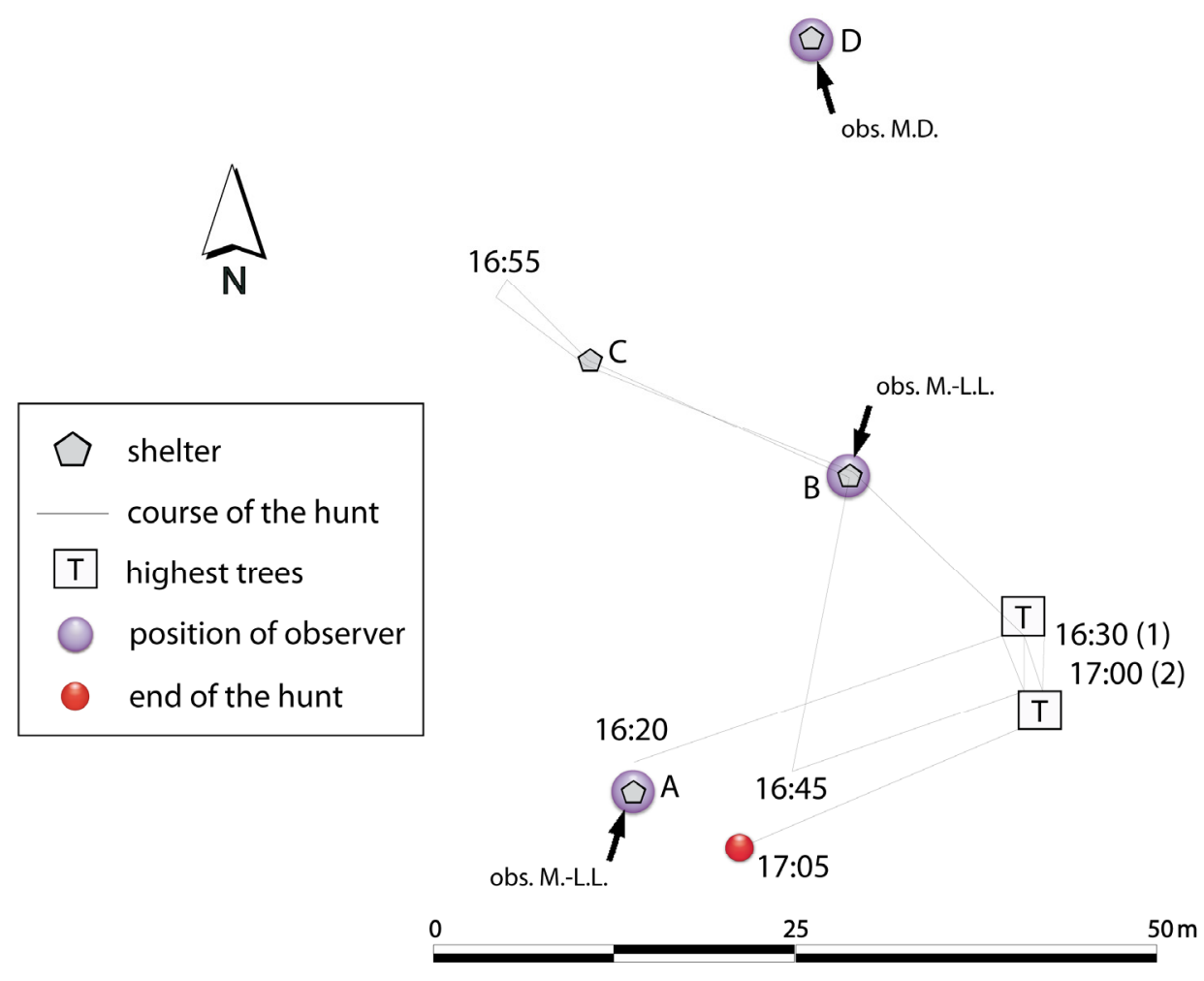

Fig. 1 Course of the hunt with chronological information and indicated positions of the observers (obs.). Letters assigned to platforms are given according to their occurrence in the text. 
Two fosas climbed up two different trees and chased the sifaka in an easterly direction. The third fosa followed the sifaka on the ground. The latter fled up the highest tree in the area where it was forced to jump to the neighbouring second highest tree by a climbing fosa. It followed a sequence of five changes between the two trees (ca. $15 \mathrm{~m}$ in height) when one fosa consistently followed the sifaka, which on each occasion climbed up to the highest point of the tree until the fosa came as close as $5 \mathrm{~m}$ before it jumped to the neighbouring tree. A second fosa climbed up smaller trees surrounding the scene but could not find access to the sifaka. The third fosa moved rapidly on the ground. During the chase, a breaking branch led to the fall of one fosa to the ground. Thereafter, the hunt paused for $12 \mathrm{~min}$. The sifaka stayed at the top of the highest tree and lowered volume and frequency of its alarm calls.

When the hunt resumed, the fosas changed their hunting behaviour. Instead of one fosa following the sifaka, two individuals alternated in climbing up the two highest trees until the lemur jumped again to the other one. This led again to a sequence of changes between the two trees until two fosas appeared simultaneously in both trees and forced the sifaka to jump into the lower canopy. One fosa followed up in the tree, another on the ground. The third lay down on a branch for a moment and did not follow until the hunt went on in westerly direction. In the following, two fosas up in trees chased the sifaka back to northerly direction, the third following the sifaka on the ground. When at shelter $B$, one observer (MLL) was surrounded by the animals and could observe that the three fosas alternated in their roles of tree-chasing and ground-following and vocalised with each other by guttural sounds, which are better known to be uttered in aggressive interactions (Albignac 1973). The chase proceeded to the direction of shelter C, close to shelter $D$ where the second observer was located (MD). M. D. reported that the guttural vocalisation always preceded a change in the hunting roles among the fosas but none of the observers could determine which of the fosas addressed it to which other. At this stage, the chase was performed at much higher speed and the fosas never jumped more than twice behind the sifaka before they alternated with another individual. The sifaka fled back to the highest trees and was chased afterwards in southern direction to shelter A. By now, all three fosas hunted up in the trees and jumped as quickly and as far as the lemur. After another fall of one of the fosas and an adjacent re-formation of the hunters, they finally succeeded in driving the lemur towards the ground where they rapidly took it down (17:05). A choking scream emitted by the sifaka indicated that it was killed by a throat bite but the actual killing occurred out of view. One observer (MLL) hid on shelter C in order to observe the fosas feeding on their prey, whereby the carcass itself was out of view but sounds clearly indicated feeding activity.

During the following feeding bout the males shared the prey without apparent aggression. While one male was waiting at shelter $\mathrm{C}$, the other two fed together on the carcass. 15 minutes later, one male left the remains and retired under shelter $\mathrm{C}$. Only then, the third male approached the carcass and started feeding. The two males fed together for 13 minutes and then the second male returned to the shelter to rest. The third male joined the two another five minutes later and all fosas rested together. At 17:50, all three males set off together in direction of the remains and finally left the area at 18:00. 


\section{Discussion}

Cooperative hunting has been described for gregarious carnivores only and has been explained for group-living species by a number of factors relating to prey or predator. Prey which is difficult to hunt might necessitate the cooperative action of several individuals to hunt successfully (Kruuk 1972, 1975; Schaller 1972). For example, the chances of taking down highly resistant or agile prey might be unlikely when hunting alone. One main prey type of fosas are sifakas (Wright et al. 1997; Hawkins \& Racey 2008), which are highly agile arboreal leapers, and thus difficult to hunt in 3-dimensional space. It has been argued that a similar challenge has led to complex cooperative hunting behaviour in chimpanzees, even including different hunting roles adopted by the individuals involved (Boesch 2002). Given the agility of their prey, single fosas might have difficulties to catch sifakas other than by ambush at night.

Cooperative hunting can further be advantageous when the prey is too large to be taken down by a single individual. With $3 \mathrm{~kg}$ body mass, sifakas are much smaller than fosas. Furthermore, the per capita energy intake from a sifaka prey might not be sufficient to fuel a 35-min intensive chase of several hunting individuals, as we reported here. Yet, prey size might have played a role in the evolution of cooperative hunting in fosas because the fauna of Madagascar has changed dramatically during the recent past. Only $500-1500$ years ago, larger lemurs such as the most recently extinct giant sloth lemurs, weighing 9-55 kg, were widely distributed across the island (Godfrey \& Jungers 2003). Even though these lemurs might have been mainly preyed upon by the extinct giant fosa (Cryptoprocta spelea; Goodman et al. 2004), its smaller congener might have hunted sloth lemurs by joint action. Hence, fosas could have evolved cooperative hunting to take down larger lemur prey. Because this type of prey went extinct quite recently, this behaviour may still exist although there is little benefit left.

Alternatively, hunting associations may be a by-product of sociality when associating is beneficial for other reasons, e.g. communal protection of young and territory defence (e.g., lions: Packer et al. 1990; Fryxell et al. 2007; Mosser \& Packer 2009). Fosas are most often encountered solitarily and inhabit wide ranges which seem to be exclusive at least for females (Hawkins and Racey 2005). However, in Kirindy, mainly during the end of the dry season, coinciding with the annual mating season, males are frequently observed in close and stable associations (Chapter 1 and 3) indicating a possible function in the reproductive context. The social organisation of fosas may resemble that of cheetahs, where male coalitions consist of two to three individuals, most often brothers, which associate in order to jointly defend a territory and frequently hunt together (Caro \& Collins 1987a; Caro et al. 1989; Caro 1994). In the case of the fosa, males might primarily associate to jointly defend access to females in a highly competitive polyandrous mating system (Hawkins \& Racey 2009). The existence of such male coalitions have been reported for more closely related solitary mongooses as well (e.g., Waser et al. 1994) and may be the prerequisite for male sociality and social hunting.

In contrast, male-female associations in fosas have never been observed outside the mating season, except for mother-offspring-dyads. It appears likely therefore that the observations of males and females hunting socially include mothers and their male offspring.

Overall, cooperatively hunting carnivores show high plasticity in their social organisation ranging from otherwise non-synchronised individuals to highly cohesive groups (e.g., lions: Schaller 
1972). Hence, fosas may represent the least gregarious species within a continuum of gregariousness among cooperatively hunting carnivores. A better understanding of the primary causes of sociality in fosas may therefore illuminate the relationship between gregariousness and food acquisition in carnivores in general. 


\title{
Chapter 3
}

\section{Strength in numbers: males in a carnivore grow bigger when they associate and hunt cooperatively}

Mia-Lana Lührs, Melanie Dammhahn \& Peter M. Kappeler

\begin{abstract}
Group-living has been recognised as one of the major transitions in evolution. Male sociality along with solitary females is rare in mammals, but it can provide unique insights into the evolution of sociality and cooperation. Because males compete with each other over females, male cooperation in mammals has been explained by joint defence of females against other males. Here we demonstrate that the benefits of male cooperative hunting can play a major role in shaping sociality. By quantifying differences in morphology, activity, diet and mating success, we show that in Madagascar's top predator, the fosa (Cryptoprocta ferox), some males associate to jointly hunt large prey, which allows them to grow bigger than both solitary males and females. These associated males' physical superiority also represents an advantage in contest competition for females, as reflected by higher mating success. Our results demonstrate that enhanced access to food resources by cooperative hunting is a key to physical development and competitiveness in fosas. In contrast to previous findings, we show that male sociality must not be limited to joint defence of territory and females, but that cooperation in food acquisition can favour sociality in sexually dimorphic species.
\end{abstract}

Revised manuscript for publication in Behavioral Ecology 


\section{Introduction}

The evolution of group-living from solitary ancestors remains a hot topic in behavioural ecology (e.g., Port et al. 2011; Shultz et al. 2011; Ebensperger et al. 2012; Schradin et al. 2012). Sociality yields both benefits in terms of decreased predation risk and improved resource defense, but also costs in the form of enhanced feeding and mating competition (reviewed in Krause \& Ruxton 2002). According to socio-ecological theory (Crook \& Gartlan 1966; Macdonald 1983; Terborgh \& Janson 1986; Ims 1988), female sociality is largely determined by the distribution and quality of food resources, whereas male sociality is mainly a response to female distribution. Since females compete with each other over food, whereas males compete over females (Darwin 1871; Emlen \& Oring 1977; Clutton-Brock 1989; Andersson 1994), males rarely exhibit gregarious tendencies in species where females are solitary. However, such male associations have been described, inter alia, in some carnivores with solitary females (cheetahs (Acinonyx jubatus): Caro \& Collins 1987a,b; slender mongooses (Galerella sanguinea): Rood 1989; Waser et al. 1994; kinkajous (Potos flavus): Kays \& Gittleman 2001), where cooperation among allies can outweigh the costs of competition for access to females when cooperation serves joint defence of territory and females against other males (Axelrod \& Hamilton 1981; Caro \& Collins 1987a,b; Waser et al. 1994; Clutton-Brock 2009). The fact that male sociality is a very rare phenomenon indicates, however, that the related costs are presumably high.

Precursory forms of sociality, such as facultative sociality in carnivores (e.g., herpestids: Rood 1989; Waser et al. 1994; felids: Caro \& Collins 1986, 1987; canids: Cavallini 1996; mustelids: Kruuk \& Parish 1987; procyonids: Gompper 1996; Kays \& Gittleman 2001), represent an ideal test case to identify the forces that favoured the evolutionary origins of group-living. We therefore studied the social system of fosas (Cryptoprocta ferox, Eupleridae), the largest Malagasy carnivore, in a seasonal environment where intense competition for food resources is expected during large parts of the year for an exclusively carnivorous species (Hawkins \& Racey 2008). Adult female fosas are solitary, whereas males are either solitary or associate in pairs or trios (Chapter 1). Male associations are stable across seasons and years, and members of the same association have been observed to hunt cooperatively (Lührs \& Dammhahn 2010). The fosa's mating system is unique among mammals in that it is characterised by seasonal aggregations of males at traditional mating trees (Hawkins \& Racey 2009), which are temporarily occupied by up to three females (Chapter 4). Large numbers of males accumulate during a female's oestrous period, leading to intense pre-copulatory contest competition (Hawkins \& Racey 2009) and supposedly intense sperm competition due to polyandrous matings (Chapter 4). Copulations are prolonged and involve a copulatory tie (Albignac 1970; Hawkins \& Racey 2009). Accordingly, males achieving longer copulations may gain an advantage in sperm competition by monopolising access to the female for the duration of the copulatory tie and accordingly increased ejaculation frequencies (Lanier et al. 1979; Oglesby et al. 1981).

The interdependencies between male sociality and the reversed lek-like mating system in this species remain unknown. While contest competition may favour coalition formation, small litter-size and sperm competition imply high costs of sharing access to females by unrelated males, thereby constraining sociality. In order to determine why some males in this species exhibit permanent association despite high costs of competition for food and mates, we compared solitary and associated males with respect to their morphology, relatedness, ranging and hunting behaviour, diet, and mating success. Using parallel GPS-tracking and accelerometry in combination with dietary analyses based on stable isotopes and direct behavioural observation, we aimed to illuminate (1) 
whether males differ morphologically depending on their type of social organisation, (2) whether associated males hunt cooperatively, and if so, (3) whether there is a dietary divergence between males of different types of social organisation. In light of the promiscuous mating system, we were further interested in (4) whether solitary and associated males differ in mating success, and (5) how associated males compensate for the costs of mating competition. Based on these data, we will discuss why two types of male social organisation coexist and how this can be related to socioecological theory.

\section{Material and methods}

Study system

We collected morphometric data, tissue samples, ranging and activity data, hair samples and behavioural data from a population of 33 wild fosas ( 25 males, 8 females $\left(n_{\mathrm{f}}\right)$ ) trapped between 2007

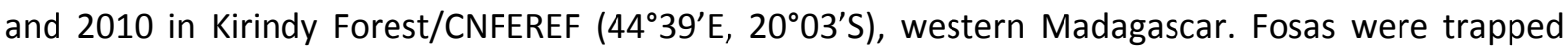
annually during the dry season (weeks 34 to 48 ) with 10 live-traps ( $42 \times 15 \times 20$ cin. bobcat trap, Tomahawk, USA) along transects that were shifted weekly over a $9 \mathrm{~km}^{2}$ area in the forest centre. Trapped animals were briefly anesthetised, measured, sampled for tissue and some adults were equipped with GPS-tags in individually designed collars (150-200 g, e-obs GmbH, Germany) that made up less than $5 \%$ of the individuals' body mass (Gannon \& Sikes 2007). After recovery from anaesthesia, animals were released at the site of capture.

Solitary males were distinguished from associated males based on direct sightings, trapping and GPS-tracking data (Chapter 1). In contrast to solitary males, associated males were sighted in stable dyads sharing home ranges, synchronising their activity and showing affiliative behaviour (resting and sleeping in body contact, grooming) as well as occasional coalitional support, which has never been observed among any other types of fosa dyads.

\section{Morphometry}

Morphometric analyses of body length, absolute body mass, scaled body mass (Peig \& Green 2009), canine width and testis volume were based on eight solitary $\left(n_{s}\right)$ and ten associated males $\left(n_{\mathrm{a}}\right)$ forming five dyads, with occasional exceptions where measures were missing (see results for precise sample sizes). Body length was measured from the base of the skull to the base of the tail. If several measures of fully grown individuals were available for consecutive years, values were averaged. To control for seasonal variation in body mass and testis volume, we included only data from males trapped between weeks 38 and 43 of a given year. Canine width was preferred over canine length as a proxy for age as it is more robust and less prone to variation due to dietary differences. Individuals included into the analyses were at least five years old as estimated from patterns of tooth eruption and tooth wear. While a minimum age could be calibrated based on experience in captivity (J. Reiter, pers. comm.), older individuals could be estimated in relation to each other only or based on canine width. Since all associated males could be trapped within one trapping period, associates could be directly compared based on tooth wear. One adult male was excluded from analyses on body mass and condition because it suffered from an unknown disease at the time of trapping. 
Testis volume was calculated from testis length and width using an ellipsoid formula as a proxy: $V=4 / 3^{*} \pi^{*}(\text { width } / 2)^{2 *}$ length/2. We determined both absolute and relative testis volume (residual volume after correlation with body length) to account for allometric effects.

\section{Relatedness}

Pairwise relatedness of associated males was determined using 16 microsatellite markers applied to a population of 33 individuals (Appendix II, Table S1). DNA was extracted from tissue samples using the Qiagen extraction kit for tissue. We used the 16 most polymorphic (5.1 alleles per locus on average) of 26 markers developed from a captive fosa population (Vogler et al. 2009) and adapted PCR protocols to local laboratory conditions (Appendix II, Table S2). PCR products were detected on an ABI 377 DNA Sequencer and evaluated using the software GeneMapper. PCRs were repeated one to four times for homozygous individuals at any locus. Relatedness coefficients were calculated with the software COANCESTRY (Wang 2011), which provides the triadic likelihood estimator 'TrioML' (Wang 2007); a robust estimator accounting for inbreeding and genotyping errors. Male dyads of equal age estimate were tested for being littermates (paternal half- or full-siblings) using the software COLONY 2.0.1.1 (Wang 2004). A subset of eight males was repeated from extraction onwards to replicate our results.

\section{Spatial data}

Ranging data were obtained from three solitary and four associated males (two dyads) tracked simultaneously during the month of October. Another two associated males (a third dyad) could not be tracked simultaneously in October and were therefore evaluated based on two different years. Data on association pattern (\% time spent in close proximity to the association partner and average distance to the partner) were based for this dyad on simultaneous tracking in July, while equivalent data were available for the other dyads in October. GPS tags recorded locations at hourly intervals with occasional loss of positions due to signal disturbance. Home ranges were determined as $100 \%$ minimum convex polygons using the Animal Movement Extension (Hooge \& Eichenlaub 2000) in ArcView 3.3 (Esri, USA). Daily path length was calculated as average distance covered by an individual in a day in October.

\section{Accelerometry}

Acceleration data were obtained from three-axes accelerometers embedded in the GPS-RF-collars (eobs $\mathrm{GmbH}$, Germany), which sampled at three-minute intervals at $3 \mathrm{~Hz}$ with a resolution of 54 bytes. Absolute differences of acceleration measures were averaged for each sequence and categorised into classes of acceleration of $\geq 1 g$ (class I), $\geq 2 g$ (II), $\geq 4 g$ (III), and $\geq 8 g$ (IV). Matrices of pair-wise comparison of the two partners of an association counting occurrences of each partner in each class were determined for hours in which they were tracked in close proximity $(\leq 100 \mathrm{~m})$ and when separated $(>100 \mathrm{~m})$. We then tested for deviations from random expectation probability matrices using a chi-square test. 


\section{Stable isotope analyses}

For dietary analyses, stable carbon and nitrogen isotope ratios were measured in hair samples of six associated males (three dyads), ten solitary males, eight females and seven common mammalian prey species (Hawkins \& Racey 2008) using mass spectrometer analyses at the KOSI (Centre for Stable Isotope Research \& Analysis, Göttingen, Germany). We assessed whether individual spread (Euclidean distances to the group centroid) in the $\delta^{13} \mathrm{C}-\delta^{15} \mathrm{~N}$ bi-plot differed between associated and solitary males by comparing mean group distances to null distributions generated by residual permutation procedure (Turner et al. 2010). Using nearest-neighbour analyses (Krebs 1999), we assessed whether associated males represent only a part of the trophic diversity of the population. Using Bayesian isotope mixing models (Parnell et al. 2010), we estimated proportions of prey species in the diet of associated and solitary males.

\section{Behavioural observations}

Observational data were obtained by continuous behavioural sampling of mating activity of seven females (one female remaining unidentified) between 2007 and 2010. Six females were observed continuously over the course of their mating activity (530 observation hours) and one female was observed continuously for the last three nights of mating (30 observation hours), whereby length and number of copulations indicated that these included peak mating activity. Marked individuals could be identified by individual earmarks, tail shaving patterns or GPS collars. Unmarked fosas could be distinguished by scars, natural earmarks, body size and fur colour. In order to assess differences in male mating success, we first investigated individual mean copulation duration based a subset of 207 matings where the social category of the mating male was known $\left(n_{\mathrm{s}}=9, n_{\mathrm{a}}=7\right)$. Copulation duration was measured as the time between intromission and external emergence of the penis. We assumed mean copulation duration a proxy of a male's contest competitive abilities because $70 \%$ of all matings were terminated by other males disturbing the mating couple (Chapter 4). Since a male's likelihood of successful fertilisation presumably increases with the total time it manages to monopolise the female (Altmann et al. 1996; Simmons 2001), i.e. its total mating time per female and year, we further tested for differences in total monopolisation duration for seven solitary and five associated males mating with five females for which continuous observational data were available. Two of the seven females in our sample mated in two different years of the study period and were annually regarded as independent samples because of inter-annual variability in male communities and the high importance of male contest competition in the system.

We used linear mixed models (LMMs) with female and male identity as random factors and male social organisation (solitary, associated) as fixed factor for normally distributed response variables. For the analysis of single copulation duration, the activity period of the female (whether the copulation was observed when the female's daily mating activity peaked or not) and the absolute number of heavier males present (in comparison to the mating male) were added as fixed factors to the model to account for the female's receptivity and the potential for male-male competition. Copulation durations were log-transformed to achieve a normal distribution. For the analysis of total monopolisation duration, a male's total number of matings and the interaction of the latter with the 
type of social organisation were added as fixed factors to the model to illuminate possible differences in the number of copulations needed for each group to achieve a certain mating time. Monopolisation durations were z-transformed to account for differential monopolisation potential of different females and female-years. This standardisation was performed on the basis of the complete continuous raw dataset, i.e. including monopolisation durations of all males present.

Model selection was based on AICs and normality of residual distribution. If not otherwise stated, all statistical calculations were performed in R 2.14.1 (R Development Core Team 2011). Pvalues for LMMs were calculated from 1000 Monte Carlo simulations. The accepted significance level was $P<0.05$.

\section{Results}

In total, we found 10 out of 22 adult males trapped to be associated in either dyads or triads (four dyads and one triad with a third individual remaining untrapped). Genetic analyses and age estimation based on tooth wear revealed that four out of six dyads in the population were composed of littermates (TrioML, $r \geq 0.40$; Appendix II, Table S1). We could not detect any brothers among solitary males in the population but one litter of paternal half-siblings appeared to span two different associations (Appendix II, Table S1).

Simultaneous GPS tracking of associated males indicated a highly variable degree of association, ranging from low cohesion ( $21 \%$ of time tracked spent in close proximity of $\leq 50 \mathrm{~m}$ ) to near full-time association (91\% of time tracked in close proximity; Table 1). All individual ranges of associated males were about twice as large as those of solitary males (median minimum convex polygons: $61.7 \mathrm{~km}^{2}$ vs. $33.0 \mathrm{~km}^{2}, n_{\mathrm{a}}=6, n_{\mathrm{s}}=3$; Table 1). However, daily travel distances within ranges were similar for associated and solitary males (median $6.5 \mathrm{~km}$ vs. $5.3 \mathrm{~km}$; Table 1), despite higher energy demands for male dyads. As this indicates that associated males manage to compensate for the costs of food competition, we explored morphological consequences in both types of males.

Table 1 Spatial data obtained from GPS tracking.

\begin{tabular}{|c|c|c|c|c|c|c|c|c|c|c|}
\hline Individual & $\begin{array}{c}\text { Social } \\
\text { organisation }\end{array}$ & $\begin{array}{l}\text { No. } \\
\text { positions }\end{array}$ & Year & $\begin{array}{l}\text { Tracking } \\
\text { started }\end{array}$ & $\begin{array}{l}\text { Tracking } \\
\text { ended }\end{array}$ & $\begin{array}{l}\text { Days } \\
\text { tracked }\end{array}$ & $\begin{array}{l}\mathrm{MCP} \\
\text { area } \\
\left(\mathrm{km}^{2}\right) \\
\end{array}$ & $\begin{array}{c}\text { Mean daily } \\
\text { path length } \\
(\mathbf{k m})\end{array}$ & $\begin{array}{c}\text { Close to } \\
\text { partner (\%) }\end{array}$ & $\begin{array}{c}\text { Mean } \\
\text { distance to } \\
\text { partner }(\mathbf{k m})\end{array}$ \\
\hline CF18 & solitary & 425 & 2009 & $01 / 10 / 2009$ & $31 / 10 / 2009$ & 31 & 42.45 & 7.48 & & \\
\hline CF29 & solitary & 485 & 2010 & 01/10/2010 & $31 / 10 / 2010$ & 31 & 33.01 & 4.34 & & \\
\hline CF30 & solitary & 355 & 2010 & 09/10/2010 & $31 / 10 / 2010$ & 23 & 21.83 & 5.28 & & \\
\hline CF2 & associated & 297 & 2009 & 01/10/2009 & $31 / 10 / 2009$ & 31 & 76.19 & 8.76 & $43^{*}$ & $0.4^{*}$ \\
\hline CF15 & associated & 488 & 2008 & $01 / 10 / 2008$ & $31 / 10 / 2008$ & 31 & 77.39 & 4.95 & $43^{*}$ & $0.4^{*}$ \\
\hline CF20 & associated & 317 & 2009 & 01/10/2009 & $24 / 10 / 2009$ & 24 & 55.68 & 7.02 & 91 & 0.2 \\
\hline CF21 & associated & 321 & 2009 & 01/10/2009 & $24 / 10 / 2009$ & 24 & 54.88 & 7.04 & 91 & 0.2 \\
\hline CF27 & associated & 210 & 2010 & $15 / 10 / 2010$ & $31 / 10 / 2010$ & 17 & 67.74 & 6.02 & 21 & 2 \\
\hline CF31 & associated & 239 & 2010 & $15 / 10 / 2010$ & $31 / 10 / 2010$ & 17 & 42.34 & 3.88 & 21 & 2 \\
\hline
\end{tabular}

* simultaneous tracking data from a different tracking period (18/06/2009 - 11/07/2009; 24 days; 271 positions) 
Morphometric analyses revealed that associated males were considerably larger and heavier than solitary males (median body length $67.2 \mathrm{~cm}$ vs. $58.7 \mathrm{~cm}$; Mann-Whitney $U$ test, $Z=3.18, P=$ $0.001, n_{\mathrm{a}}=9, n_{\mathrm{s}}=8$; median body mass $9.9 \mathrm{~kg}$ vs. $7.5 \mathrm{~kg}, Z=-3.12, P=0.002, n_{\mathrm{a}}=9, n_{\mathrm{s}}=6$; Fig. 1). Since both classes of males neither differed in body condition (scaled body mass $M_{i}$ (Peig and Green 2009), Mann-Whitney $U$ test, $Z=-0.24, P=0.810, n_{\mathrm{a}}=9, n_{s}=8$ ) nor in age (operationalised by canine width; $Z=0.00, n_{\mathrm{a}}=10, n_{\mathrm{s}}=9, P=1.000$ ), there is pronounced difference in male physical development as a function of sociality. While solitary males did not differ from females in body mass (Mann-Whitney $U$ test, $Z=0.58, n_{\mathrm{s}}=8, n_{\mathrm{f}}=8, P=0.564$ ) and body size (body length: $Z=0.68, P=$ 0.495 ), associated males exhibited pronounced sexual dimorphism with females (body mass: $Z=-$ 2.65, $P=0.006, n_{\mathrm{a}}=9, n_{\mathrm{f}}=8$; body length: $Z=-3.03, P=0.002$; Fig. 1 ). In addition, associated males had higher absolute testis volume than solitary males (Mann-Whitney $U$ test, $Z=2.65, n_{\mathrm{a}}=9, n_{\mathrm{s}}=8, P$ $=0.008)$, whereas relative testis volume did not differ between the two groups $(Z=-0.47, P=0.641)$. Given these results, we further explored whether the physical advantage of associated males could be mediated by benefits of cooperative hunting.

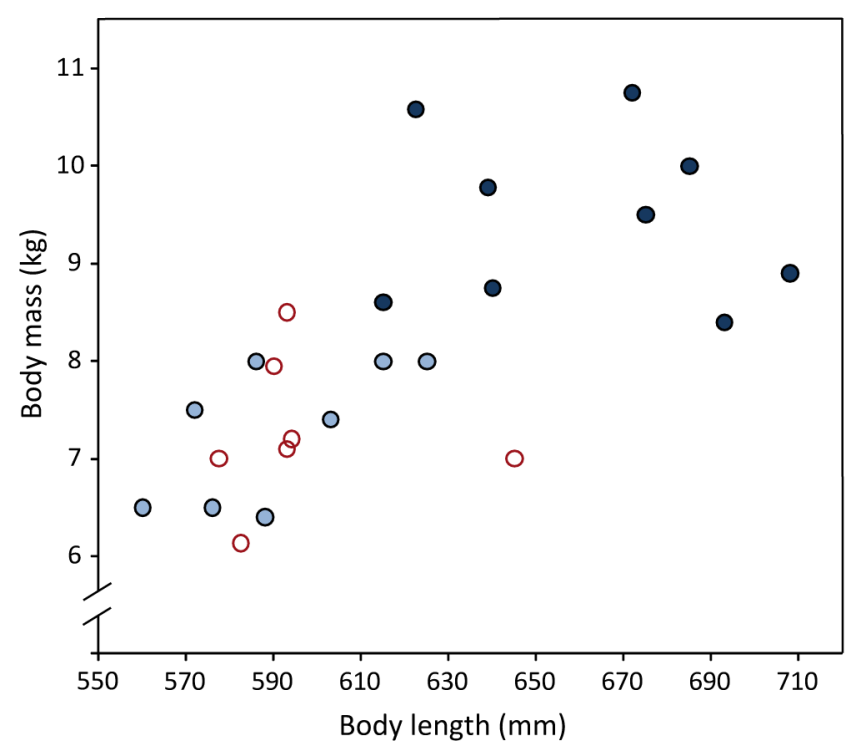

Fig. 1 Morphological characteristics of two male phenotypes as determined by their social organisation. Adult solitary males $\left(n_{\mathrm{s}}=8\right.$, light blue circles) cannot be distinguished in body length and weight from adult females $\left(n_{\mathrm{f}}=7\right.$, open red circles, Mann-Whitney $\mathrm{U}$ tests, $P>0.4)$, whereas associated males $\left(n_{\mathrm{a}}=9\right.$, dark blue circles) exceed solitary males by far in both size and weight and exhibit pronounced sexual dimorphism $(P<0.007)$.

We determined the degree of synchrony between four classes of body acceleration among pairs of associated males in order to quantify cooperative hunting. Categorisation was equivalent to the following activities: head movements during resting - walking (class I), walking - slow running (II), running (III), and jumping - falling (IV). We then tested whether associated males synchronise their activities across all four of these acceleration classes, which for classes III and IV would imply joint fast running and jumping, i.e. hunting or fighting. Individuals of all three dyads synchronised their activity across all four classes when in close proximity $\left(\leq 100 \mathrm{~m} ; \chi^{2}\right.$-tests: $P<0.01$ for all simultaneous occurrences across all classes), but not when they were spatially separated (Table 2 ). If synchronised bouts of extreme acceleration (class III and IV) were indeed related to cooperative hunting, we predicted associated males to be more similar in their diet than solitary males, and to have higher proportions of more profitable prey (i.e. large lemurs) in their diet. 
Table 2 Matrices of acceleration class counts from simultaneous tracking of associates.

\begin{tabular}{|c|c|c|c|c|c|c|c|c|c|c|c|}
\hline Association & $\begin{array}{c}\text { Spatial } \\
\text { proximity }\end{array}$ & $\begin{array}{c}\text { Acceleration } \\
\text { class }\end{array}$ & 1 & II & III & IV & Total & $x^{2} 1$ & $\chi^{2} I I$ & $\chi^{2}$ III & $\chi^{2}$ IV \\
\hline \multirow[t]{10}{*}{ CF20-CF21 } & associated & 1 & 337 & 121 & 29 & 9 & 496 & $118.3^{* * *}$ & 48.3 & 22.7 & 2.0 \\
\hline & & II & 140 & 428 & 101 & 5 & 674 & 52.1 & $48.6^{* * *}$ & 0.7 & 10.9 \\
\hline & & III & 21 & 58 & 47 & 13 & 139 & 19.0 & 0.4 & $40.4^{* * *}$ & 19.8 \\
\hline & & IV & 10 & 2 & 8 & 12 & 32 & 0.4 & 10.8 & 2.9 & $131.7^{* * *}$ \\
\hline & & total & 508 & 609 & 185 & 39 & 1341 & & & & \\
\hline & separated & 1 & 34 & 34 & 15 & 2 & 85 & 0.1 & 0.0 & 0.2 & 0.0 \\
\hline & & II & 41 & 38 & 21 & 2 & 102 & 0.1 & 0.2 & 0.0 & 0.1 \\
\hline & & III & 5 & 14 & 3 & 1 & 23 & 1.6 & 2.6 & 0.5 & 0.4 \\
\hline & & IV & 2 & 0 & 4 & 0 & 6 & 0.0 & 2.4 & 6.6 & 0.1 \\
\hline & & total & 82 & 86 & 43 & 5 & 216 & & & & \\
\hline \multirow[t]{10}{*}{ CF27-CF31 } & associated & 1 & 129 & 85 & 15 & 1 & 230 & $25.4^{* * *}$ & 6.9 & 7.8 & 1.9 \\
\hline & & II & 61 & 148 & 23 & 2 & 234 & 6.5 & $9.5^{* *}$ & 2.0 & 0.8 \\
\hline & & III & 16 & 45 & 32 & 2 & 95 & 9.8 & 0.1 & $30.2 * * *$ & 0.2 \\
\hline & & IV & 2 & 5 & 6 & 4 & 17 & 2.8 & 1.3 & 6.3 & $52.5^{* * *}$ \\
\hline & & total & 208 & 283 & 76 & 9 & 576 & & & & \\
\hline & separated & I & 238 & 253 & 63 & 14 & 568 & 2.2 & 1.1 & 1.0 & 1.4 \\
\hline & & II & 177 & 242 & 59 & 6 & 484 & 0.3 & 0.6 & 0.1 & 0.9 \\
\hline & & III & 57 & 100 & 29 & 3 & 189 & 3.1 & 1.2 & 1.2 & 0.1 \\
\hline & & IV & 13 & 10 & 9 & 0 & 32 & 0.1 & 1.8 & 6.2 & 0.6 \\
\hline & & total & 485 & 605 & 160 & 23 & 1273 & & & & \\
\hline \multirow[t]{10}{*}{ CF2-CF15 } & associated & 1 & 122 & 41 & 7 & 0 & 170 & $15.0^{* * *}$ & 5.9 & 9.9 & 2.6 \\
\hline & & II & 36 & 55 & 17 & 1 & 109 & 6.7 & $7.3^{* *}$ & 0.7 & 0.3 \\
\hline & & III & 7 & 19 & 14 & 1 & 41 & 9.1 & 1.5 & $14.8^{* * *}$ & 0.2 \\
\hline & & IV & 2 & 1 & 4 & 3 & 10 & 1.9 & 1.8 & 5.8 & $53.6 * * *$ \\
\hline & & total & 167 & 116 & 42 & 5 & 330 & & & & \\
\hline & separated & 1 & 54 & 28 & 7 & 3 & 92 & 0.2 & 0.0 & 0.1 & 2.1 \\
\hline & & II & 18 & 10 & 1 & 3 & 32 & 0.0 & 0.0 & 0.6 & 0.2 \\
\hline & & III & 8 & 7 & 2 & 3 & 20 & 0.8 & 0.1 & 0.3 & 1.6 \\
\hline & & IV & 2 & 1 & 0 & 2 & 5 & 0.2 & 0.2 & 0.3 & $7.2^{* *}$ \\
\hline & & total & 82 & 46 & 10 & 11 & 149 & & & & \\
\hline
\end{tabular}

Indication of significance levels for diagonals (coincident classes): ${ }^{*} P<0.05, * * P<0.01,{ }^{* * *} P<0.001$

Comparison of time-integrated information based on stable carbon and nitrogen isotope analyses revealed that (1) associated males were more similar in their diet than solitary males and covered only a subset of the population's isotopic space, reflected by a smaller mean Euclidean distance of individuals to the groups' centroids $(C D)$ in the $\delta^{13} \mathrm{C}-\delta^{15} \mathrm{~N}$ bi-plot (residual permutation procedure, $\left|C D_{\text {associated males }}-C D_{\text {solitary males }}\right|=1.21, P=0.001$ ) and a clumped pattern of associated males in the $\delta^{13} \mathrm{C}-\delta^{15} \mathrm{~N}$ bi-plot (nearest neighbour analysis, index of aggregation $R=0.47, Z=-2.50, P$ $=0.012)$, whereas the distribution of solitary males did not deviate from a random pattern $(R=0.73$, $Z=-1.66, P=0.10 ;$ Fig. 2). (2) Associated males had higher proportions of the locally largest lemur (3 kg Propithecus verreauxi) in their diet, whereas the most important prey species for solitary males were medium-sized lemurs and rodents (Bayesian isotope mixing models; Fig. 3). 


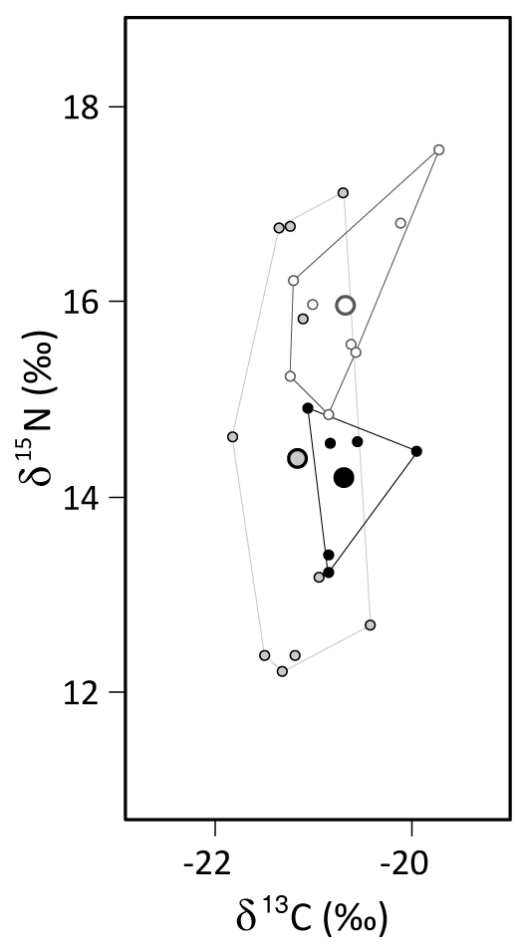

Fig. 2 Trophic differentiation as reflected in isotope space for fosas with different social organisation. Associated males ( $n_{\mathrm{a}}=6$, black filled circles) cluster in the $\delta^{13} \mathrm{C}-\delta^{15} \mathrm{~N}$ bi-plot and represent only a part of the trophic diversity of the population in contrast to highly variable solitary males $\left(n_{\mathrm{s}}\right.$ $=8$, grey filled circles). Females $\left(n_{\mathrm{f}}=8\right.$, open circles), solitary males and associated males form main clusters.

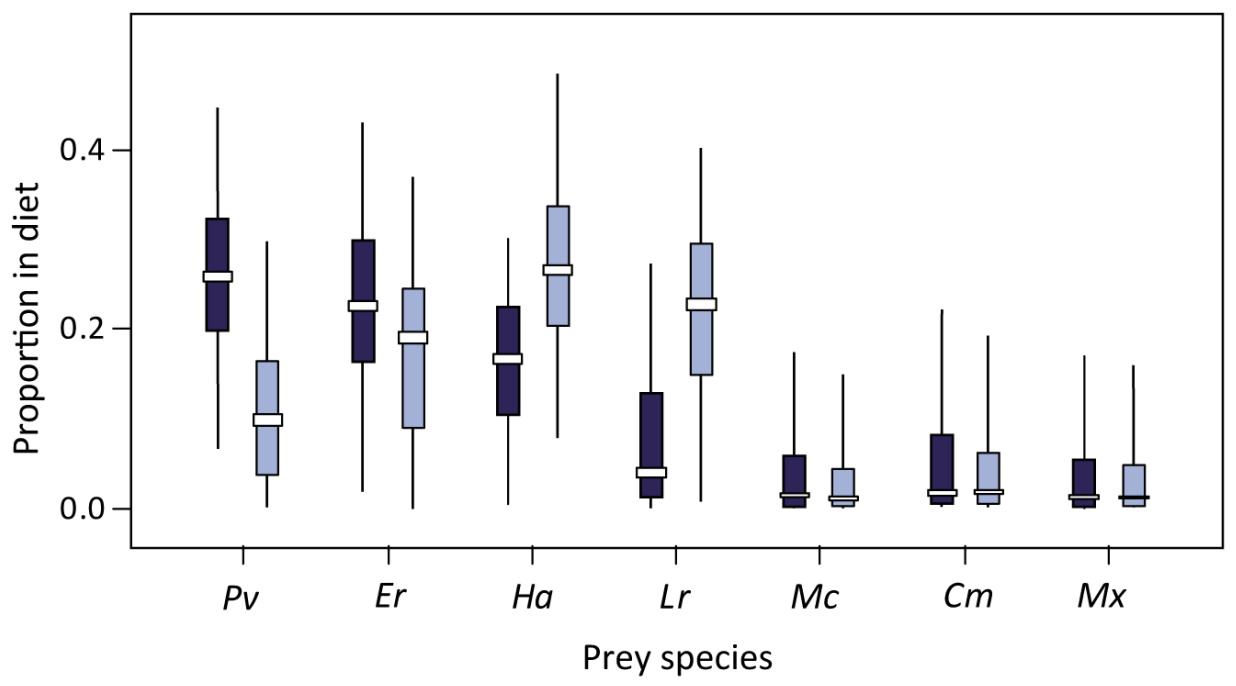

Fig. 3 Proportions of major mammal prey species in the diet of solitary (light blue bars) and associated males (dark blue bars) during the dry season. While associated males feed to a higher extent on larger-bodied diurnal lemurs, solitary males are specialized on different medium-sized nocturnal mammals. Prey species are sorted by size and were chosen based on earlier dietary analysis (Hawkins and Racey 2008). Nocturnal lemurs include Lepilemur ruficaudatus ( $\mathrm{Lr}, 900 \mathrm{~g}$ ), Mirza coquereli (Mc, $300 \mathrm{~g})$, Cheirogaleus medius (Cm, $180 \mathrm{~g})$, and Microcebus sp. ( $M x, 30-60 \mathrm{~g})$. Larger group-living and predominantly diurnal lemurs are represented by Eulemur rufifrons (Er, $1700 \mathrm{~g})$ and Propithecus verreauxi $(P v, 3000 \mathrm{~g})$, the biggest lemur in Kirindy Forest. Another quantitatively important prey species is included with the Giant jumping rat, Hypogeomys antimena $(\mathrm{Ha}, 1000 \mathrm{~g})$. Plotted are 90, 50 and $10 \%$ credibility intervals of Bayesian mixing model results (SIAR; Parnell et al. 2010). 
Based on the numerical and physical differences between solitary and associated males, we further predicted an advantage for associated males over solitary males in contest competition over access to females. We found higher individual copulation durations for associated males compared to solitary individuals ( $\left(\mathrm{MMM}, t=2.01, P=0.045, n_{\mathrm{a}}=7, n_{\mathrm{s}}=9, n_{\mathrm{f}}=7,207\right.$ matings; Table 3(a)), with a general increase in copulation length during a female's peak activity $(t=2.20, P=0.029)$ but no effect for the number of heavier males present on the tree $(t=0.78, P=0.435)$. Within dyads, dominant individuals mated on average longer than their subordinate associates (median $77.2 \mathrm{~min}$ vs. $40.9 \mathrm{~min}$, $n_{\mathrm{a}}=6$ ), whereas the latter achieved mating durations comparable to solitary males (median $37.2 \mathrm{~min}$, $\left.n_{\mathrm{s}}=6\right)$.

Table 3 Model outputs. Statistically significant predictors are depicted in bold. SE standard error, $d f$ degrees of freedom

(a) Determinants of single copulation duration (LMM)

\begin{tabular}{lcccrr}
\hline & Estimate & SE & df & \multicolumn{1}{c}{$\boldsymbol{t}$} & \multicolumn{1}{c}{$\boldsymbol{P}$} \\
\hline Intercept & $\mathbf{2 . 4 5}$ & $\mathbf{0 . 2 3}$ & $\mathbf{8}$ & $\mathbf{1 0 . 6 7 8}$ & $<\mathbf{0 . 0 0 0 1}$ \\
Social organisation & $\mathbf{0 . 4 4}$ & $\mathbf{0 . 2 2}$ & $\mathbf{8}$ & $\mathbf{2 . 0 1 3}$ & $\mathbf{0 . 0 4 5 4}$ \\
Peak activity & $\mathbf{0 . 4 6}$ & $\mathbf{0 . 2 1}$ & $\mathbf{8}$ & $\mathbf{2 . 2 0 1}$ & $\mathbf{0 . 0 2 8 9}$ \\
Presence of heavier males & 0.11 & 0.15 & 8 & 0.783 & 0.4345 \\
\hline
\end{tabular}

Sample size: 207 matings of 9 solitary and 7 associated males mating with 7 females ( 9 female-years). The response variable (copulation duration) was log-transformed to fit normal distribution. Presence of heavier males was counted absolutely in relation to the mating male. Female and male identity were included as random factors.

(b) Determinants of total monopolisation of mating (LMM)

\begin{tabular}{lrrrrc}
\hline & Estimate & SE & df & \multicolumn{1}{c}{} & $\boldsymbol{P}$ \\
\hline Intercept & $-\mathbf{0 . 8 7}$ & $\mathbf{0 . 2 9}$ & $\mathbf{6}$ & $\mathbf{- 3 . 0 0 1}$ & $\mathbf{0 . 0 0 4 9}$ \\
Social organisation & $\mathbf{0 . 8 8}$ & $\mathbf{0 . 3 6}$ & $\mathbf{6}$ & $\mathbf{2 . 4 6 7}$ & $\mathbf{0 . 0 1 8 5}$ \\
No. matings & $\mathbf{0 . 2 3}$ & $\mathbf{0 . 0 5}$ & $\mathbf{6}$ & $\mathbf{5 . 1 7 3}$ & $\mathbf{0 . 0 0 0 0}$ \\
Social organisation : no. matings & -0.12 & 0.06 & 6 & -1.951 & 0.0588 \\
\hline
\end{tabular}

Sample size: 41 observations of 7 solitary and 5 associated males mating with 5 females ( 7 female-years). The response variable (total monopolisation duration) was z-transformed over all data per female and year to account for differences in competitive environment and thus differences in monopolization potential resulting from differences in total male presence and male group composition. An interaction of male social organisation and a male's total number of matings was included to test for differences in the effectiveness of monopolisation. Female and male identity were included as random factors.

Summing up copulations to total monopolisation duration revealed that associated males monopolised females for longer than solitary males (LMM, $t=2.47, P=0.019, n_{\mathrm{a}}=5, n_{\mathrm{s}}=7, n_{\mathrm{f}}=5$, 178 matings; Table 3(b); Fig. 4). Since both male categories did not differ in the total number of copulations (Mann-Whitney $U$ test, $Z=-0.11, n_{\mathrm{a}}=5, n_{\mathrm{s}}=7, P=0.913$ ), associated males tended to need fewer copulations to achieve comparable mating durations (LMM, $t=-1.95, P=0.059$; Table $\mathbf{3}(\mathbf{b}))$. Furthermore, associated males interrupted matings of solitary males more often than vice versa (Mann-Whitney $U$ test, $Z=2.01, n_{\mathrm{a}}=7, n_{\mathrm{s}}=3, P=0.045$ ). 


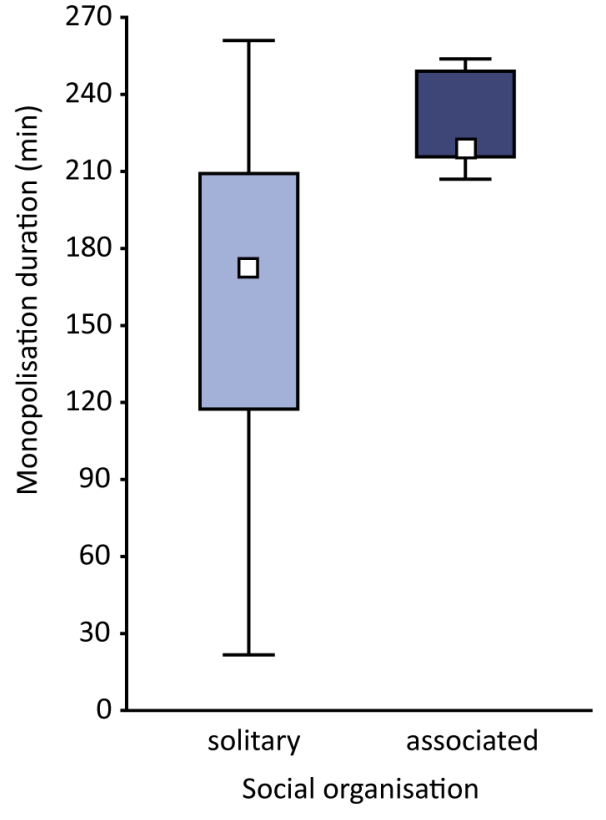

Fig. 4 Male monopolisation potential, as reflected in total mating duration per female-year for males of different social organisation. Mid-points represent median monopolisation duration, boxes span inter-quartile range, whiskers non-outlier range. Associated males ( $n_{\mathrm{a}}=5$, dark blue box) managed to monopolise females about an hour longer than solitary males $\left(n_{\mathrm{s}}=8\right.$, light blue box), with most pronounced advantage for the dominant male of a dyad.

\section{Discussion}

We showed that two male phenotypes can be distinguished in fosas, which differ in their type of social organisation. Whereas solitary males reach about the same size as adult females, associated males grow considerably larger and exhibit sexual size dimorphism with females. The present analyses indicate that this somatic advantage of associated males is linked to cooperative hunting, allowing them to take down larger-bodied and more agile prey. These benefits of cooperative hunting may compensate for the costs of sociality related to feeding competition. As a result of their physical superiority, associated males also gain reproductive advantages, if mating duration in fosas is positively correlated with fertilisation success. Hence, their somatic advantage is likely to translate directly into reproductive benefits.

Depending on their type of social organisation, male fosas may physically develop differentially with a pronounced advantage for associated males with respect to body mass and size. As this difference is not explained by age, it is most likely due to dietary divergence because associated males differ remarkably in their diet from solitary individuals of either sex. A combination of a higher proportion of larger-bodied prey in their diet and no difference in searching time (as reflected in daily travel distances) indicated higher foraging efficiency of associated males, which is most likely achieved by cooperative hunting. This hunting technique may allow associated males to hunt large lemurs at higher success rates than solitary males. In cheetahs, another hypercarnivorous specialised hunter, cooperative hunting has also been shown to allow associated males to hunt larger prey (Caro 1994). Yet, an increase in prey intake rate per capita could not be shown for this species and thus male association in cheetahs has been attributed to benefits of cooperative territory defense rather than benefits of cooperative hunting (Caro 1989).

Since there was no difference in condition between solitary and associated fosa males, both strategies most likely differ in their energy allocation to growth. As a result, two male phenotypes 
exist; solitary males, which do not exceed adult females in size and associated male that are on average $38 \%$ heavier and $13 \%$ larger than females. In meerkats, growth rates have been shown to be individually variable over even longer life trajectories with significant environmental influence (English et al. 2012). In fosas, variability in growth patterns may be similarly related to highly seasonal environmental conditions in Madagascar, which have been linked to various behavioural, physiological and morphological adaptations in other endemic taxa (Wright 1999; Dewar \& Richard 2007). The fact that fosa females remain solitary indicates that the potential energetic costs of feeding competition for communally raising offspring are too high. Similar constraints seem to apply to males. Despite obvious benefits of sociality for each member of a male dyad, the costs of food sharing cannot be outweighed by any larger association, as indicated by the observation that each of the two male triads in this study comprised one individual that was in very poor condition (data not shown). Sociality in fosas may thus function as a means to overcome energy limitation. We therefore propose that fosas represent an example of a species, where energetic and nutritional factors have a tangible impact on male sociality.

Patterns of male sociality in fosas can contribute to a better understanding of the evolution of carnivore sociality and cooperation in general as the trade-off between the costs and benefits of group-living seems to offer very limited opportunities for sociality in this species. Intrasexual competition for reproductive opportunities is intense in this highly promiscuous mating system, raising the question of how associated males share limited mating opportunities. In four out of six associations, which were all composed of likely litter-mates, inclusive fitness benefits may compensate for the costs of mating competition (Hamilton 1964). The only unrelated adult dyad in this study achieved generally high mean mating durations compared to the population average (92 min for the dominant individual and $69 \mathrm{~min}$ for the subordinate) and balanced mean monopolisation durations per female (216 $\mathrm{min}$ for the dominant individual and $207 \mathrm{~min}$ for the subordinate), indicating both efficient monopolisation of access to females as well as equitable share of mating between the two associates. Unrelated associates may therefore enjoy higher fertilisation probabilities than solitary individuals due to longer monopolisation times.

Given somatic and potentially reproductive benefits of male sociality in fosas, the persistence of solitary males raises the question whether these males are solitary because of a lack of opportunity (e.g. because they were the only male of their litter), or whether they may represent an alternative strategy maintained by frequency-dependent selection (Gross 1996). Since we did not detect male littermates for any solitary male in our sample, they are likely constrained in their opportunities to associate with a familiar male. Interestingly, our genetic analyses revealed that male CF20 of the only unrelated adult association was closely related to the dyad CF27-CF31 but not to its associate (Appendix II, Table S1). CF20 is a confirmed (probability $p=1.000$ ) half-sibling of CF27 even though it could not be statistically confirmed as a half-sibling of CF31 ( $p=0.047)$. If CF20 is a third litter-mate of CF27 and CF31, early development in an all-male litter may have facilitated social tolerance towards other males in this case. A putative brother of its partner CF21 could not be found in the population, however, and the triadic relationship could not be resolved. The importance of familiarity and social tolerance for male sociality therefore remains speculative.

On the other hand, our results also indicate that solitary males remain small but do not suffer from reduced body condition, and that they seem to be highly diverse in their diet and hunting strategies (as indicated by a wide spread of solitary individuals in stable isotope space; Fig. 2). Their 
small body size may allow solitary males to extract small lemurs from tree-holes or rodents from their burrows more effectively. When it comes to mating, however, solitary males face a significant disadvantage in contest competition. In some mammals, physically inferior males have been shown to invest more in sperm competition by producing more sperm (Parker 1990; Stockley \& Purvis 1993). In fosas, however, the two types of males appear to invest equally in relative testes size. Based on the currently available evidence, we therefore conclude that the demographic constraint as a result of a lack of male littermates may therefore explain the existence of solitary males.

In summary, we described a rare phenomenon of male sociality with functional significance for growth and sexual dimorphism in a carnivore. Most likely, physical superiority of associated males over solitary individuals of either sex is determined by higher foraging efficiency due to cooperative hunting. Sociality is limited to a subset of males, mostly littermates, however, as food limitation generally promotes a solitary lifestyle in this strictly carnivorous species, and social tolerance among unrelated males is likely constrained. Based on the link of facilitated access to food by cooperative hunting and subsequent mating benefits due to physical superiority, we suggest that food resources can also be important ultimate determinants of male sociality. Furthermore, this example indicates that cooperative hunting can precede group-living rather than being a consequence or a by-product of the latter (Packer \& Ruttan 1988) and can act as an evolutionary force promoting it (Creel \& Creel 1995). 


\title{
Chapter 4
}

Polyandry in treetops: how male competition and female choice interact to determine an unusual mating system in a carnivore

Mia-Lana Lührs \& Peter M. Kappeler

\begin{abstract}
The diversity of mammalian mating systems is primarily shaped by sex-specific reproductive strategies. In the present study, we aimed to explore determinants and consequences of a unique mammalian mating system. In fosas (Cryptoprocta ferox), the largest Malagasy carnivore, females mate polyandrously and for extended periods on traditional mating trees. Males face both contest and scramble competition and sexual dimorphism can be pronounced but depends on the type of male social organisation. Using continuous behavioural observation of six oestrous females over four years, we investigated correlates of male-male contest competition and female choice based on 316 copulations. Furthermore, we assessed correlates of male scramble competition based on testes size and movement data obtained from GPS-tracking. We found that females dominated males regardless of their physical dissimilarity and actively solicited copulations. Heavy males had highest mating success during the female's most likely period of conception but were discriminated against after they had mated. Female choice and male-male competition thus converged to generate a mating advantage for heavier males. Our results suggest that females actively seek polyandrous matings, presumably for indirect genetic benefits. Since body mass is the major determinant of male mating success and is at the same time dependent on the degree of sociality and associated hunting mode, food acquisition is likely to represent a basal entity of male fitness. A combination of benefits from polyandry and the consequences of different subsistence strategies may thus ultimately explain this unusual mating system.
\end{abstract}

Manuscript for submission 


\section{Introduction}

Mating systems are shaped by sex-specific reproductive strategies adapted to given environmental conditions (Clutton-Brock 1989). Since males of the majority of species have higher potential reproductive rates than females leading to a male-biased operational sex ratio (Emlen \& Oring 1977; Clutton-Brock \& Parker 1992), they can maximise their reproductive success by improving access to females and thus fertilisations (Bateman 1948; Trivers 1972). By contrast, females often provide maternal care and can maximise fitness primarily by increasing offspring quality and survival (Trivers 1972). Females are therefore selected to be choosy with regard to their mates, whereas males are selected to compete with each other over the monopolisation of fertilisations (Darwin 1871; Williams 1966; Clutton-Brock \& Parker 1992; Andersson 1994). Depending on the monopolisation potential of receptive females, i.e. their spatial and temporal distribution, males either compete with each other directly (contest competition) or indirectly (scramble competition) (Emlen \& Oring 1977; Andersson 1994). Where females are clumped in space and receptive asynchronously and therefore monopolisable for single males, contest predominates and the development of sexual dimorphism is being favoured, as reflected in male weaponry or physical superiority in comparison to females (Clutton-Brock 1991). By contrast, where females are difficult to be monopolised by single males because they are solitarily dispersed or synchronously cycling, male scramble competition predominates, favouring mate finding abilities and sperm competitive abilities (Schwagmeyer \& Woontner 1985, 1986; Birkhead 1995). Likewise, several mechanisms of female choice can be distinguished, in that it can operate either by direct mate choice on the pre-copulatory level or indirectly by the promotion of male-male competition (Wiley \& Poston 1996) or by cryptic choice on the post-copulatory level (Birkhead \& Møller 1993; Birkhead \& Pizzari 2002).

Despite their lower potential reproductive rates and various costs of mating (Daly 1978; Rowe 1994; Chapman et al. 1995), females in the majority of species have been found to mate multiply with single males or multiple partners (e.g., Thornhill \& Alcock 1983; Birkhead \& Møller 1998; Birkhead 2000; Wolff \& Macdonald 2004). A number of benefits have been attributed to such polyandry (reviewed in Hunter et al. 1993; Hosken \& Stockley 2003; Slatyer et al. 2012a), including fertilisation assurance (Hoogland 1998), increased fertility (Arnqvist \& Nilsson 2000) and fecundity (Ridley 1988), concealment of paternity and infanticide avoidance (Hrdy 1979; Ebensperger 1998; Wolff \& Macdonald 2004) as well as indirect benefits with respect to genetic diversity and quality (Brown 1997; Yasui 1998; Baer \& Schmid-Hempel 1999), genetic compatibility (Zeh \& Zeh 1997; Newcomer et al. 1999), and the promotion of cryptic female choice and sperm competition (Birkhead \& Møller 1993; Eberhard 1996; Jennions \& Petrie 2000; Birkhead \& Pizzari 2002; Simmons 2005). Alternative to polyandry by choice due to benefits of multiple mating per se, 'convenience polyandry' has been proposed as a means for females to avoid sexual harassment by persistent males when the costs of female resistance exceed the costs of multiple matings (Thornhill \& Alcock 1983; Rowe 1992; Rowe et al. 1994). The risk of sexual harassment and coerced copulations is generally increased in species with pronounced sexual dimorphism (with superior males) and under a male-biased operational sex ratio (Rowe 1992; Clutton-Brock \& Parker 1995). In recent years, several studies investigated the evolution of polyandry, most of which support female polyandry by choice rather than convenience polyandry regardless of the prevalence of male harassment (e.g., Huchard et al. 2012; Slatyer et al. 2012b). 
An unusual polyandrous mating system has been described for Madagascar's largest carnivore, the fosa (Cryptoprocta ferox, Eupleridae). These medium-sized Madagascar mongooses mate on traditional mating trees, which are visited by oestrous females for about one month during their annual mating season (Hawkins \& Racey 2009). Females may use mating trees singly (this study), sequentially (Hawkins \& Racey 2009) or simultaneously (this study) and attract multiple males. It has therefore been argued that fosas evolved mating at predetermined locations to facilitate mate location because of low population density (Hawkins \& Racey 2005, 2009), and that the use of mating trees served to protect the female from male harassment (Hawkins \& Racey 2009). Pronounced sexual dimorphism in body mass and size renders male harassment a likely threat to oestrous fosa females. There are indications, however, that oestrous females dominate males regardless of their physical inferiority in the mating context (Hawkins \& Racey 2009; M. Kirschner, pers. comm.). Furthermore, prolonged copulations under a copulatory tie and multiple matings with the same mates suggest that this unique mating system was driven by additional evolutionary forces related to adaptive polyandry than mate location alone. Moreover, adaptations such as penile spines, a long baculum and female transient masculinisation in this species (Hawkins et al. 2002) imply that sexual conflict over female resistance and male persistence is prevalent and morphologically manifest (Arnqvist \& Rowe 1995; Chapman et al. 2003).

In addition to this set of morphological and behavioural traits, a recent study found that sexual dimorphism in fosas is linked to sociality and cooperative hunting (Chapter $\mathbf{3}$ ). While females are strictly solitary, sexually monomorphic males live solitary lives while physically superior, sexually dimorphic males are permanently associated with one or two other such males. Both this high variance in male body mass and size and its link to facultative male sociality suggest a high potential for different male mating tactics depending on their degree of sociality and competitiveness and a potential for female preference for either phenotype. Since Hawkins \& Racey (2009) did not observe mating activities continuously, they were unable to investigate mechanisms of mate choice and male-male competition in detail, and therefore explanations for polyandry in fosas and its interaction with the species' social organisation and morphology are still lacking.

We studied sex-specific mating strategies in fosas in more detail to elucidate form, causes and consequences of polyandry in a mating system with male-male contest competition and female dominance. In contrast to Hawkins \& Racey (2009), we were able to follow several females continuously during their mating activity, allowing us to study male and female reproductive strategies on the pre-copulatory level. We posed the following specific questions: (1) Do females actively seek multiple mating or are they coerced to do so? (2) Which benefits may arise from polyandry and multiple mating? (3) What is the major determinant of male mating success? (4) Are there indications for males of different body mass and competitiveness to adopt different tactics with respect to their investment in scramble and contest competition? And (5) are there parallels in male and female mating strategies that could explain the evolution of this particular set of morphological and behavioural traits?

To address these questions, we studied male ranging behaviour in relation to mating trees, differences in physical development between males and competitive consequences thereof, as well as temporal patterns of male mating success. From the females' perspective, we estimated their potential to resist a male's mating attempt, and investigated aggression rates, solicitation rates and temporal acceptance or resistance as indications of female choice. 


\section{Methods}

Study population, trapping and morphometry

We studied a wild population of fosas in Kirindy Forest/CNFEREF ( $\left.44^{\circ} 39^{\prime} \mathrm{E}, 20^{\circ} 03^{\prime} \mathrm{S}\right)$ from 2007 to 2010. Fosas were annually trapped at the end of the local dry season (months August to October), right before the onset of the mating season (November), using 10 live-traps (42 $\times 15 \times 20$ cin. bobcat trap, Tomahawk, USA) set along $2 \mathrm{~km}$ transects. Trapped animals were briefly anaesthetised, measured and some of them equipped with GPS-tags (150-200 g, e-obs GmbH, Germany). After recovery from anaesthesia, the animals were released at the site of capture.

We measured body mass, body length (measured from base of the head to the base of the tail) and left and right testis length and width. Since the population's variance in adult male body mass was high $\left(s^{2}=2.04\right)$, we categorised individuals according to three classes of 2 kg-range: $5-7 \mathrm{~kg}$ $\left(n_{1}=4\right),>7$ to $<9 \mathrm{~kg}\left(n_{\mathrm{m}}=8\right)$, and more than $9 \mathrm{~kg}\left(n_{\mathrm{h}}=6\right)$. This categorisation was chosen based on the total male sample to achieve balanced samples for statistical analyses. Body mass of unmarked males was estimated and categorised accordingly. Testis volume was calculated from average testis length and width, using the formula for a spherical ellipsoid: $V=4 / 3^{*} \pi^{*}(\text { width/2) })^{2 *}$ length $/ 2$.

\section{Spatial data}

GPS-tracking data for the present study were obtained from 9 adult males tracked before $(n=9)$, during $(n=6)$ and after the mating season $(n=4)$. GPS-tags recorded an animal's position every hour on the hour, with occasional loss of positions. Since our sample size was too low for statistical analyses, we partially explored seasonal or body mass dependent trends graphically. Locations of mating trees were either known $(n=4)$, i.e. mating activity had been witnessed, or assumed $(n=5)$, with criteria for assumed mating trees being repeated visits of more than two hours by more than one male before or during more than one mating season, with no other resource (e.g. water-holes) being evident from ground-truthing. Since fosas neither den nor use preferred sleeping or resting sites, the latter criteria were assumed to fit mating trees only. Visits of mating trees were recorded as such based on localisations of animals within a $200 \mathrm{~m}$ radius around the known or putative location of a mating tree. Locations of assumed mating trees were inferred from the arithmetic mean of positions accumulating after repeated visits of the area by males.

Home range areas were estimated from 100\% minimum convex polygons (MCPs; Mohr 1947; Kenward 2001) using the 'adehabitatHR' package (Calenge 2006) in R 2.14.1 (R Development Core Team 2011). GPS-tracking and spatial data analyses are described in more detail in Chapter 1.

\section{Behavioural observation}

In total, we collected 540 continuous observation hours of mating behaviour data, including 316 copulations from six different females mating between 2007 and 2010 on four different trees (Table 1). In order to ensure continuous tracking of all mating activity, two known mating trees were 48 
controlled for male aggregation and female appearance during October in 2007 to 2010. In 2009, a third tree could be patrolled additionally. Use of mating trees involved male aggregation long before the onset of female activity, which could easily be noticed by traces from scent-marking and fights. Once these traces were evident, we spent days and nights close to the respective tree to document the arrival of the female. Since fosa females vocally indicate the beginning of behavioural oestrus by loud miaowing calls from up the tree a few days before they actually accept matings, we could further be sure not to have missed mating activity if we located a female during this phase. Once a female visited a tree and started calling, we stayed with her permanently around the clock. Most mating activity was concentrated during night hours, with the female typically arriving at the site in the late afternoon and leaving in the late morning when temperature rose above ca. $30^{\circ} \mathrm{C}$. Males often arrived a few hours earlier than the female and scent-marked and fought with each other at the site.

Individuals were distinguished by tail shaving pattern and/or collars (individuals trapped in the same year), earmarks (previously trapped individuals or injuries in unmarked individuals), scars and natural physical properties (colouration of fur, body size, testes size, extent and colour intensity of the red breast secretion in males). Overall, distinction of individuals was easily possible due to frequent scars and we used minimum estimates of male presence for counts (i.e. males that could not be reliably distinguished were not additionally counted unless they were observed simultaneously with other known males). Yet, unmarked males could not reliably be recognised in subsequent years and may therefore occur multiply in our sample.

From the onset of mating activity on, we recorded the identity of all individuals present and all kinds of interactions between them (approaches, vocalisations, body contacts, mounts, intromission and mating, attacks, retreats, fights) as well as ongoing ascents and descents of individuals. Matings were evaluated with respect to the cause of initiation and termination. Termination was attributed to the individual that aggressively approached a mating couple (other males) or that attacked its mate immediately prior to separation (female or mating male). Since a dominant male's ascent often led to immediate effort of the mating male to separate from the female, respective situations were regarded as another male's initiation of termination regardless of the distance between mating couple and ascending male. Female 'solicitation' of mating was characterised by peaceful approach of a male with subsequent movement to the female's preferred mating branch. Solicitations often involved a characteristic vocalisation uttered by the female (M.-L. Lührs \& G. Peters, unpubl. data), which never occurred in agonistic contexts. Mating duration was measured as the time between the moment of intromission until re-emergence of the penis. Even very short matings of one minute length were considered as such because intromission was always followed by immediate pelvic thrusting and occasionally involved suspected ejaculation (as indicated by emerging fluid).

Since all females showed a distinct temporal development in their mating activity, we divided mating data into three different temporal phases. At the beginning of their activity females showed an incremental increase in time spent on the tree and time spent mating (hereafter referred to as the 'pre-peak period'), followed by one or two nights of highest absolute and relative (in relation to the time spent on the tree) mating duration ('peak period'), which occasionally ended in a phase of incrementally decreasing activity of variable length ('post-peak period') (Appendix III, Fig. A1). Since peak activity phases were characterised by highest mating activity, oestrus is likely to have occurred 
in one of the peak nights. We therefore included phases of activity into our analyses to account for potential temporal patterns in female preference and resistance (cf. Stumpf et al. 2008; Knott et al. 2010).

\section{Statistical analyses}

Since the majority of analyses involved repeated measurements from the same individuals, we used linear mixed-effects models (LMMs) with male identity and female-year as random factors to test for effects of male body mass, male presence and approaches, activity period and female aggression on variables relevant in the mating context, such as duration of a single copulation, total time mating (monopolisation duration), monopolisation during female peak activity, female aggression and the reception of solicitations. Since two females were observed twice in two different years with high variability between years both in their behaviour but also in mating conditions (e.g. male presence), we treated those as independent by using the more conservative random factor 'female-year' instead of female identity. Monopolisation duration, peak monopolisation duration and number of aggressive encounters received from the female were z-transformed to account for individual differences between females and years. While z-transformation was based on total datasets (including unidentified males), analyses were only based on data from males for which body mass was known.

While all continuous response variables were normally distributed and therefore allowed for the use of linear models, the reception of solicitations was explored based on two states (solicitations received or not) using a generalised linear mixed model (GLMM) fitted with a binomial distribution. In order to avoid inflation of type I error rates in stepwise model selection procedures (Mundry \& Nunn 2009), we started model selection with all relevant dependent variables and reduced their number only where indicated due to over-parameterisation. Generally, model fit was optimised based on the normal distribution of residuals and, in models of equivalent information gain, selection was based on Akaike's information criterion.

Aspects of male-male competition, which were independent of the female's identity, were analysed using non-parametric tests. Comparisons between three independent male body mass classes concerning travel distance, home range size, residual travel distance (travel distance controlled for home range area), residual testis volume (testis volume controlled for body length) and body condition ('scaled mass index'; Peig \& Green 2009) were conducted using Kruskal-Wallis ANOVA in Statistica 10. Post-hoc Mann-Whitney $U$ tests for pair-wise comparison were performed where differences between groups were evident. Differences in contest competitive abilities were inferred from successful termination of matings by rival males. Of 152 copulations where both the mating male's and the approaching male's body mass was known, frequencies of terminations initiated by males of different body mass were evaluated in relation to the number of dyadic body mass combinations possible. Observed frequencies were compared with expected frequencies using a chi-squared test. If not otherwise stated, all statistical analyses were performed in R 2.14.1 with an accepted significance level of $P<0.05$. $P$-values for LMMs were calculated from 1000 Monte Carlo simulations. 


\section{Results}

\section{General aspects of female mating behaviour}

Table 1 summarises general observations based on the females' perspective. Females varied both with respect to the time they spent up on the mating tree and the respective time they mated, but every female mated with a rather large set of partners $(10 \pm 2)$ and mated multiply with the same male ( $4 \pm 3$ times; Table 1 ). Average durations of single copulation were comparable between females (39 $\pm 13 \mathrm{~min})$ as was the total time spent mating $(27.5 \pm 11.5 \mathrm{~h})$ and the number of copulations $(41 \pm 11)$ when considering individual differences in overall mating activity duration (Table 1).

Table 1 Summary of mating behaviour.

\begin{tabular}{ccccccccc}
\hline ID & Year & $\begin{array}{c}\text { Nights on tree } \\
\text { (Nights mating) }\end{array}$ & $\begin{array}{c}\text { Time on } \\
\text { tree (h:min) }\end{array}$ & $\begin{array}{c}\text { Time mating } \\
\text { (h:min) }\end{array}$ & $\begin{array}{c}\text { No. } \\
\text { males }\end{array}$ & $\begin{array}{c}\text { No. } \\
\text { mates }\end{array}$ & $\begin{array}{c}\text { No. } \\
\text { copulations }\end{array}$ & $\begin{array}{c}\text { Mean copulation } \\
\text { duration (h:min) }\end{array}$ \\
\hline F1 & $2007^{1}$ & $6(2)$ & $27: 12$ & $6: 54$ & 11 & 9 & 33 & $0: 12$ \\
& $2008^{2}$ & $8(6)$ & $76: 16$ & $23: 54$ & 18 & 11 & 32 & $0: 44$ \\
F2 & $2007^{1}$ & $6(3)$ & $46: 32$ & $21: 02$ & 8 & 7 & 29 & $0: 43$ \\
F3 & $2008^{2}$ & $12(7)$ & $79: 42$ & $40: 04$ & 20 & 12 & 41 & $0: 58$ \\
& $2009^{3}$ & $9(5)$ & $118: 28$ & $34: 31$ & 10 & 10 & 54 & $0: 38$ \\
F4 & $2009^{3}$ & $11(6)$ & $115: 47$ & $37: 38$ & 10 & 10 & 57 & $0: 39$ \\
F5 & 2009 & $6(4)$ & $46: 12$ & $28: 10$ & 10 & 10 & 41 & $0: 41$ \\
F6 & 2010 & $\geq 3(3)$ & $\geq 29: 30$ & $\geq 17: 34$ & $\geq 9$ & $\geq 8$ & $\geq 29$ & $0: 38$ \\
\hline
\end{tabular}

${ }^{1}$ females used the same tree consecutively

${ }^{2,3}$ females used the same tree simultaneously

Females either used mating trees singly or shared a tree with one or two females that were not necessarily related (data not shown). Sharing of trees could occur sequentially without any overlap between the different females or simultaneously. Simultaneous use of a tree was characterised by frequent socio-positive interactions between the females and generally prolonged mating activity for all females involved. This effect may have been confounded, however, by higher male presence when females were mating simultaneously (Table 1).

Male scramble competition: mate searching and sperm competition

We found no indication for greater investment in scramble competition by lighter males. Males of different body mass did not appear to visit different numbers of mating trees (Fig. 1A). In contrast to our predictions, light males did not travel farther per day than heavier males (Kruskal-Wallis ANOVA: $H=3.24, \mathrm{df}=2, n=9\left[n_{\mathrm{l}}=2, n_{\mathrm{m}}=2, n_{\mathrm{h}}=5\right], P=0.198$; Mann-Whitney $\mathrm{U}$ test: $Z=1.59, n_{\mathrm{l}, \mathrm{m}}=4, n_{\mathrm{h}}=5$, $P=0.111$ ) and inhabited smaller ranges even during the peak roaming month of October (KruskalWallis ANOVA: $H=6.53, \mathrm{df}=2, n=9\left[n_{1}=2, n_{\mathrm{m}}=2, n_{\mathrm{h}}=5\right], P=0.038$; Mann-Whitney U test: $Z=2.32$, 
$n_{l, \mathrm{~m}}=4, n_{\mathrm{h}}=5, P=0.020$; Fig. 1B). Since male home range size and daily travel distances were correlated $(r=0.70, P<0.0001)$, we additionally plotted residual travel distances controlling for home range size to see whether lighter males moved more within their range. But again, there was no such trend (Kruskal-Wallis ANOVA: $H=0.09$, $\mathrm{df}=2, n=9\left[n_{1}=2, n_{\mathrm{m}}=2, n_{\mathrm{h}}=5\right], P=0.954$; MannWhitney $U$ test: $Z=0.12, n_{1, \mathrm{~m}}=4, n_{\mathrm{h}}=5, P=0.903$; Fig. 1C).
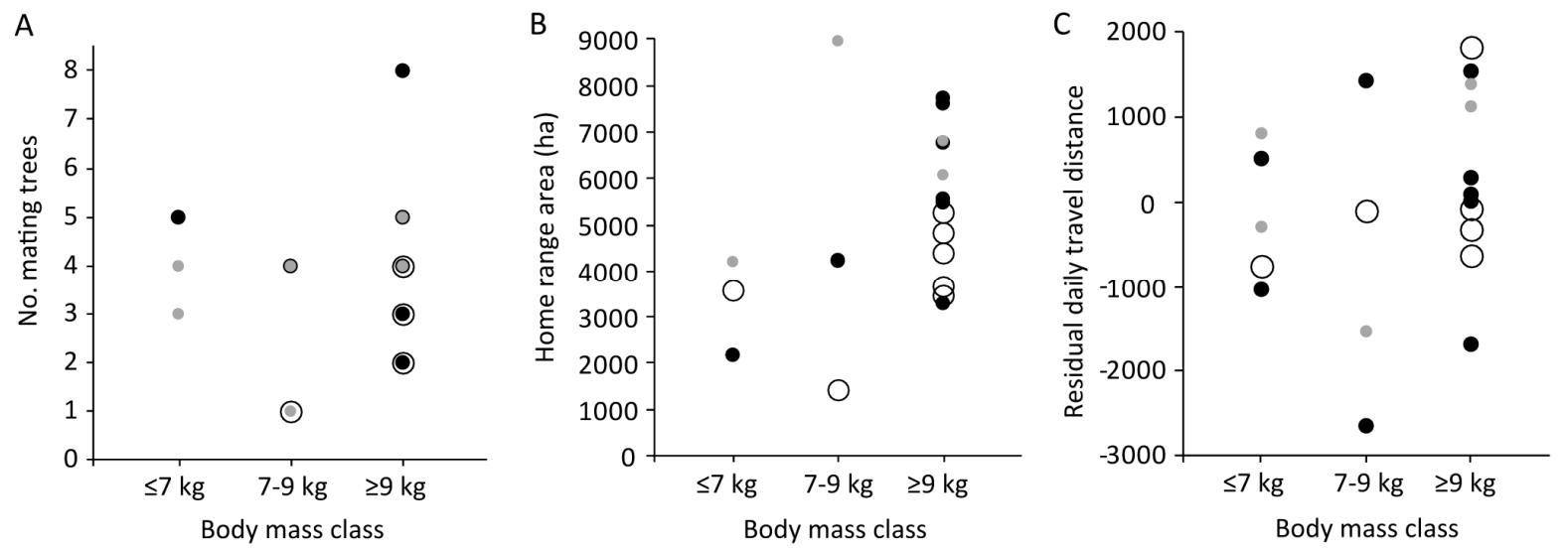

Fig. 1 Spatial data for males of different body mass. (A) Number of mating trees encompassed by a male's home range, (B) Home range area (MCP) in ha, (C) Daily travel distance controlled for differences in home range area. Data are shown for three months: September (open circles), October (black filled circles), November (mating season; grey filled circles).

Besides equivalent investment in movement, we could not find any higher somatic investment in post-copulatory scramble competition for lighter males. Instead, relative testis volume tended to increase with absolute body mass (Kruskal-Wallis ANOVA: $H=4.61, \mathrm{df}=2, n=14\left[n_{1}=2, n_{\mathrm{m}}\right.$ $\left.=6, n_{\mathrm{h}}=6\right], P=0.099$ ) and the lightest males clustered at the lower end of relative testis volume (Fig. 2). There was no difference in body condition between males of different body mass class $(H=3.17$, $\left.\mathrm{df}=2, n=18\left[n_{1}=4, n_{\mathrm{m}}=8, n_{\mathrm{h}}=6\right], P=0.205\right)$.

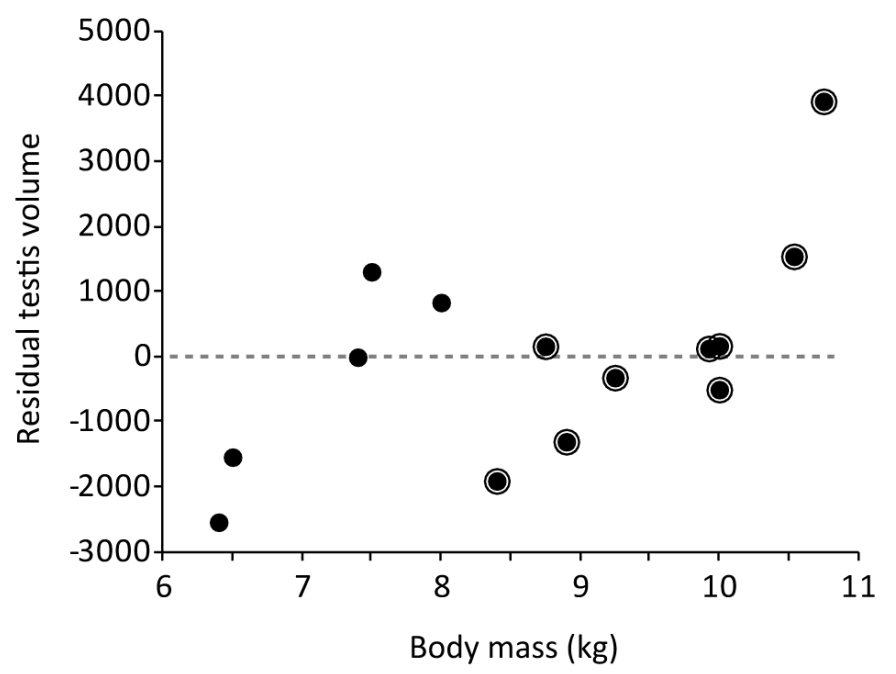

Fig. 2 Relative testis volume of males of different body mass and social organisation. Absolute testis volume was controlled for body length. Associated males are marked by external rings. 
Of 263 matings where the initiator of termination was known, $182(69.7 \pm 13.2 \%)$ were terminated by rival males disturbing the mating couple, $63(23.8 \pm 11.3 \%)$ were terminated by the female and 17 $(6.5 \pm 4.3 \%)$ were voluntarily terminated by the mating male (Fig. 3). Males of highest body mass interrupted matings of males of either body mass more often than expected based on their number (low body mass $\left[n_{1}=6, n_{\mathrm{h}}=6\right]: \chi^{2}=10.68, P=0.001$; medium body mass $\left[n_{\mathrm{m}}=10, n_{\mathrm{h}}=6\right]: \chi^{2}=23.03$, $n_{\mathrm{m}}=10, P<0.0001$; high body mass $\left.\left[n_{\mathrm{h}, \text { addressed }}=n_{\mathrm{h} \text {, disturbing }}=7\right]: \chi^{2}=33.07, P<0.0001\right)$. While 98 of 152 matings for which both males' body mass was known were interrupted by males from the highest body mass class, lightest males managed to do so only in 20 cases. Moreover, males that were lighter than the mating male managed to successfully disturb the latter's matings only on 24 occasions. Accordingly, males of lowest body mass interrupted matings of heavier males less often than expected based on their number (medium body mass: $\chi^{2}=9.77, n_{1}=5, n_{m}=4, P=0.002$; high body mass: $\chi^{2}=6.37, n_{1}=3, n_{h}=2, P=0.012$ ) but males of equal body mass as often as expected $\chi^{2}=$ $0.35, n_{1}$, addressed $=6, n_{1}$, disturbing $\left.=8, P=0.554\right)$. This skew in mating maintenance may amongst other factors explain longer copulation duration for the heaviest males (56.7 $\pm 59.4 \mathrm{~min}$ (high) vs. $36.8 \pm$ $41.7 \mathrm{~min}$ (medium) and $31.6 \pm 36.0 \mathrm{~min}$ (low), LMM: $t=2.17, \mathrm{df}=8, P=0.031$ ), even though the termination of matings by rival males did not explain variance in copulation duration $(t=-0.33, P=$ 0.745; Appendix III, Table A1).

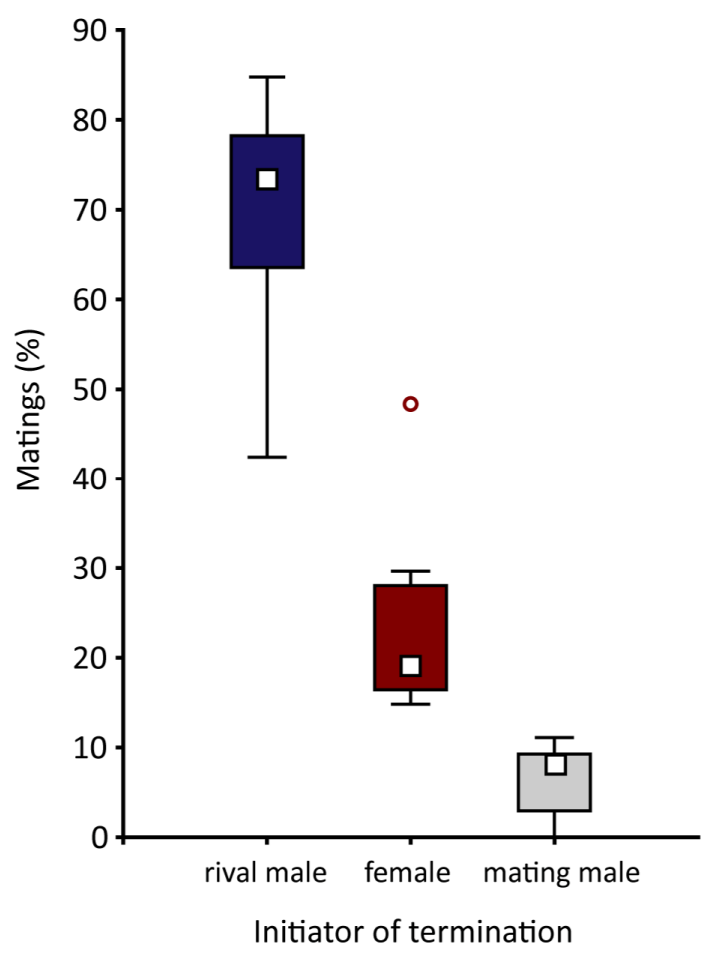

Fig. 3 Proportion of 263 matings terminated by the mating male (light grey), by the mating female (red) and by rival males disturbing the mating couple (dark blue). Plotted are medians, quartiles (boxes) and range (whiskers) with separated outliers (circles). 
Both males of highest and medium body mass monopolised female mating periods for longer than the lightest males (LMM, high class: $t=2.25, P=0.027$; medium class: $t=2.00, P=0.049, n_{1}=18, n_{\mathrm{m}}=$ 17, $n_{\mathrm{h}}=12, n_{\mathrm{fy}}=7$; Appendix III, Table A1; absolute monopolisation durations are shown in Fig. 4). A male's monopolisation success further increased with the number of nights it managed to mate $(t=$ 5.95, $P<0.0001)$ and with its presence during the female's peak activity $(t=2.66, P=0.010)$, whereby males of different body mass neither differed in the number of total nights present (Kruskal-Wallis test: $H=0.09, \mathrm{df}=2, n=43\left[n_{\mathrm{l}}=15, n_{\mathrm{m}}=16, n_{\mathrm{h}}=12\right], P=0.954$ ) nor in the number of mating nights $(H=0.55, P=0.758)$. Males of the highest body mass class were more likely, however, to be present during peak nights (binomial regression: $z=2.22, P=0.027)$. Accordingly, the heaviest males monopolised females for longer during peak nights than the lightest males (LMM: $t=2.87, P=$ $0.007)$ as did medium mass males $(t=2.32, P=0.026)$. Monopolisation during peak nights was generally decreased by higher aggression rates from the female $(t=-2.98, P=0.005)$. There was no difference, however, in aggression rates between males of different body mass during peak nights (Kruskal-Wallis test: $H=2.77, \mathrm{df}=2, n=55\left[n_{\mathrm{l}}=16, n_{\mathrm{m}}=13, n_{\mathrm{h}}=26\right], P=0.250$ ).

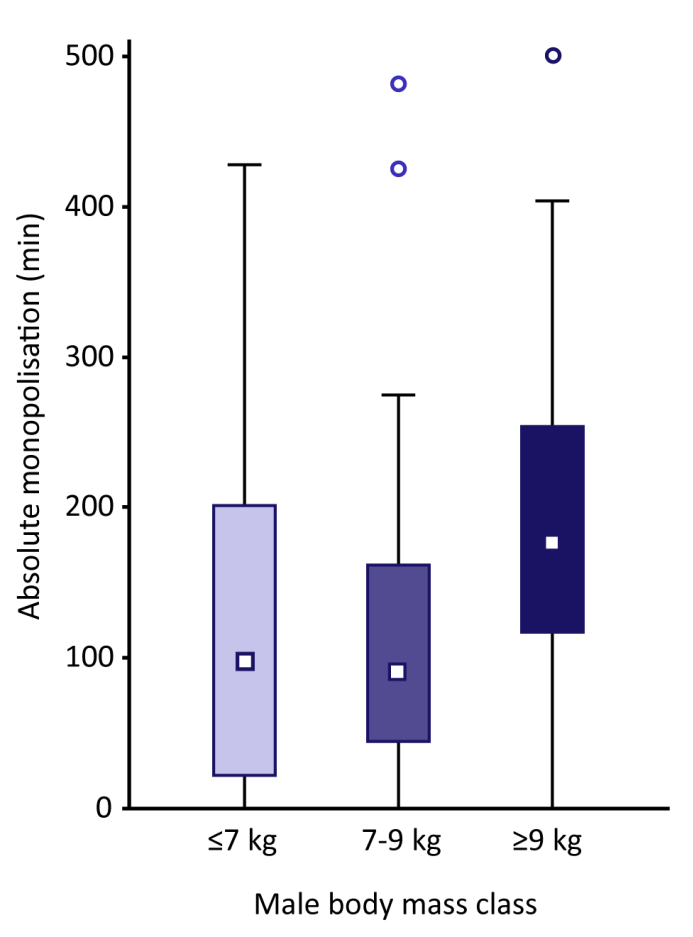

\section{Female control over mating}

In contrast to lighter males, males of greatest body mass received more aggression by the female the more often they tried to approach (LMM: $t=5.97, \mathrm{df}=11, P<0.0001 ;$ Fig. 5). Heavier males received more aggression overall $(t=4.60, P<0.0001)$, which appeared to be mainly driven by higher rates of aggression in periods flanking the female's peak mating activity (Appendix III, Fig. A2). Females were generally more aggressive in the post period when their mating activity decreased $(t=2.45, P=$ $0.015)$. In contrast, females were more likely to actively solicit matings from males of the lowest body 
mass (binomial regression: $\left.z=3.01, n_{1}=13, n_{\mathrm{h}}=11, P=0.003\right)$ and of medium body mass $\left(z=2.08, n_{\mathrm{m}}\right.$ $=16, n_{\mathrm{h}}=11, P=0.038$; Appendix III, Table A1). This effect appeared to be mostly driven by the female's post-peak activity period (Appendix III, Fig. A3). Besides an advantage of the heavier male subset (see above), there was no indication for female preference for certain individuals (see Appendix III, Fig. A4, for individual monopolisation success).

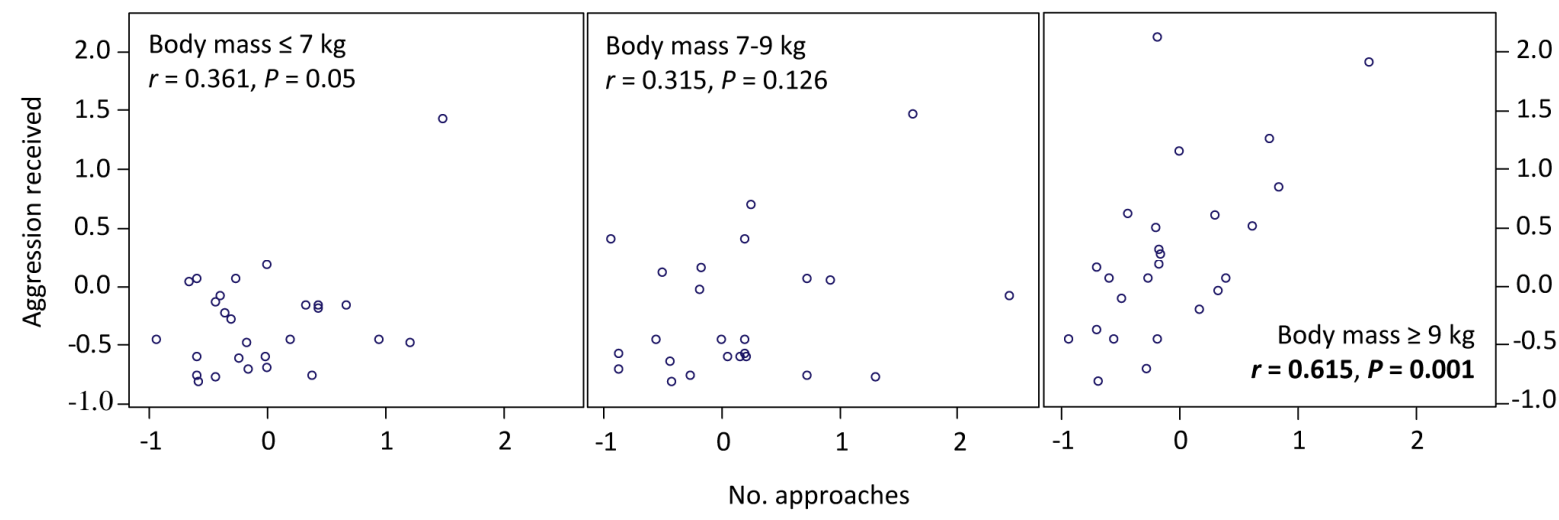

Fig. 5 Aggression received per approach for males of different body mass. Relative aggression was ztransformed to account for individual settings. Note that the heaviest males receive more aggression from the female the more often they try to approach. Correlation coefficients are given as Pearson's $r$.

\section{Discussion}

This study revealed that male body mass explained both variation in male success in search for mating trees and in male mating success. Males of different body mass are therefore unlikely to adopt different reproductive tactics. We also found a female preference for males of greatest body mass only during the presumed period of highest receptivity, and a preference for lighter males during the post-peak period. Females were potentially able to fight off males of all sizes and strictly discriminated against the heaviest males during the post-peak period. Heavy males thus enjoyed a twofold benefit with respect to male-male competition and female choice. Females, on the other hand, were not coerced to mate, but actively sought polyandrous matings. Polyandry in fosas is therefore likely promoted by benefits from polyandry per se rather than by the facilitation of mate location alone. The unique combination of sexual size dimorphism, female dominance and polyandry by choice has implications for the evolution of polyandry, indirect female choice and evolutionary forces shaping mating systems.

First of all, female fosa behaviour eliminates convenience polyandry as an explanation for female multiple mating. Even though females were potentially able to resist matings with any male, they actively solicited matings from multiple males and even more so with those males that were physically inferior to others and therefore disadvantaged in male-male competition. On the other hand, this preference was evident only after peak mating activity and therefore limited to a presumed period of lower fertilisation probability. While fosa females appeared to intervene in malemale competition in the post-peak period by aggressive resistance to the heaviest males and higher solicitation rates towards the lightest males, they seemed to concede to the outcome of male 
contest during peak mating activity, as indicated by lower aggression rates overall and high monopolisation success by physically superior males. The avoidance of sexual harassment can therefore be excluded as the primary explanation for female multiple mating in this species.

The fact that females actively search multiple matings raises the question about potential benefits of polyandry. Infanticide avoidance represents an obvious direct benefit with respect to higher fertility (Hrdy 1979; Smuts \& Smuts 1993). Although infanticide has never been observed in fosas, general socio-ecological conditions make it a likely male strategy to shorten a female's nonreceptive period. First, inter-birth interval is about three to four years because the species' life history is slow (Albignac 1969, 1973) and offspring likely stay with their mother for at least two years (Albignac 1973). When dependent offspring is killed within the first year, females come into oestrus in the following mating season (M.-L. Lührs, pers. obs.), whereas they would only do so after three to four years when they successfully raise their young (M. Kirschner, pers. comm.). Males that did not mate with a respective female may therefore adapt infanticidal behaviour to shorten the interoestrus interval and thereby achieve a competitive advantage (Hrdy 1974). In brown bears (Ursus arctos), sexually selected infanticide has been shown to account for a substantial part of cub mortality (Swenson et al. 2001), whereby males could be shown not to kill their own progeny and to subsequently reproduce with the mother (Bellemain et al. 2006a). Female brown bears developed a counterstrategy to prevent infanticide by mating polyandrously (resulting in mixed paternity litters) and by preferably mating with males ranging spatially close (Bellemain et al. 2006b). Litter size, interbirth interval, inter-sexual range overlap, extent of sexual dimorphism and degree of promiscuity are comparable between brown bears and fosas, making infanticide avoidance a plausible but speculative explanation for polyandry in both species.

Post-copulatory female choice for either certain genotypes and sperm characteristics or superior sperm competitors represents another plausible explanation for adaptive polyandry in fosas. Not only did fosa females actively seek matings with several males, but they also mated multiply with the same male. In peak nights, females mated virtually consecutively without interruption and thereby presumably promoted intense sperm competition among ejaculates of different mates (Parker 1970). This indicates both the importance of ejaculate diversity to choose from, and provides a potential basis for indirect female choice by promoting sperm competition (Smith 1984; Birkhead \& Møller 1993). Unfortunately, we were unable to evaluate the outcome of sperm competition as fertilisation success, but we measured testis volume as a correlate of the intensity and significance of sperm competition. Figure 6 indicates the placement of fosa testes volume in comparison to other carnivore species below $15 \mathrm{~kg}$ body mass based on data reviewed by lossa et al. (2008). As depicted, fosas appear to represent an outlier of exceeding relative testes volume, both in comparison to other families but also within the Eupleridae. This fact underlines the importance of sperm competition in reproductive strategies and renders indirect female choice for the best sperm competitor a likely female strategy to increase competitive abilities of their offspring (Fisher 1930; Yasui 1997). Despite its independence from sperm quantity, cryptic female choice for certain sperm characteristics cannot be ruled out, however, because superior ejaculate production may alternatively represent a concomitant male counterstrategy to female multiple mating (Parker 1998). Further research under controlled conditions is needed to disentangle direct and indirect female choice at the post-copulatory level. 


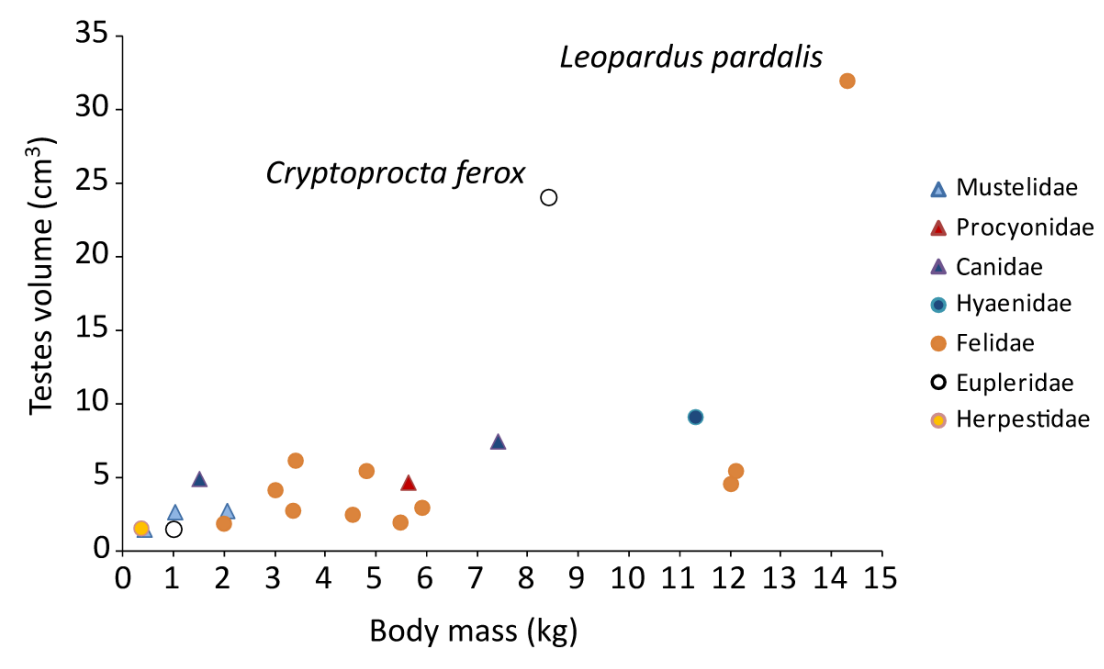

Fig. 6 Absolute testes volumes for species of different body mass from different families of the Carnivora (see lossa et al. 2008 for details). Outliers (the fosa, Cryptoprocta ferox, and the ocelot, Leopardus pardalis) are depicted. Note that volume of a single testis is doubled as opposed to earlier analyses in this study.

Altogether, the mating system of fosas appears to be shaped both to enhance male-male competition and to allow for female choice among a set of competitors. Female fosas combine all five mechanisms of indirect female choice for the best competitor proposed by Wiley and Poston (1996) in (1) the use of specific mating trees, i.e. predetermined locations, (2) vocal advertisement of oestrus (M.-L. Lührs \& G. Peters, unpubl. data) and (3) highly vocal copulations (Albignac 1970), (4) evasive behaviour against males, and (5) synchronisation of mating behaviour with other females. This behavioural manifoldness to enhance male-male competition indicates great importance of indirect female choice in evolutionary terms. A female's need to extract the best competitors from a large number of males to father her offspring may result from the challenge to successfully raise offspring under harsh environmental conditions in Madagascar. Pronounced seasonality with long periods of food limitation likely accounts for a substantial portion of infant mortality in a hypercarnivorous species (cf. Packer et al. 1988). Females should therefore have an interest in both mixed paternities to increase genetic diversity among competitive siblings as well as in high genetic and phenotypic quality of each single offspring. This combination is likely to increase a female's reproductive success both in terms of offspring survival and a male offspring's chances to reproduce.

From the males' perspective, body mass emerged as the primary determinant of mating success in fosas. Not only did heavier males search for females on a larger area and tended to exhibit relatively larger testes, but they also gained better access to females at mating trees because they successfully displaced lighter males. Even though success in contest alone does not ensure copulations because females are dominant over males, heavier males also enjoyed female acceptance of matings during her peak activity period and faced aggressive resistance only after they had mated. This heavier male advantage in contest competition is not surprising and has been demonstrated in a number of polyandrous mammals under similar conditions (e.g., Preston et al. 2003; Eberle \& Kappeler 2004; Fisher \& Cockburn 2006). What is unique in fosas, however, is considerable variance in adult male body mass and size (ranging from sexually monomorphic males to those exhibiting pronounced sexual dimorphism compared to females) and the interaction of male morphology with the degree of sociality (Chapter 3). Since a male's physical development depends 
on its ability to associate with other males and to hunt cooperatively, male reproductive strategies in fosas are taken to a higher level of behavioural complexity. Male sociality hereby becomes a major determinant of male mating success (and presumably reproductive success) but on a less direct line of conditions than in male coalitions in primates and carnivores where direct ally support can increase a male's access to females (Bygott et al. 1979; Bercovitch 1988; Noë \& Sluijter 1990; Rood 1990; Watts 1998; Duffy et al. 2007). In fosas, body mass is the major predictor of a male's position in the locally established dominance hierarchy while coalitional support in the mating context appears of minor importance. Male reproductive strategies are therefore closely linked to their social organisation and related feeding efficiency as a major determinant of male competitiveness. Since male social organisation in fosas appears to be closely linked to relatedness and familiarity (Chapter 3), males are likely constrained in their opportunity to adopt different tactics than those predetermined by litter sex ratio. Slowly growing solitary males may therefore exclusively rely in their reproductive strategy on sperm characteristics and females' ready acceptance of mating.

Taking the observed interplay of sociality and food acquisition, sexual dimorphism, female dominance, male contest and female choice together, three major conclusions can be drawn concerning determinants and consequences of a unique mating system. First, polyandry in fosas can be assumed to represent an adaptive female strategy serving other purposes than the avoidance of sexual harassment, whereby mating up on a tree may still serve this function. Even though they remain to be quantified, indirect benefits from female multiple mating must be significant to explain this 'super-polyandrous' mating behaviour and might ultimately be related to harsh environmental conditions. Second, female dominance over males potentially allows for effective intervention of females in the outcome of male-male contest competition. Since female preference and male competitiveness converge, however, in that females appear to choose superior competitors, equivalent selective forces are likely to operate on males compared to species where sexual dimorphism results in male dominance over physically inferior females in the mating context. Third, the role of sociality and related mode of food acquisition as a determinant of male mating success stands out in this mating system. In contrast to frequent assumption, access to food can have a significant impact on male reproductive success where physical development determines competitiveness. In the seasonal and unpredictable environment of Madagascar (Dewar \& Richard 2007), food limitation may have shaped both male and female reproductive strategies and ultimately explain an unusual mating system. 


\section{General Discussion}

The study of social systems provides important insights into the interplay of ecological determinants of sociality and reproductive strategies and thus is a major topic in behavioural ecology. A large body of literature has described the astonishing diversity of social systems and explained common patterns based on socio-ecological theory. Some species, however, developed unique solutions to common evolutionary problems. Illuminating the specific configuration of ecology, sociality and sexspecific reproductive strategies, which gave rise to these social systems, might not only contribute important test cases of current theory but also potentially give rise to new ideas. By definition, exceptions are rare, however, and consequently underrepresented in the literature. In this thesis, I focussed on the unusual social system of the fosa and provided new data on the species' social organisation and mating system. This in-depth field study illuminated several rare characteristics of social systems as well as their potential determinants and consequences. With respect to the fosa's social organisation, I empirically revealed the existence of stable male associations along with solitary males and females (Chapter 1). Male associations in otherwise solitary species are a rare phenomenon, which requires explanation. Based on the integrated information of multiple direct and indirect methodological approaches, I demonstrated in Chapter $\mathbf{3}$ that cooperative hunting is the key to differences in male morphology and mating success. These results confirmed the importance of initial direct observations of this behaviour (Chapter 2). In order to explore the unique mating system of the fosa, I used continuous behavioural observation of oestrous females to unravel male and female mating strategies (Chapter 4). In the following, I will discuss possible socio-ecological determinants of the fosa's social system and sketch likely evolutionary driving forces shaping the system based on the results of this thesis. I will discuss both the social organisation and mating system against the background of general mammalian and carnivore patterns and emphasize the contribution of this thesis to the study of social systems in general. Finally, I will provide an outlook for future studies and research directions that could build on the findings presented in this thesis.

\section{Social organisation of the fosa: drivers and constraints of facultative male sociality}

As described in Chapter 1, the social organisation of the fosa can be classified as basically solitary with the notable feature of frequently occurring permanent male associations. Home range size and overlap patterns of females and solitary males meet predictions of socio-ecological theory for a hypercarnivorous species with unpredictable and spatially dispersed food resources (McNab 1963; Gittleman \& Harvey 1982; Gompper \& Gittleman 1991). Whereas females showed indications for territoriality, i.e. exclusive home range core areas, solitary males had larger ranges overlapping with several females but also with other males. This pattern is found in the majority of carnivoran species (Sandell 1989). In the fosa, however, about half of the males (11 out of 24 males trapped) were permanently associated with one or two stable male partners. Based on simultaneous tracking of three of those male associations, I demonstrated in Chapter 1 that associated males not only overlap extensively in their home range area but in contrast to their solitary conspecifics also spent a large proportion of time in close proximity to each other indicating frequent social interaction. Associated males thus synchronise their activity and therefore cannot be classified as solitary. 
Anecdotal observations presented in Chapter 2 suggested that this synchronisation of activity also involves cooperative hunting activities. In Chapter 3, I could demonstrate based on indirect measurement of body acceleration, stable isotope analyses of dietary components and direct observation of mating behaviour that cooperative hunting results in a dietary divergence between solitary and associated males with remarkable effects on their morphology and their mating success. Whereas solitary males appeared to grow more slowly in the wild and were therefore inferior contest competitors, associated males were found to be physically superior, gained on average $38 \%$ higher body mass and $13 \%$ larger body size than solitary males at equivalent body condition and age. This physical advantage translated into higher mating success due to their physical advantage in male-male contest. Morphological differences between solitary and associated males were coherent with a difference in prey types hunted. Dietary mixing models based on stable isotopes revealed that associated males hunt larger prey species more often than solitary males. This within-species trophic differentiation potentially offsets the energetic costs of larger home range areas and longer travel distances for associated males and supported the hypothesis that associated males enjoyed higher hunting efficiency. The mode of hunting as a function of male social organisation may therefore explain the observed correlates of physical development.

Male sociality along with solitary females has been reported for a few other carnivore species, including cheetahs (Acinonyx jubatus: Caro \& Collins 1986, 1987a,b; Caro 1994) and several mongoose species (Galerella sanguinea: Rood \& Waser 1978; Waser et al. 1994; Galerella pulverulenta: Cavallini \& Nel 1990; Herpestes javanicus: Hays \& Conant 2003; Galerella nigrata: Rathbun \& Cowley 2008). Whereas descriptions of male associations in mongooses are yet of anecdotal kind, associations among male litter-mates in cheetahs are well-studied and the outcome of male sociality is well known (Caro \& Collins 1987a,b; Caro 1989; Caro 1994; Durant et al. 2004; Gottelli et al. 2007). In both cheetahs and mongooses, male sociality has been hypothesised to function in joint defence of a territory in an attempt to monopolise access to encompassing females (Caro \& Collins 1987a; Caro 1994; Waser et al. 1994). In cheetahs, just as in fosas, associated males have been shown to hunt cooperatively, which enables them to take down larger prey (Caro 1994). In contrast to fosas, however, associated males do not differ from solitary males in their physical properties, which is probably due to the fact that, while the benefits obtained from cooperative hunting compensates for the costs of sharing food items, per capita intake rates were not higher in associated males compared to solitary conspecifics (Caro 1989). Associated cheetah males therefore primarily benefit from a numerical advantage in combination with indirect fitness benefits from shared reproduction among relatives.

The morphological consequences of male association in fosas are unique in their extent and have important implications for other aspects of the species' social system, particularly for the mating system (discussed below). The somatic benefit of male sociality in a contest governed mating system appears high enough to allow for association even among unrelated individuals. These advantages are likely to result in fitness benefits, which are notoriously difficult to demonstrate in long-lived species with slow life-histories, particularly within the comparatively short time-frame of a thesis. The morphological difference between associated and solitary males is evident, however, as is the dietary divergence (Chapter 3). Furthermore, both males and females consistently reach body size and mass of associated males in captivity (pers. obs.), while even under ad libitum access to food growth is comparably slow (Albignac 1969). Based on the results of my thesis, it is most parsimonious to assume that physical divergence is driven by dietary divergence, which again is likely explained by 60 
differences between hunting singly versus hunting in groups. Consequently, the social organisation of the fosa in its interplay with aspects of feeding ecology, life-history and reproductive strategies yields a high potential to contribute to the understanding of the driving factors shaping social systems. After an equivalent discussion of the fosa's mating system, I will draw conclusions concerning the species' social system as a whole.

\section{Mating system of the fosa: the interplay of male social organisation and female choice}

Based on an earlier investigation by Hawkins \& Racey (2009), it was previously known that the mating system of the fosa is unique among mammals in that (1) mating is restricted to predetermined locations without being a true lek, (2) females gain access to a high number of males compared to their low population density, (3) male contest competition is at least as important as is scramble competition, and (4) copulatory activity is unusually prolonged. In this thesis, I focused on these peculiar aspects and investigated the mating behaviour in more detail. Overall, this thesis adds three major insights concerning the species' mating behaviour, which advance our knowledge about a previously enigmatic social system (Chapter 4). First, direct continuous observation of complete female mating activities revealed that females unrestrictedly dominated males regardless of their physical inferiority. Second, in line with their dominance over males, I could not find any indication for sexual coercion and convenience polyandry. Instead, the quantification of solicitation of matings by females in combination with their control over the outcome of male-male competition strongly suggests that fosa females actively seek polyandrous matings. Third, I found that fosa females do not mate randomly with random mates but instead show a clear temporal pattern in their preference for males of different body size and mass. The way female fosas choose their mates is rather indirect and presumably serves to select the best competitor on both the pre- and post-copulatory level from a large set of mates. For the time being, the ultimate function of excessive polyandry compared to other mammals with similar life-history remains puzzling though and requires further enquiry.

Among carnivores and mammals in general, the mating system of the fosa is clearly distinct. Whereas other carnivores of equivalent social organisation most often developed scramble competition polygyny (Sandell 1989), fosas have developed a system that facilitates the reunion of mates in a species of low population density (Hawkins \& Racey 2005, 2009). It thereby serves to increase the number of available mates from a female's perspective and at the same time elevates the importance of contest competition between males by increasing spatial and temporal predictability of females and thus their monopolisation potential for males. Furthermore, I showed that a male's social organisation determines its mating success (Chapter $\mathbf{3}$ ) and that dominant females actively intervene in male-male competition by targeted aggression, thereby manipulating its outcome (Chapter 4). As such, this mating system is unique and can only be compared in specific aspects to other mammals.

An unusual mating behaviour of similar kind can be found in the Australian marsupial carnivore species Antechinus stuartii (Lazenby-Cohen \& Cockburn 1988) and Dasyurus hallucatus (Oakwood 2002) of the family Dasyuridae. Females in these species mate in tree-holes and receive largely prolonged copulations from multiple males (Lazenby-Cohen \& Cockburn 1988). Males face both scramble and contest competition and sexual dimorphism is accordingly pronounced (LazenbyCohen \& Cockburn 1988). A large-male advantage in reproductive success has been demonstrated 
for $A$. stuartii in the field (Fisher \& Cockburn 2006) and polyandrous matings were shown to increase female lifetime fitness (Fisher et al. 2006). Males are semelparous in these species, however, and aspects of male reproductive strategies are therefore exposed to different selective pressures than in long-lived fosas. More explicitly, facultative male association and differential somatic development can unlikely be established as an evolutionarily stable pattern where males gain access to females in only a single year. Unusually long copulations indicate instead that selective pressures primarily act on male tactics to form 'living sperm plugs' (Parker 1970). In fosas, I demonstrated that even though copulations are prolonged, males do not manage to monopolise females for a long time because both rival males and the mating female effectively prevent monopolisation. No indication for analogous patterns was found in the Dasyuridae, however.

It appears reasonable to assume that despite major difference in life-history, the evolution of excessive polyandry in both Antechinus and fosas was driven by significant benefits from female polyandry per se. The fact that females bear considerable costs of multiple matings in the form of increased infection risk (Lockhart et al. 1996; Nunn et al. 2003) and physical injury (Parker 1979) could not be explained otherwise. While in $A$. stuartii, polyandry has been shown to increase offspring survival rates (Fisher et al. 2006), putative benefits of polyandry in fosas remain elusive for the time being. In Chapter 4, I proposed two likely explanations for the importance of polyandry in fosas: infanticide avoidance and offspring genetic diversity. First, the concealment of paternity by multiple mating may be a crucially important female counterstrategy to sexually selected infanticide. Even though a long inter-birth interval makes infanticide a potentially adaptive male strategy, it has never been observed in fosas and is yet insufficient to explain how it initially prompted the evolution of 'super-polyandry' whereas it did not lead to comparable patterns in species with similar lifehistory and sexually selected infanticide (e.g. brown bears, Ursus arctos: Dahle \& Swenson 2003; Bellemain et al. 2006a,b; Steyaert et al. 2012). As an alternative but not necessarily exclusive explanation I therefore propose genetic benefits from polyandry related to genetic diversity of offspring.

When searching for explanations for a unique behavioural pattern, both the natural history of the species and its specific environment over evolutionary time scales can provide important insights. The fact that the fosa's mating system serves to increase the set of potential mates for females and the resulting form of pronounced polyandry compared to most other solitary species indicate that a distinct element in the species' biology which is subject to both natural and sexual selection had a major influence. Two aspects of Madagascar's evolutionary history distinguish the island from any other environment on the mainland: its pronounced climatic seasonality and presumably severe effects of the dry Quartenary periods (cf. Haffer 1969; Hewitt 2000) promoted by the island's geomorphology (Dixey 1960). Both of these characteristics have been hypothesised to explain Madagascar's most mysterious behavioural and physiological phenomena such as female dominance, a lack of sexual dimorphism and low basal metabolic rates in lemurs (Wright 1999) or the prevalence of pair-living on the island. Four factors render environmental restriction of food availability a likely driver of the fosa's social system. First, in fosas, as a hypercarnivorous species, seasonal differences in diet have been shown to exist and my own observations suggest that food availability is a major constraint on individual growth (Chapter $\mathbf{3}$ ). Second, sociality among females is not promoted, although socio-ecological theory would predict it to precede male sociality, indicating that the availability of food resources does not allow the subsistence of more than one female and her offspring (Chapter 1). Third, association between males appears to be restricted to dyads and 62 
triads and may only be sustained by the related shift in prey spectrum (Chapters 1, 2, 3). Fourth, offspring survival is likely most closely linked to food availability during the lean dry season, in recent times at least in the dry areas of western and southern Madagascar. All of these restrictions of sociality and growth were thereby putatively exacerbated by the recent extinction of Madagascar's megafauna (Burney 1997; discussed in Chapter 2).

In light of the assumed environmental constraints on offspring survival, I suggest that multiple paternities within a litter, which I could demonstrate to exist based on genetic analyses of relatedness (Chapter 3), may be of vital importance. Not only does increased genetic diversity among offspring provide a larger gene-pool for natural selection to operate on, but it also sets the scope for male offspring in particular to yield genetic traits of a subset of superior competitors. The interplay of female choice for the best contest competitors in the first instance and presumably the best sperm competitors thereafter (Chapter 4) and the incidence of multiple paternities potentially allows females to produce highly competitive male progeny without narrowing the subset of available genes necessary to meet variable conditions. In similar lines, increased genetic variability among littermates would decrease the importance of within-offspring genetic diversity and thereby attribute higher relevance to other male traits to choose from on the pre-copulatory level (e.g., contest competitiveness). Moreover, additional fitness effects resulting from genetic diversity, such as inbreeding avoidance (Stockley et al. 1993), are likely co-fostering polyandry in a species with low population density. In order to test predictions of these hypotheses, information on offspring survival rates, differential offspring development and female lifetime fitness would be essential, which cannot be collected within the time frame of a thesis, however.

\section{The social system of the fosa: trying to explain the inexplicable}

Taking the findings of my study on the social organisation and mating system of the fosa together, I finally aim to highlight correspondence between these two elements of a social system in order to understand the system as a whole. A clear intersection is evident from the importance of male sociality for male contest competition and mating success (Chapter $\mathbf{3}$ ). If mating success is correlated with reproductive success in fosas, which remains to be demonstrated (but see Altmann et al. 1996 for primates), associated males enjoy reproductive advantage over solitary males and male sociality would be generally promoted. Possible adaptive scenarios would include a female's ability to manipulate the offspring sex ratio, as has been demonstrated in captivity for co-occurring grey mouse lemurs (Microcebus murinus: Perret 1990), or increased male social tolerance facilitating male sociality even among unrelated males. Both litter sex ratio and male sociality would thereby underlie frequency-dependent selection. Given the fact that females could be shown to preferably mate with physically superior, i.e. associated males, during their period of supposedly highest receptivity (Chapter 4), female choice would drive the associated males' advantage as much as does male-male competition. Yet, females were also shown to seek polyandrous matings, which I hypothesised to serve the purpose of increasing offspring genetic diversity in a seasonal and unpredictable environment. Assuming that both male sociality and female polyandry (and female dominance) have been selected to overcome challenges posed by an unfavourable environment, most notably energetic restriction, one possible explanation for unique aspects of this social system may be rooted in Madagascar's seasonality in climate and food availability. Food limitation has been hypothesised 
to explain the general prevalence of female dominance over males in lemurs (Wright 1999; but see van Schaik \& Kappeler 1996 and Jolly 1998 for alternative explanations), slow life-histories and pronounced seasonal changes in body mass across different taxa (Fietz 1998; Richard et al. 2000, 2002). It appears reasonable to assume that fosas on the highest trophic level experience even higher nutritional stress during the lean season (cf. White 1978). Consequently, decelerated growth may represent an adaptation of life-history to a temporally food-limited environment. Only this adaptation may explain why cooperative hunting qualifies as a selective force promoting sociality in fosas whereas it presumably developed from sociality secondarily in other carnivores (Packer \& Ruttan 1988; Packer et al. 1990), cetaceans (Connor 2000) and primates (Boesch 1994). The interplay of feeding ecology and social organisation in fosas therefore provides new insights into the evolution of group-living from a different angle. First, its precursory form of sociality with co-occurrence of solitary males and small male groups allows disentangling costs and benefits of group-living under control of confounding factors. Second, food limitation to an extent which allows association only among males but not in females exposes a previously neglected factor in socio-ecological theory, which is the importance of food resources for males. As I could show in this thesis, access to food can be crucial for male development and has major impact on male mating success under contest competition in a sexually dimorphic species.

In line with previous ideas concerning food limitation, female preference for physically superior males could be explained by the fact that large and heavy males signal to cope well with a harsh environment and thereby signal high genetic quality. To disentangle the relative importance of female choice and male-male competition, quantitative modelling based on the empirical data provided in this thesis might be a promising approach.

\section{Outlook}

Even though this thesis is based on a large set of data from the field on multiple behavioural and ecological aspects of fosa biology, some open questions remain and a number of new questions arose based on new results. Further investigations are therefore needed to explore ecological determinants of and reproductive strategies within social systems.

First, profound resolution of female spatial organisation could shed more light on the ecological determinants of the fosa's social system. In light of the hypothesis I derived based on the results of this thesis - stating food limitation as the major driving factor to shape this system - more information on the extent of female territoriality and its interaction with offspring care, survival, and development as well as dispersal patterns would be of vital importance to understand the relevance of bottom-up determinants. This would require sampling at a larger spatial scale, however, due to the large ranges of females and their absolutely low numbers. Furthermore, long-term data would be needed to acquire sufficient sample sizes for a long-lived species.

Second, the reproductive outcome and thus actual fitness correlates of sex-specific mating strategies need to be clarified in future research. During the period of this thesis, offspring mortality was too high to gain access to genetic samples from offspring sired during the field observations. Again, a larger spatial and temporal scale would be required to illuminate fitness consequences of sex-specific strategies. Addressing specific questions on genetic benefits of polyandry is difficult for 
mammalian species because controlled mating experiments are often impossible to implement in the field and the captive setting. Small species with fast life-histories, which can be kept and bred in captivity, are more suitable models to explore the costs and benefits of polyandry, as has recently been demonstrated in a experiment by Huchard et al. (2012) with grey mouse lemurs (Microcebus murinus).

Third, this thesis highlighted two previously neglected determinants of a social system: (1) the potential of cooperative hunting as a driving force for sociality and (2) the importance of food acquisition for male mating success in a sexually dimorphic species. Evident advantage of cooperatively hunting individuals over single hunters as found in fosas should stimulate novel discussion about the relevance of cooperative food acquisition for sociality in carnivores, cetaceans and primates (including humans). Although male reproductive success is certainly limited by access to females, the importance of access to food resources determining male physical development and ultimately facilitating access to females in male-male competition should not be underestimated. In sexually dimorphic species, where a male's physical development is crucial for its reproductive success, feeding efficiency and growth represent major determinants of male fitness and should therefore be carefully addressed. The interaction of cooperative hunting, feeding efficiency, somatic development and mating tactics might be worth addressing inter alia in other solitary species with male associations. Continuing advances in technological support of behavioural study may soon allow us to explore such rare but the more insightful phenomena.

Finally, the detailed study of several aspects of the fosa's behaviour and ecology also has important conservation implications for the species. The data presented in this thesis together with unpublished information strongly suggest that Madagascar's largest carnivore is threatened with extinction and that its current IUCN red list status 'vulnerable' is underestimating the actual situation. Future research on the species should therefore particularly focus on applied conservation and population management to conserve this enigmatic species and its ecologically important function as the top predator in Madagascar's forest habitats. 


\section{References}

Albignac R (1969) Naissance et élevage en captivité de jeunes Cryptoprocta ferox, Viverridae malgaches. Mammalia 33: 93-97.

Albignac R (1970) Notes éthologiques sur quelques carnivores malgaches: le Cryptoprocta ferox (Bennett). Terre et Vie 24: 395-402.

Albignac R (1973) Mammifères carnivores. O.R.S.T.O.M.: Paris.

Altmann J (1990) Primate males go where the females are. Animal Behaviour 39: 193-195.

Altmann J, Alberts SC, Haines SA, Dubach J, Muruthi P, Coote T, Geffen E, Cheesman DJ, Mututua RS, Saiyalel SN, Wayne RK, Lacy RC, Bruford MW (1996) Behavior predicts genetic structure in a wild primate group. Proceedings of the National Academy of Sciences 93: 5797-5801.

Andersson MB (1994) Sexual selection. Princeton University Press: Princeton, NJ.

Arnqvist G, Rowe L (1995) Sexual conflict and arms races between the sexes: a morphological adaptation for control of mating in a female insect. Proceedings of the Royal Society B 261: 123-127.

Arnqvist G, Nilsson T (2000) The evolution of polyandry: multiple mating and female fitness in insects. Animal Behaviour 60: 145-164.

Axelrod R, Hamilton WD (1981) The evolution of cooperation. Science 211: 1390-1396.

Baer B, Schmid-Hempel P (1999) Experimental variation in polyandry affects parasite loads and fitness in a bumble-bee. Nature 397: 151-154.

Baker PJ, Funk SM, Harris S, White PCL (2000) Flexible spatial organization of urban foxes, Vulpes vulpes, before and during an outbreak of sarcoptic mange. Animal Behaviour 59: 127-146.

Bandeira de Melo LF, Lima Sábato MA, Vaz Magni EM, Young RJ, Coelho CM (2007) Secret lives of maned wolves (Chrysocyon brachyurus Illiger 1815): as revealed by GPS tracking collars. Journal of Zoology 271: 27-36.

Barash DP (1971) Cooperative hunting in the lynx. Journal of Mammalogy 52: 480.

Barlow ACD, Smith JLD, Ahmad IU, Hossain ANM, Rahman M, Howlader A (2011) Female tiger Panthera tigris home range size in the Bangladesh Sundarbans: the value of this mangrove ecosystem for the species' conservation. Oryx 45: 125-128.

Bateman AJ (1948) Intrasexual selection in Drosophila. Heredity 2: 349-368.

Bekoff M, Daniels TJ, Gittleman JL (1984) Life history patterns and the comparative social ecology of carnivores. Annual Review of Ecology and Systematics 15: 191-232.

Bellemain E, Swenson JE, Taberlet $P$ (2006a) Mating strategies in relation to sexually selected infanticide in a non-social carnivore: the brown bear. Ethology 112: 238-246. 
Bellemain E, Zedrosser A, Manel S, Waits LP, Taberlet P, Swenson JE (2006b) The dilemma of female mate selection in the brown bear, a species with sexually selected infanticide. Proceedings of the Royal Society B 273: 283-291.

Bercovitch FB (1988) Coalitions, cooperation and reproductive tactics among adult male baboons. Animal Behaviour 36: 1198-1209.

Bertram BC (1975) The social system of lions. Scientific American 232: 54-65.

Birkhead TR, Møller AP (1993) Female control of paternity. Trends in Ecology \& Evolution 8: 100-104.

Birkhead TR (1995) Sperm competition: evolutionary causes and consequences. Reproduction, Fertility and Development 7: 755-775.

Birkhead TR, Møller AP (1998) Sperm competition and sexual selection. Academic Press: San Diego, CA.

Birkhead TR (2000) Promiscuity: an evolutionary history of sperm competition. Harvard University Press: Cambridge, MA.

Birkhead TR, Pizzari T (2002) Postcopulatory sexual selection. Nature Reviews Genetics 3: 262-273.

Boesch C (1994) Cooperative hunting in wild chimpanzees. Animal Behaviour 48: 653-667.

Boesch C (2002) Cooperative hunting roles among Tai chimpanzees. Human Nature 13: 27-46.

Bonduriansky R, Chenoweth SF (2009) Intralocus sexual conflict. Trends in Ecology \& Evolution 24: 280-288.

Börger L, Franconi N, De Michele G, Gantz A, Meschi F, Manica A, Lovari S, Coulson T (2006) Effects of sampling regime on the mean and variance of home range size estimates. Journal of Animal Ecology 75: 1393-1405.

Boydston EE, Kapheim KM, Van Horn RC, Smale L, Holekamp KE (2005) Sexually dimorphic patterns of space use throughout ontogeny in the spotted hyena (Crocuta crocuta). Journal of Zoology 267: 271281.

Bradbury JW, Vehrencamp SL (1976) Social organization and foraging in emballonurid bats. Behavioral Ecology and Sociobiology 1: 337-381.

Brown JL (1997) A theory of mate choice based on heterozygosity. Behavioral Ecology 8: 60-65.

Burney D (1997) Tropical islands as paleoecological laboratories: gauging the consequences of human arrival. Human Ecology 25: 437-457.

Bygott JD, Bertram BCR, Hanby JP (1979) Male lions in large coalitions gain reproductive advantages. Nature 282: 839-841.

Calenge C (2006) The package "adehabitat" for the R software: a tool for the analysis of space and habitat use by animals. Ecological Modelling 197: 516-519. 
Carbone C, Gittleman JL (2002) A common rule for the scaling of carnivore density. Science 295: 2273-2276.

Carbone C, Teacher A, Rowcliffe JM (2007) The costs of carnivory. PLoS Biology 5: 363-368.

Caro TM, Collins DA (1986) Male cheetahs of the Serengeti. National Geographic Research 2: 75-86.

Caro TM, Collins DA (1987a) Male cheetah social organization and territoriality. Ethology 74: 52-64.

Caro TM, Collins DA (1987b) Ecological characteristics of territories of male cheetahs (Acinonyx jubatus). Journal of Zoology 211: 89-105.

Caro TM, Fitzgibbon CD, Holt ME (1989) Physiological costs of behavioural strategies for male cheetahs. Animal Behaviour 38: 309-317.

Caro TM (1989) Determinants of asociality in felids. In: Comparative socioecology: the behavioural ecology of humans and other mammals (eds. V Staden, RA Foley), pp. 41-74. Blackwell Press: Oxford.

Caro TM (1994) Cheetahs of the Serengeti plains: group living in an asocial species. University of Chicago Press: Chicago.

Caro TM, Stoner CJ (2003) The potential for interspecific competition among African carnivores. Biological Conservation 110: 67-75.

Carr GM, Macdonald DW (1986) The sociality of solitary foragers: a model based on resource dispersion. Animal Behaviour 34: 1540-1549.

Cavallini P, Nel JAJ (1990) Ranging behaviour of the Cape grey mongoose Galerella pulverulenta in a coastal area. Journal of Zoology 222: 353-362.

Cavallini P (1996) Variation in the social system of the red fox. Ethology Ecology \& Evolution 8: 323342.

Chapman T, Liddle LF, Kalb JM, Wolfner MF, Partridge L (1995) Cost of mating in Drosophila melanogaster females is mediated by male accessory gland products. Nature 373: 241-244.

Chapman T, Arnqvist G, Bangham J, Rowe L (2003) Sexual conflict. Trends in Ecology \& Evolution 18: 41-47.

Clutton-Brock TH, Guinness FE, Albon SD (1982) Red deer: behavior and ecology of two sexes. University of Chicago Press: Chicago.

Clutton-Brock TH, Albon SD, Guinness FE (1989) Fitness costs of gestation and lactation in wild mammals. Nature 337: 260-262.

Clutton-Brock TH (1989) Review lecture: Mammalian mating systems. Proceedings of the Royal Society B 236: 339-372.

Clutton-Brock TH (1991) The evolution of parental care. Princeton University Press: Princeton, NJ.

Clutton-Brock TH, Parker GA (1992) Potential reproductive rates and the operation of sexual selection. The Quarterly Review of Biology 67: 437-456. 
Clutton-Brock TH, Parker GA (1995) Sexual coercion in animal societies. Animal Behaviour 49: 13451365.

Clutton-Brock TH, Russell AF, Sharpe LL, Brotherton PNM, Mcllrath GM, White S, Cameron EZ (2001) Effects of helpers on juvenile development and survival in meerkats. Science 293: 2446-2449.

Clutton-Brock TH, Hodge SJ, Spong G, Russell AF, Jordan NR, Bennett NC, Sharpe LL, Manser MB (2006) Intrasexual competition and sexual selection in cooperative mammals. Nature 444: 10651068.

Clutton-Brock TH (2009) Cooperation between non-kin in animal societies. Nature 462: 51-57.

Collet J, Richardson DS, Worley K, Pizzari T (2012) Sexual selection and the differential effect of polyandry. Proceedings of the National Academy of Sciences 109: 8641-8645.

Concannon PW, Castracane VD, Temple M, Montanez A (2009) Endocrine control of ovarian function in dogs and other carnivores. Animal Reproduction 6: 172-194.

Connor RC (2000) Group living in whales and dolphins. In: Cetacean societies: field studies of dolphins and whales (eds. J Mann, RC Connor, PL Tyack, H Whitehead), pp. 199-218. The University of Chicago Press: Chicago.

Creel S, Creel NM (1995) Communal hunting and pack size in African wild dogs, Lycaon pictus. Animal Behaviour 50: 1325-1339.

Creel S, Creel NM (1996) Limitation of African wild dogs by competition with larger carnivores. Conservation Biology 10: 526-538.

Creel S, Creel NM (2002) The African wild dog: behavior, ecology, and conservation. Princeton University Press: Princeton, NJ.

Crook JH, Gartlan JS (1966) Evolution of primate societies. Nature 210: 1200-1203.

Crook JH (1970) Social organization and the environment: aspects of contemporary social ethology. Animal Behaviour 18: 197-209.

da Silva J, Woodroffe R, Macdonald DW (1993) Habitat, food availability and group territoriality in the European badger, Meles meles. Oecologia 95: 558-564.

da Silva J, Macdonald DW, Evans PGH (1994) Net costs of group living in a solitary forager, the Eurasian badger (Meles meles). Behavioral Ecology 5: 151-158.

Dahle B, Swenson JE (2003) Seasonal range size in relation to reproductive strategies in brown bears Ursus arctos. Journal of Animal Ecology 71: 660-667.

Dalerum F (2005) Sociality in a solitary carnivore, the wolverine. PhD thesis, Stockholm University.

Dalerum F, Creel S, Hall SB (2006) Behavioral and endocrine correlates of reproductive failure in social aggregations of captive wolverines (Gulo gulo). Journal of Zoology 269: 527-536.

Dalerum F (2007) Phylogenetic reconstruction of carnivore social organizations. Journal of Zoology 273: 90-97. 
Daly M (1978) The cost of mating. The American Naturalist 112: 771-774.

Dammhahn M, Kappeler P (2009) Females go where the food is: does the socio-ecological model explain variation in social organisation of solitary foragers? Behavioral Ecology and Sociobiology 63: 939-952.

Darwin C (1871) The descent of man and selection in relation to sex. Appleton: New York.

Davies EM, Boersma PD (1984) Why lionesses copulate with more than one male. The American Naturalist 123: 594-611.

Davies NB, Hartley IR, Hatchwell BJ, Desrochers A, Skeer J, Nebel D (1995) The polygynandrous mating system of the alpine accentor, Prunella collaris. I. Ecological causes and reproductive conflicts. Animal Behaviour 49: 769-788.

de Oliveira TG (1998) Herpailurus yagouaroundi. Mammalian Species 578: 1-6.

De Solla SR, Bonduriansky R, Brooks RJ (1999) Eliminating autocorrelation reduces biological relevance of home range estimates. Journal of Animal Ecology 68: 221-234.

Dewar RE, Richard AF (2007) Evolution in the hypervariable environment of Madagascar. Proceedings of the National Academy of Sciences 104: 13723-13727.

Dickie L (2005) The behaviour and reproductive physiology of the fossa (Cryptoprocta ferox) in captivity. PhD thesis, Queen Mary University of London.

Dixey $F(1960)$ The geology and geomorphology of Madagascar, and a comparison with Eastern Africa. Quarterly Journal of the Geological Society 116: 255-268.

Dixson AF (1987) Baculum length and copulatory behavior in primates. American Journal of Primatology 13: 51-60.

Dollar L, Ganzhorn JU, Goodman SM (2007) Primates and other prey in the seasonally variable diet of Cryptoprocta ferox in the dry deciduous forest of western Madagascar. In: Primate anti-predator strategies (eds. SL Gursky \& KAI Nekaris), pp. 63-76. Springer US: New York.

Doncaster CP (1990) Non-parametric estimates of interaction from radio-tracking data. Journal of Theoretical Biology 143: 431-443.

Doolan SP, Macdonald DW (1996) Diet and foraging behaviour of group-living meerkats, Suricata suricatta, in the southern Kalahari. Journal of Zoology 239: 697-716.

Duffy KG, Wrangham RW, Silk JB (2007) Male chimpanzees exchange political support for mating opportunities. Current Biology 17: R586-R587.

Durant SM (1998) Competition refuges and coexistence: an example from Serengeti carnivores. Journal of Animal Ecology 67: 370-386.

Durant SM, Kelly M, Caro TM (2004) Factors affecting life and death in Serengeti cheetahs: environment, age, and sociality. Behavioral Ecology 15: 11-22. 
East ML, Burke T, Wilhelm K, Greig C, Hofer H (2003) Sexual conflicts in spotted hyenas: male and female mating tactics and their reproductive outcome with respect to age, social status and tenure. Proceedings of the Royal Society B 270: 1247-1254.

Ebensperger LA (1998) Strategies and counterstrategies to infanticide in mammals. Biological Reviews 73: 321-346.

Ebensperger LA, Rivera DS, Hayes LD (2012) Direct fitness of group living mammals varies with breeding strategy, climate and fitness estimates. Journal of Animal Ecology. DOI: 10.1111/j.13652656.2012.01973.x

Eberhard WG (1996) Female control: sexual selection by cryptic female choice. Princeton University Press: Princeton, NJ.

Eberhard WG (2009) Postcopulatory sexual selection: Darwin's omission and its consequences. Proceedings of the National Academy of Sciences 106: 10025-10032.

Eberle M, Kappeler PM (2004) Sex in the dark: determinants and consequences of mixed male mating tactics in Microcebus murinus, a small solitary nocturnal primate. Behavioral Ecology and Sociobiology 57: 77-90.

Emlen ST, Oring LW (1977) Ecology, sexual selection, and the evolution of mating systems. Science 197: 215-223.

Engh AL, Funk SM, Van Horn RC, Scribner KT, Bruford MW, Libants S, Szykman M, Smale L, Holekamp KE (2002) Reproductive skew among males in a female-dominated mammalian society. Behavioral Ecology 13: 193-200.

English S, Bateman AW, Clutton-Brock TH (2012) Lifetime growth in wild meerkats: incorporating life history and environmental factors into a standard growth model. Oecologia 169: 143-153.

Estes RD, Goddard J (1967) Prey selection and hunting behavior of the African wild dog. The Journal of Wildlife Management 31: 52-70.

Feist JD, McCullough DR (1975) Reproduction in feral horses. Journal of Reproduction and Fertility Suppl. 23: 13-18.

Fichtel C, Kappeler PM (2002) Anti-predator behavior of group-living Malagasy primates: mixed evidence for a referential alarm call system. Behavioral Ecology and Sociobiology 51: 262-275.

Fietz J (1998) Body mass in wild Microcebus murinus over the dry season. Folia Primatologica 69: 183-190.

Fisher DO, Cockburn A (2006) The large-male advantage in brown antechinuses: female choice, male dominance, and delayed male death. Behavioral Ecology 17: 164-171.

Fisher DO, Double MC, Blomberg SP, Jennions MD, Cockburn A (2006) Post-mating sexual selection increases lifetime fitness of polyandrous females in the wild. Nature 444: 89-92.

Fisher RA (1930) The genetical theory of natural selection. Clarendon Press: Oxford. 
Frame LH, Malcolm JR, Frame GW, van Lawick H (1979) Social organization of African wild dogs (Lycaon pictus) on the Serengeti Plains. Zeitschrift für Tierpsychologie 50: 225-249.

Frank LG (1986a) Social organization of the spotted hyaena (Crocuta crocuta). I. Demography. Animal Behaviour 34: 1500-1509.

Frank LG (1986b) Social organization of the spotted hyaena (Crocuta crocuta). II. Dominance and reproduction. Animal Behaviour 34: 1510-1527.

Fryxell JM, Mosser A, Sinclair ARE, Packer C (2007) Group formation stabilizes predator-prey dynamics. Nature 449: 1041-1043.

Gannon WL, Sikes RS (2007) Guidelines of the American Society of Mammalogists for the use of wild mammals in research. Journal of Mammalogy 88: 809-823.

Geffen E, Hefner R, Macdonald DW, Ucko M (1992) Habitat selection and home range in the Blanford's fox, Vulpes cana: compatibility with the resource dispersion hypothesis. Oecologia 91: 7581.

Gehrt SD, Fritzell EK (1998) Resource distribution, female home range dispersion and male spatial interactions: group structure in a solitary carnivore Animal Behaviour 55: 1211-1227.

Ginsberg JR, Huck UW (1989) Sperm competition in mammals. Trends in Ecology \& Evolution 4: 7479.

Gittleman JL, Harvey PH (1982) Carnivore home-range size, metabolic needs and ecology. Behavioral Ecology and Sociobiology 10: 57-63.

Gittleman JL (1984) The behavioural ecology of carnivores. PhD thesis, University of Sussex.

Godfrey LR, Jungers WL (2003) The extinct sloth lemurs of Madagascar. Evolutionary Anthropology 12: $252-263$.

Gomendio M, Roldan ERS (1993) Mechanisms of sperm competition: linking physiology and behavioural ecology. Trends in Ecology \& Evolution 8: 95-100.

Gomendio M, Harcourt AH, Roldan ERS (1998) Sperm competition in mammals. In: Sperm competition and sexual selection (eds. TR Birkhead, AP Møller), pp. 667-753. Academic Press: New York.

Gompper ME, Gittleman JL (1991) Home range scaling: intraspecific and comparative trends. Oecologia 87: 343-348.

Gompper ME (1996) Sociality and asociality in white-nosed coatis (Nasua narica): foraging costs and benefits. Behavioral Ecology 7: 254-263.

Goodman SM, Rasoloarison RM, Ganzhorn JU (2004) On the specific identification of subfossil Cryptoprocta (Mammalia, Carnivora) from Madagascar. Zoosystema 26: 129-143.

Gorman ML, Trowbridge BJ (1989) The role of odor in the social lives of carnivores. In: Carnivore behavior, ecology, and evolution (ed. JL Gittleman), pp. 57-88. Cornell University Press: Ithaca, NY. 
Gottelli D, Wang J, Bashir S, Durant SM (2007) Genetic analysis reveals promiscuity among female cheetahs. Proceedings of the Royal Society B 274: 1993-2001.

Gould E, Eisenberg JF (1966) Notes on the biology of the Tenrecidae. Journal of Mammalogy 47: 660686.

Gross MR (1996) Alternative reproductive strategies and tactics: diversity within sexes. Trends in Ecology \& Evolution 11: 92-98.

Haffer J (1969) Speciation in Amazonian forest birds. Science 165: 131-137.

Hairston NG, Smith FE, Slobodkin LB (1960) Community structure, population control, and competition. The American Naturalist 94: 421-425.

Hamilton WD (1964) The genetical evolution of social behaviour. I. Journal of Theoretical Biology 7: 116.

Hawkins CE (1998) The behaviour and ecology of the fossa, Cryptoprocta ferox, (Carnivora: Viverridae) in a dry deciduous forest in western Madagascar. PhD thesis, University of Aberdeen.

Hawkins CE (2003) Cryptoprocta ferox, fossa, fosa. In: The natural history of Madagascar (eds. SM Goodman \& JP Benstead), pp. 1360-1363. The University of Chicago Press: Chicago.

Hawkins CE, Dallas JF, Fowler PA, Woodroffe R, Racey PA (2002) Transient masculinization in the fossa, Cryptoprocta ferox (Carnivora, Viverridae). Biology of Reproduction 66: 610-615.

Hawkins CE, Racey PA (2005) Low population density of a tropical forest carnivore, Cryptoprocta ferox: implications for protected area management. Oryx 39: 35-43.

Hawkins CE, Racey PA (2008) Food habits of an endangered carnivore, Cryptoprocta ferox, in the dry deciduous forests of western Madagascar. Journal of Mammalogy 89: 64-74.

Hawkins CE, Racey PA (2009) A novel mating system in a solitary carnivore: the fossa. Journal of Zoology 277: 196-204.

Hays WST, Conant S (2003) Male social activity in the small Indian mongoose Herpestes javanicus. Acta Theriologica 48: 485-494.

Herrera EA, Macdonald DW (1989) Resource utilization and territoriality in group-living capybaras (Hydrochoerus hydrochaeris). Journal of Animal Ecology 58: 667-679.

Hewitt G (2000) The genetic legacy of the Quaternary ice ages. Nature 405: 907-913.

Hofer H, East ML (1993) The commuting system of Serengeti spotted hyaenas: how a predator copes with migratory prey. I. Social organization. Animal Behaviour 46: 547-557.

Hooge PN, Eichenlaub B (2000) Animal movement extension to Arcview. ver. 2.0. Alaska Science Center - Biological Science Office, U.S. Geological Survey: Anchorage, AK, USA.

Hoogland JL (1998) Why do female Gunnison's prairie dogs copulate with more than one male? Animal Behaviour 55: 351-359. 
Hosken DJ, Stockley P (2003) Benefits of polyandry: a life history perspective. Evolutionary Biology 33: 173-194.

Hrdy SB (1974) Male-male competition and infanticide among the langurs (Presbytis entellus) of Abu, Rajasthan. Folia Primatologica 22: 19-58.

Hrdy SB (1979) Infanticide among animals: a review, classification, and examination of the implications for the reproductive strategies of females. Ethology and Sociobiology 1: 13-40.

Huchard E, Canale Cl, Le Gros C, Perret M, Henry P-Y, Kappeler PM (2012) Convenience polyandry or convenience polygyny? Costly sex under female control in a promiscuous primate. Proceedings of the Royal Society B 279: 1371-1379.

Hunter FM, Petrie M, Otronen M, Birkhead TR, Møller AP (1993) Why do females copulate repeatedly with one male? Trends in Ecology \& Evolution 8: 21-26.

Ims RA (1988) The potential for sexual selection in males: effect of sex ratio and spatiotemporal distribution of receptive females. Evolutionary Ecology 2: 338-352.

lossa G, Soulsbury CD, Baker PJ, Harris S (2008) Sperm competition and the evolution of testes size in terrestrial mammalian carnivores. Functional Ecology 22: 655-662.

Jarman PJ (1974) The social organisation of antelope in relation to their ecology. Behaviour 48: 215267.

Jenness J (2004) Weighted mean of points (weightmean.avx). Extension for ArcView 3.x, v. 1.2c. Jenness Enterprises.

Jennions MD, Petrie M (2000) Why do females mate multiply? A review of the genetic benefits. Biological Reviews 75: 21-64.

Johnson DDP, Macdonald DW, Newman C, Morecroft MD (2001) Group size versus territory size in group-living badgers: a large-sample field test of the Resource Dispersion Hypothesis. Oikos 95: 265274.

Johnson DDP, Kays R, Blackwell PG, Macdonald DW (2002) Does the resource dispersion hypothesis explain group living? Trends in Ecology \& Evolution 17: 563-570.

Jolly A (1998) Pair-bonding, female aggression and the evolution of lemur societies. Folia Primatologica 69: 1-13.

Kappeler PM, van Schaik CP (2002) Evolution of primate social systems. International Journal of Primatology 23: 707-740.

Kappeler PM, Schäffler L (2008) The lemur syndrome unresolved: extreme male reproductive skew in sifakas (Propithecus verreauxi), a sexually monomorphic primate with female dominance. Behavioral Ecology and Sociobiology 62: 1007-1015.

Kappeler PM, Fichtel C (2012) A 15-year perspective on the social organization and life history of sifaka in Kirindy Forest. In: Long-Term Field Studies of Primates (eds. PM Kappeler, DP Watts), pp. 101-121. Springer: Berlin Heidelberg. 
Kays RW, Gittleman JL (2001) The social organization of the kinkajou Potos flavus (Procyonidae). Journal of Zoology 253: 491-504.

Kenward RE (2001) A manual for wildlife radiotracking. Academic Press: London.

Kleiman DG, Eisenberg JF (1973) Comparisons of canid and felid social systems from an evolutionary perspective. Animal Behaviour 21: 637-659.

Kleiman DG (1977) Monogamy in mammals. The Quarterly Review of Biology 52: 39-69.

Kleiman DG, Peters G (1990) Auditory communication in the giant panda: motivation and function. In: Second international symposium on the giant panda (eds. S Asakura, S Nakagawa), pp. 107-122. Tokyo Zoological Park Society: Tokyo.

Klingel H (1975) Social organization and reproduction in equids. Journal of Reproduction and Fertility Suppl. 23: 7-11.

Knott CD, Emery Thompson M, Stumpf RM, Mclntyre MH (2010) Female reproductive strategies in orangutans, evidence for female choice and counterstrategies to infanticide in a species with frequent sexual coercion. Proceedings of the Royal Society B 277: 105-113.

Köhncke M, Leonhardt K (1986) Cryptoprocta ferox. Mammalian Species 254: 1-5.

Kotiaho JS, LeBas NR, Puurtinen M, Tomkins JL (2008) On female choice, heterozygosity and the lek paradox. Animal Behaviour 75: e1-e3.

Krause J, Ruxton GD (2002) Living in groups. Oxford University Press: Oxford.

Krebs CJ (1999) Ecological methodology. Addison-Welsey Educational Publishers: Menlo Park.

Kruuk HH (1972) The spotted hyena: a study of predation and social behavior. University of Chicago Press: Chicago.

Kruuk HH (1975) Functional aspects of social hunting in carnivores. In: Function and evolution in behaviour (eds. G Baerends, C Beer, A Manning), pp. 119-141. Oxford University Press: Oxford.

Kruuk HH, Parish T (1987) Changes in the size of groups and ranges of the European badger (Meles meles L.) in an area in Scotland. Journal of Animal Ecology 56: 351-364.

Lanier DL, Estep DQ, Dewsbury DA (1979) Role of prolonged copulatory behavior in facilitating reproductive success in a competitive mating situation in laboratory rats. Journal of Comparative and Physiological Psychology 93: 781-792.

Larivière S, Ferguson SH (2003) Evolution of induced ovulation in North American carnivores. Journal of Mammalogy 84: 937-947.

Lazenby-Cohen KA, Cockburn A (1988) Lek promiscuity in a semelparous mammal, Antechinus stuartii (Marsupialia: Dasyuridae)? Behavioral Ecology and Sociobiology 22: 195-202.

Lindström E (1986) Territory inheritance and the evolution of group-living in carnivores. Animal Behaviour 34: 1825-1835. 
Llewellyn LM, Enders RK (1954) Ovulation in the raccoon. Journal of Mammalogy 35: 440.

Lockhart AB, Thrall PH, Antonovics J (1996) Sexually transmitted diseases in animals: ecological and evolutionary implications. Biological Reviews 71: 415-471.

Lührs M-L, Dammhahn M (2010) An unusual case of cooperative hunting in a solitary carnivore. Journal of Ethology 28: 379-383.

Macdonald DW (1980) Patterns of scent marking with urine and faeces amongst carnivore communities. Symposia of the Zoological Society of London 45: 107-139.

Macdonald DW (1983) The ecology of carnivore social behaviour. Nature 301: 379-384.

McNab BK (1963) Bioenergetics and the determination of home range size. The American Naturalist 97: $133-140$.

Mead RA (1981) Delayed implantation in mustelids, with special emphasis on the spotted skunk. Journal of Reproduction and Fertility Suppl. 29: 11-24.

Mead RA, Bowles M, Starypan G, Jones M (1993) Evidence for pseudopregnancy and induced ovulation in captive wolverines (Gulo gulo). Zoo Biology 12: 353-358.

Mech LD (1970) The wolf: the ecology and behavior of an endangered species. Natural History Press: Garden City, NY.

Mills MGL (1982) The mating system of the brown hyaena, Hyaena brunnea in the southern Kalahari. Behavioral Ecology and Sociobiology 10: 131-136.

Mills MGL (1990) Kalahari hyaenas: comparative behavioural ecology of two species. Unwin Hyman: London.

Mohr CO (1947) Table of equivalent populations of North American small mammals. American Midland Naturalist 37: 223-249.

Møller AP, Birkhead TR (1989) Copulation behaviour in mammals: evidence that sperm competition is widespread. Biological Journal of the Linnean Society 38: 119-131.

Moreira N, Monteiro-Filho ELA, Moraes W, Swanson WF, Graham LH, Pasquali OL, Gomes MLF, Morais RN, Wildt DE, Brown JL (2001) Reproductive steroid hormones and ovarian activity in felids of the Leopardus genus. Zoo Biology 20: 103-116.

Mosser A, Packer C (2009) Group territoriality and the benefits of sociality in the African lion, Panthera leo. Animal Behaviour 78: 359-370.

Mundry R, Nunn CL (2009) Stepwise model fitting and statistical inference: turning noise into signal pollution. The American Naturalist 173: 119-123.

Newcomer SD, Zeh JA, Zeh DW (1999) Genetic benefits enhance the reproductive success of polyandrous females. Proceedings of the National Academy of Sciences 96: 10236-10241.

Noë R, Sluijter AA (1990) Reproductive tactics of male savanna baboons. Behaviour 113: 117-170. 
Nunn CL, Gittleman JL, Antonovics J (2003) A comparative study of white blood cell counts and disease risk in carnivores. Proceedings of the Royal Society B 270: 347-356.

Oakwood M (2002) Spatial and social organization of a carnivorous marsupial Dasyurus hallucatus (Marsupialia: Dasyuridae). Journal of Zoology 257: 237-248.

Oglesby JM, Lanier DL, Dewsbury DA (1981) The role of prolonged copulatory behavior in facilitating reproductive success in male syrian golden hamsters (Mesocricetus auratus) in a competitive mating situation. Behavioral Ecology and Sociobiology 8: 47-54.

Owens D, Owens M (1996) Social dominance and reproductive patterns in brown hyaenas, Hyaena brunnea, of the central Kalahari desert. Animal Behaviour 51: 535-551.

Packer C, Pusey AE (1982) Cooperation and competition within coalitions of male lions: kin selection or game theory? Nature 296: 740-742.

Packer C, Pusey AE (1983) Adaptations of female lions to infanticide by incoming males. The American Naturalist 121: 716-728.

Packer C, Ruttan L (1988) The evolution of cooperative hunting. The American Naturalist 132: 159198.

Packer C, Herbst L, Pusey AE, Bygott JD, Cairns SJ, Hanby JP, Borgerhoff-Mulder M (1988) Reproductive success of lions. In: Reproductive success (ed. TH Clutton-Brock), pp. 363-383. University of Chicago Press: Chicago.

Packer C, Scheel D, Pusey AE (1990) Why lions form groups: food is not enough. The American Naturalist 136: 1-19.

Parker GA (1970) Sperm competition and its evolutionary consequences in the insects. Biological Reviews 45: 525-567.

Parker GA (1979) Sexual selection and sexual conflict. In: Sexual selection and reproductive competition in insects (eds. MS Blum, NA Blum), pp. 123-166. Academic Press: New York.

Parker GA (1990) Sperm competition games: sneaks and extra-pair copulations. Proceedings of the Royal Society B 242: 127-133.

Parker GA (1998) Sperm competition and the evolution of ejaculates: towards a theory base. In: Sperm competition and sexual selection (eds. TR Birkhead, AP Møller). Academic Press: San Diego, CA.

Parnell AC, Inger R, Bearhop S, Jackson AL (2010) Source partitioning using stable isotopes: coping with too much variation. PLOS ONE 5: e9672.

Peig J, Green AJ (2009) New perspectives for estimating body condition from mass/length data: the scaled mass index as an alternative method. Oikos 118: 1883-1891.

Perret M (1990) Influence of social factors on sex ratio at birth, maternal investment and young survival in a prosimian primate. Behavioral Ecology and Sociobiology 27: 447-454. 
Port M, Kappeler PM, Johnstone RA (2011) Communal defense of territories and the evolution of sociality. The American Naturalist 178: 787-800.

Preston BT, Stevenson IR, Pemberton JM, Coltman DW, Wilson K (2003) Overt and covert competition in a promiscuous mammal: the importance of weaponry and testes size to male reproductive success. Proceedings of the Royal Society B 270: 633-640.

Pusey AE, Packer C (1987) Dispersal and philopatry. In: Primate Societies (eds. BB Smuts, DL Cheney, RM Seyfarth, RW Wrangham, TT Struhsaker), pp. 250-266. University of Chicago Press: Chicago.

R Development Core Team (2011) R: A language and environment for statistical computing. R Foundation for Statistical Computing: Vienna, Austria.

Rasoloarison RM, Rasolonandrasana BPN, Ganzhorn JU, Goodman SM (1995) Predation on vertebrates in the Kirindy Forest, western Madagascar. Ecotropica 1: 59-65.

Rathbun GB, Cowley TE (2008) Behavioural ecology of the black mongoose (Galerella nigrata) in Namibia. Mammalian Biology 73: 444-450.

Richard AF, Dewar RE, Schwartz M, Ratsirarson J (2000) Mass change, environmental variability and female fertility in wild Propithecus verreauxi. Journal of Human Evolution 39: 381-391.

Richard AF, Dewar RE, Schwartz M, Ratsirarson J (2002) Life in the slow lane? Demography and life histories of male and female sifaka (Propithecus verreauxi verreauxi). Journal of Zoology 256: 421436.

Ridley M (1988) Mating frequency and fecundity in insects. Biological Reviews 63: 509-549.

Rieger I, Peters G (1981) Einige Beobachtungen zum Paarungs- und Lautgebungsverhalten von Irbissen (Uncia uncia) im Zoologischen Garten. Zeitschrift für Säugetierkunde 46: 35-48.

Rood JP, Waser PW (1978) The slender mongoose (Herpestes sanguineus) in the Serengeti. Carnivore 1: 54-58.

Rood JP (1989) Male associations in a solitary mongoose. Animal Behaviour 38: 725-728.

Rood JP (1990) Group size, survival, reproduction, and routes to breeding in dwarf mongooses. Animal Behaviour 39: 566-572.

Rowe $L$ (1992) Convenience polyandry in a water strider: foraging conflicts and female control of copulation frequency and guarding duration. Animal Behaviour 44: 189-202.

Rowe L (1994) The costs of mating and mate choice in water striders. Animal Behaviour 48: 10491056.

Rowe L, Arnqvist G, Sih A, Krupa JJ (1994) Sexual conflict and the evolutionary ecology of mating patterns: water striders as a model system. Trends in Ecology \& Evolution 9: 289-293.

Sandell M (1989) The mating tactics and spacing patterns of solitary carnivores. In: Carnivore behavior, ecology, and evolution (ed. JL Gittleman), pp. 164-182. Cornell University Press: Ithaca, NY. 
Schaller GB (1972) The Serengeti lion: a study of predator-prey relations. University of Chicago Press: Chicago.

Schenk A, Kovacs KM (1995) Multiple mating between black bears revealed by DNA fingerprinting. Animal Behaviour 50: 1483-1490.

Schradin C, Lindholm AK, Johannesen JES, Schoepf I, Yuen C-H, König B, Pillay N (2012) Social flexibility and social evolution in mammals: a case study of the African striped mouse (Rhabdomys pumilio). Molecular Ecology 21: 541-553.

Schülke O (2003) To breed or not to breed-food competition and other factors involved in female breeding decisions in the pair-living nocturnal fork-marked lemur (Phaner furcifer). Behavioral Ecology and Sociobiology 55: 11-21.

Schwagmeyer PL, Woontner SJ (1985) Mating competition in an asocial ground squirrel, Spermophilus tridecemlineatus. Behavioral Ecology and Sociobiology 17: 291-296.

Schwagmeyer PL, Woontner SJ (1986) Scramble competition polygyny in thirteen-lined ground squirrels: the relative contributions of overt conflict and competitive mate searching. Behavioral Ecology and Sociobiology 19: 359-364.

Shapiro SS, Wilk MB (1965) An analysis of variance test for normality (complete samples). Biometrika 52: 591-611.

Shultz S, Opie C, Atkinson QD (2011) Stepwise evolution of stable sociality in primates. Nature 479: 219-222.

Simmons LW (2001) Sperm competition and its evolutionary consequences in the insects. Princeton University Press: Princeton, NJ.

Simmons LW (2005) The evolution of polyandry: sperm competition, sperm selection, and offspring viability. Annual Review of Ecology, Evolution, and Systematics 36: 125-146.

Slatyer RA, Mautz BS, Backwell PRY, Jennions MD (2012a) Estimating genetic benefits of polyandry from experimental studies: a meta-analysis. Biological Reviews 87: 1-33.

Slatyer RA, Jennions MD, Backwell PRY (2012b) Polyandry occurs because females initially trade sex for protection. Animal Behaviour 83: 1203-1206.

Smith JE, Kolowski JM, Graham KE, Dawes SE, Holekamp KE (2008) Social and ecological determinants of fission-fusion dynamics in the spotted hyaena. Animal Behaviour 76: 619-636.

Smith RL (1984) Sperm competition and the evolution of animal mating systems. Academic Press: Orlando.

Smuts BB, Smuts RW (1993) Male aggression and sexual coercion of females in nonhuman primates and other mammals: evidence and theoretical implications. Advances in the Study of Behavior 22: 163.

Soisalo MK, Cavalcanti SMC (2006) Estimating the density of a jaguar population in the Brazilian Pantanal using camera-traps and capture-recapture sampling in combination with GPS radiotelemetry. Biological Conservation 129: 487-496.

80 
Sorg JP, Rohner U (1996) Climate and tree phenology of the dry deciduous forest of the Kirindy Forest. In: Ecology and economy of a tropical dry forest in Madagascar (eds. JU Ganzhorn, JP Sorg), pp. $57-80$.

Spiering P, Somers M, Maldonado J, Wildt D, Gunther M (2010) Reproductive sharing and proximate factors mediating cooperative breeding in the African wild dog (Lycaon pictus). Behavioral Ecology and Sociobiology 64: 583-592.

Spong G (2002) Space use in lions, Panthera leo, in the Selous Game Reserve: social and ecological factors. Behavioral Ecology and Sociobiology 52: 303-307.

Steyaert SMJG, Endrest $\varnothing \mid$ A, Hackländer K, Swenson JE, Zedrosser A (2012) The mating system of the brown bear Ursus arctos. Mammal Review 42: 12-34.

Stockley P, Purvis A (1993) Sperm competition in mammals: a comparative study of male roles and relative investment in sperm production. Functional Ecology 7: 560-570.

Stockley P, Searle JB, Macdonald DW, Jones CS (1993) Female multiple mating behaviour in the common shrew as a strategy to reduce inbreeding. Proceedings of the Royal Society B 254: 173-179.

Stockley P (2002) Sperm competition risk and male genital anatomy: comparative evidence for reduced duration of female sexual receptivity in primates with penile spines. Evolutionary Ecology 16: 123-137.

Stockley P (2004) Sperm competition in mammals. Human Fertility 7: 91-97.

Struhsaker TT (1969) Correlates of ecology and social organization among African cercopithecines. Folia Primatologica 11: 80-118.

Stumpf R, Emery Thompson M, Knott C (2008) A comparison of female mating strategies in Pan troglodytes and Pongo spp. International Journal of Primatology 29: 865-884.

Swenson JE, Sandegren F, Brunberg S, Segerström P (2001) Factors associated with loss of brown bear cubs in Sweden. Ursus 12: 69-80.

Swihart RK, Slade NA (1985) Testing for independence of observations in animal movements. Ecology 66: 1176-1184.

Swihart RK, Slade NA (1997) On testing for independence of animal movements. Journal of Agricultural, Biological, and Environmental Statistics 2: 48-63.

Terborgh J, Janson CH (1986) The socioecology of primate groups. Annual Review of Ecology and Systematics 17: 111-135.

Thom MD, Johnson DDP, Macdonald DW (2004) The evolution and maintenance of delayed implantation in the mustelidae (Mammalia: Carnivora). Evolution 58: 175-183.

Thornhill R, Alcock J (1983) The evolution of insect mating systems. Harvard University Press: Cambridge, MA.

Trivers RL (1972) Parental investment and sexual selection. In: Sexual selection and the descent of man: 1871-1971 (ed. B Campbell), pp. 136-179. Aldine: Chicago. 
Turner TF, Collyer ML, Krabbenhoft TJ (2010) A general hypothesis-testing framework for stable isotope ratios in ecological studies. Ecology 91: 2227-2233.

Van Orsdol KG, Hanby JP, Bygott JD (1985) Ecological correlates of lion social organisation (Panthera leo). Journal of Zoology 206: 97-112.

van Schaik CP (1983) Why are diurnal primates living in groups? Behaviour 87: 120-140.

van Schaik CP, Kappeler PM (1996) The social systems of gregarious lemurs: lack of convergence with anthropoids due to evolutionary disequilibrium? Ethology 102: 915-941.

Veron G, Catzeflis FM (1993) Phylogenetic relationships of the endemic malagasy carnivore Cryptoprocta ferox (Aeluroidea): DNA/DNA hybridization experiments. Journal of Mammalian Evolution 1: 169-185.

Vogler BR, Bailey CA, Shore GD, McGuire SM, Engberg SE, Fickel J, Louis EE, Brenneman RA (2009) Characterization of 26 microsatellite marker loci in the fossa (Cryptoprocta ferox). Conservation Genetics 10: 1449-1453.

Wagner AP, Frank LG, Creel S (2008) Spatial grouping in behaviourally solitary striped hyaenas, Hyaena hyaena. Animal Behaviour 75: 1131-1142.

Wang J (2004) Sibship reconstruction from genetic data with typing errors. Genetics 166: 1963-1979.

Wang J (2007) Triadic IBD coefficients and applications to estimating pairwise relatedness. Genetics Research 89: 135-153.

Wang J (2011) Coancestry: a program for simulating, estimating and analysing relatedness and inbreeding coefficients. Molecular Ecology Resources 11: 141-145.

Waser PM, Keane B, Creel SR, Elliott LF, Minchella DJ (1994) Possible male coalitions in a solitary mongoose. Animal Behaviour 47: 289-294.

Watts DP (1998) Coalitionary mate guarding by male chimpanzees at Ngogo, Kibale National Park, Uganda. Behavioral Ecology and Sociobiology 44: 43-55.

White TCR (1978) The importance of a relative shortage of food in animal ecology. Oecologia 33: 7186.

Wiley RH, Poston J (1996) Perspective: indirect mate choice, competition for mates, and coevolution of the sexes. Evolution 50: 1371-1381.

Williams GC (1966) Adaptation and Natural Selection. Princeton University Press: Princeton, N.J.

Wolff JO, Macdonald DW (2004) Promiscuous females protect their offspring. Trends in Ecology \& Evolution 19: 127-134.

Woodroffe R, Macdonald DW (1993) Badger sociality - models of spatial grouping. Symposia of the Zoological Society of London 65: 145-169.

Worton BJ (1989) Kernel methods for estimating the utilization distribution in home-range studies. Ecology 70: 164-168.

82 
Wright PC, Heckscher SK, Dunham AE (1997) Predation on Milne-Edward's sifaka (Propithecus diadema edwardsi) by the fossa (Cryptoprocta ferox) in the rain forest of southeastern Madagascar. Folia Primatologica 68: 34-43.

Wright PC (1999) Lemur traits and Madagascar ecology: coping with an island environment. Yearbook of Physical Anthropology 42: 31-72.

Yamaguchi N, Sarno RJ, Johnson WE, O'Brien SJ, Macdonald DW (2004) Multiple paternity and reproductive tactics of free-ranging American minks, Mustela vison. Journal of Mammalogy 85: 432439.

Yamaguchi N, Dugdale HL, Macdonald DW (2006) Female receptivity, embryonic diapause, and superfetation in the European badger (Meles meles): Implications for the reproductive tactics of males and females. The Quarterly Review of Biology 81: 33-48.

Yasui Y (1997) A "good-sperm" model can explain the evolution of costly multiple mating by females. The American Naturalist 149: 573-584.

Yasui Y (1998) The 'genetic benefits' of female multiple mating reconsidered. Trends in Ecology \& Evolution 13: 246-250.

Yoder AD, Burns MM, Zehr S, Delefosse T, Veron G, Goodman SM, Flynn JJ (2003) Single origin of Malagasy carnivora from an African ancestor. Nature 421: 734-737.

Zeh JA, Zeh DW (1997) The evolution of polyandry II: post-copulatory defenses against genetic incompatibility. Proceedings of the Royal Society B 264: 69-75.

Zeh JA, Zeh DW (2001) Reproductive mode and the genetic benefits of polyandry. Animal Behaviour 61: 1051-1063. 
Appendix

Appendix I: Tables

Table A1. Determinants of home range size (GLMM).*

\begin{tabular}{lrcccr}
\hline & Estimate & SE & $d f$ & \multicolumn{1}{c}{$t$} & \multicolumn{1}{c}{$P$} \\
\hline Intercept & $\mathbf{5 3 3 6 . 0 9}$ & $\mathbf{3 7 6 . 2 7}$ & $\mathbf{3 0}$ & $\mathbf{1 4 . 1 8}$ & $<\mathbf{0 . 0 0 1}$ \\
Sex & $\mathbf{- 3 5 4 9 . 0 0}$ & $\mathbf{3 7 6 . 4 8}$ & $\mathbf{1 1}$ & $\mathbf{- 9 . 4 3}$ & $<\mathbf{0 . 0 0 1}$ \\
Ecological season & -233.88 & 323.50 & 30 & -0.72 & 0.475 \\
Reproductive season & 101.68 & 298.68 & 30 & 0.34 & 0.736 \\
\hline
\end{tabular}

Table A2. Determinants of male home range size (LMM).*

\begin{tabular}{lrlllr}
\hline & Estimate & SE & $N$ & $t$ & \multicolumn{1}{c}{$P$} \\
\hline Intercept & $\mathbf{2 1 2 3 . 0}$ & $\mathbf{6 7 1 . 1}$ & $\mathbf{9}$ & $\mathbf{3 . 1 6}$ & $\mathbf{0 . 0 0 4}$ \\
Social organisation & $\mathbf{3 3 0 1 . 3}$ & $\mathbf{6 1 7 . 6}$ & $\mathbf{9}$ & $\mathbf{5 . 3 5}$ & $<\mathbf{0 . 0 0 1}$ \\
Ecological season & 939.7 & 535.1 & 9 & 1.76 & 0.091 \\
Reproductive season & 1006.4 & 592.1 & 9 & 1.70 & 0.102 \\
\hline
\end{tabular}

Table A3. Determinants of arithmetic home range mean shifts (LMM).*

\begin{tabular}{lrrrrr}
\hline & Estimate & SE & $N$ & \multicolumn{1}{c}{$t$} & \multicolumn{1}{c}{$P$} \\
\hline Intercept & $\mathbf{7 . 0 4}$ & $\mathbf{0 . 2 8}$ & $\mathbf{1 1}$ & $\mathbf{2 4 . 8 9}$ & $<\mathbf{0 . 0 0 1}$ \\
Sex & $\mathbf{- 1 . 1 5}$ & $\mathbf{0 . 3 8}$ & $\mathbf{1 1}$ & $\mathbf{- 3 . 0 2}$ & $\mathbf{0 . 0 0 6}$ \\
Ecological season & 0.58 & 0.28 & 11 & 2.05 & 0.051 \\
Reproductive season & -0.37 & 0.25 & 11 & -1.48 & 0.152 \\
\hline
\end{tabular}

Table A4. Determinants of residual weighted home range mean shifts (LMM).*

\begin{tabular}{lrrrrc}
\hline & Estimate & SE & $N$ & \multicolumn{1}{c}{$t$} & $P$ \\
\hline Intercept & -0.22 & 0.31 & 11 & -0.73 & 0.470 \\
Sex & 0.09 & 0.41 & 11 & 0.23 & 0.823 \\
Ecological season & -0.09 & 0.30 & 11 & -0.30 & 0.205 \\
Reproductive season & 0.35 & 0.27 & 11 & 1.30 & 0.765 \\
\hline
\end{tabular}

*Statistically significant predictors are depicted in bold. 
Females
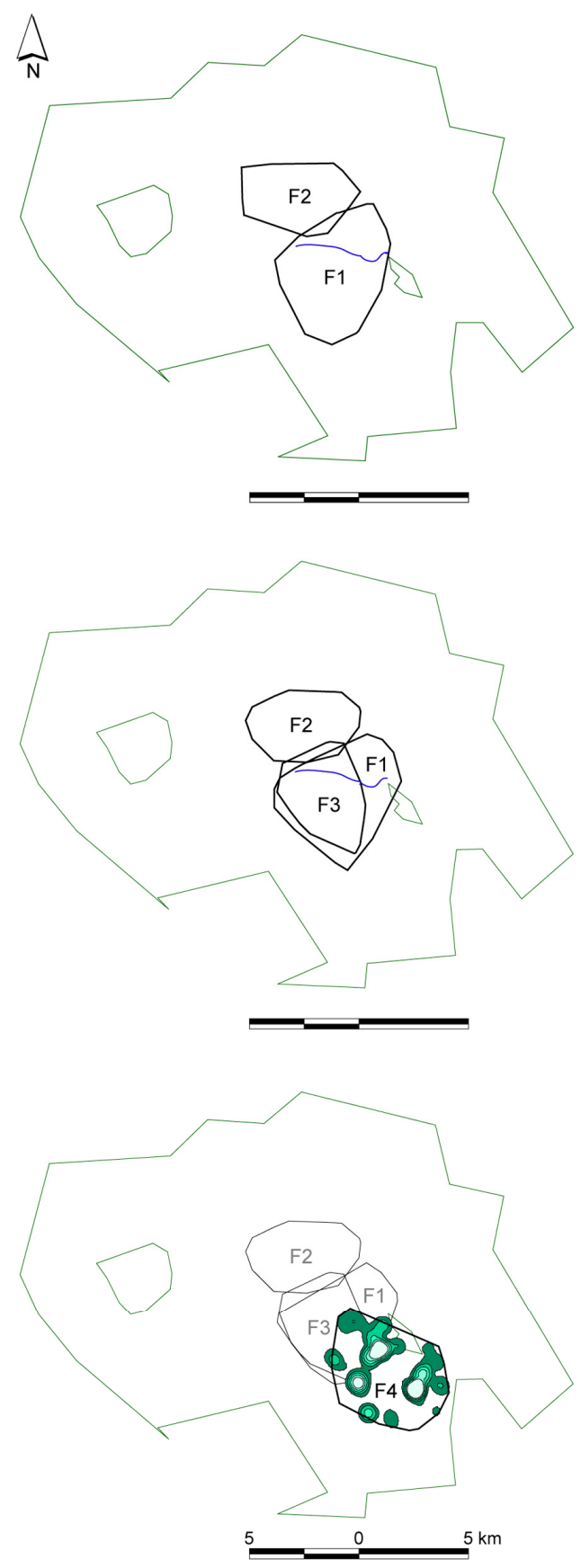

Males
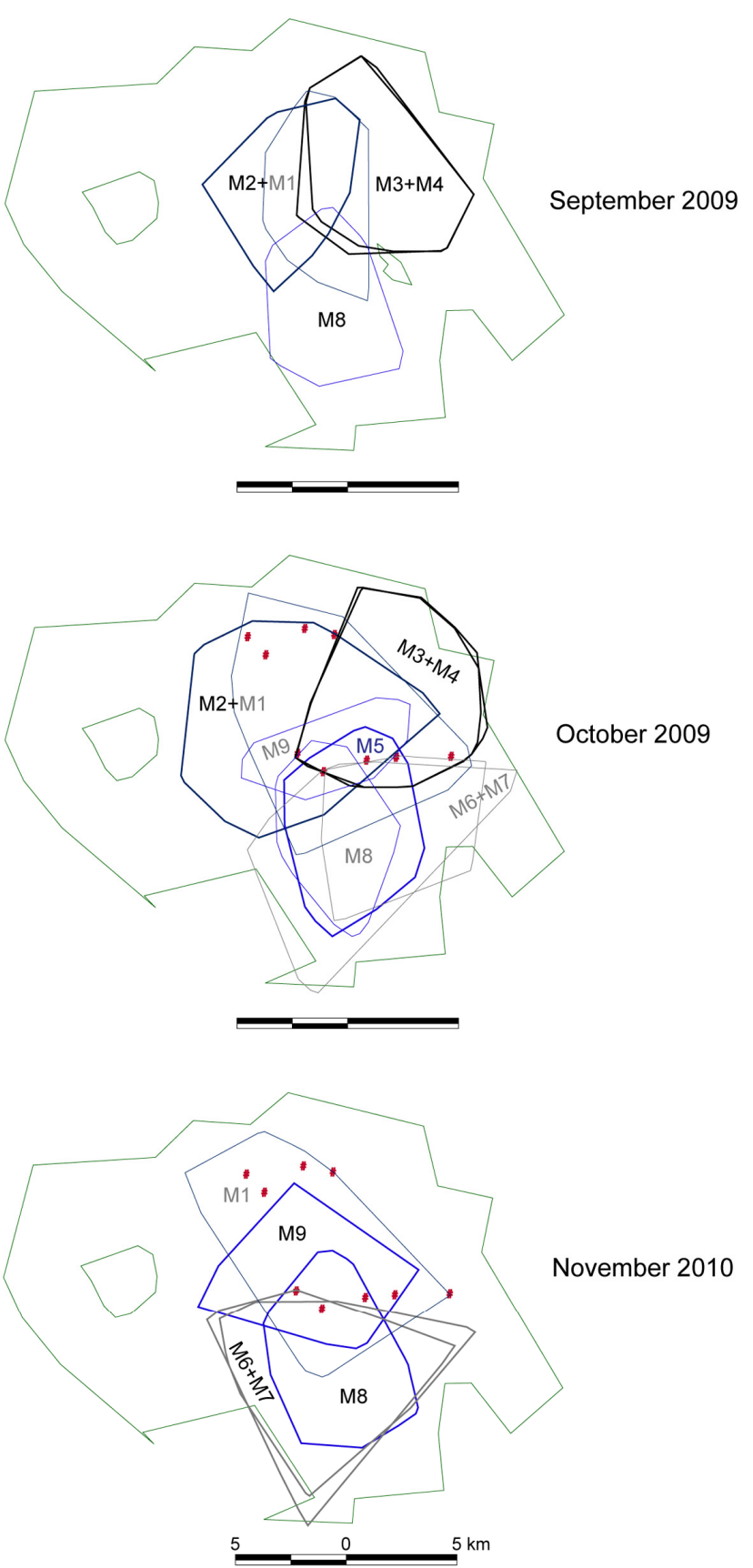

Fig. A1 Selected plots of MCP home ranges per sex and month. Home ranges (coloured lines) are presented within the Kirindy Forest (green contours) and marked individually (females F1-F4 on the left, males M1-M9 on the right). Ranges of the month stated are in thicker lines than those from other years (males) or months (females), which were included as additional information. For female ranges, resource information such as the course of a river (blue) and a central unforested area (green contour) was additionally provided. Female F4 (lower left) was tracked singly and therefore plotted with potential ranges of other females and its 50-90\% kernel ranges. For male ranges, additional information is provided for known and assumed locations of mating trees (red hash) in the area. Members of a male association are denoted with a ' + ' between their IDs. 

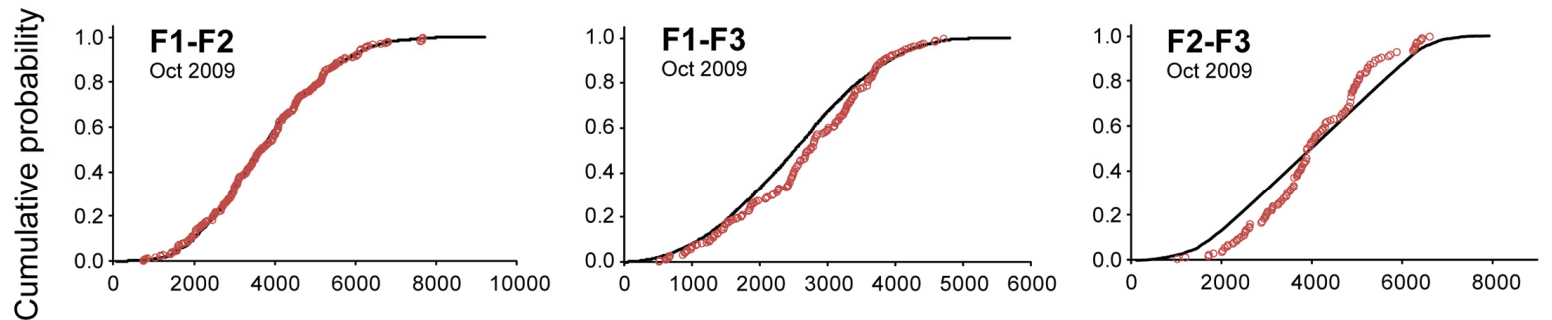

Inter-individual distance $(\mathrm{m})$

Fig. A2 Cumulative probabilities of observed (red circles) and expected (black line) inter-individual distances for simultaneously tracked female-female dyads. Expected values were calculated according to Doncaster (1990) from all possible $n^{2}$ distances between $n$ positions of both individuals.
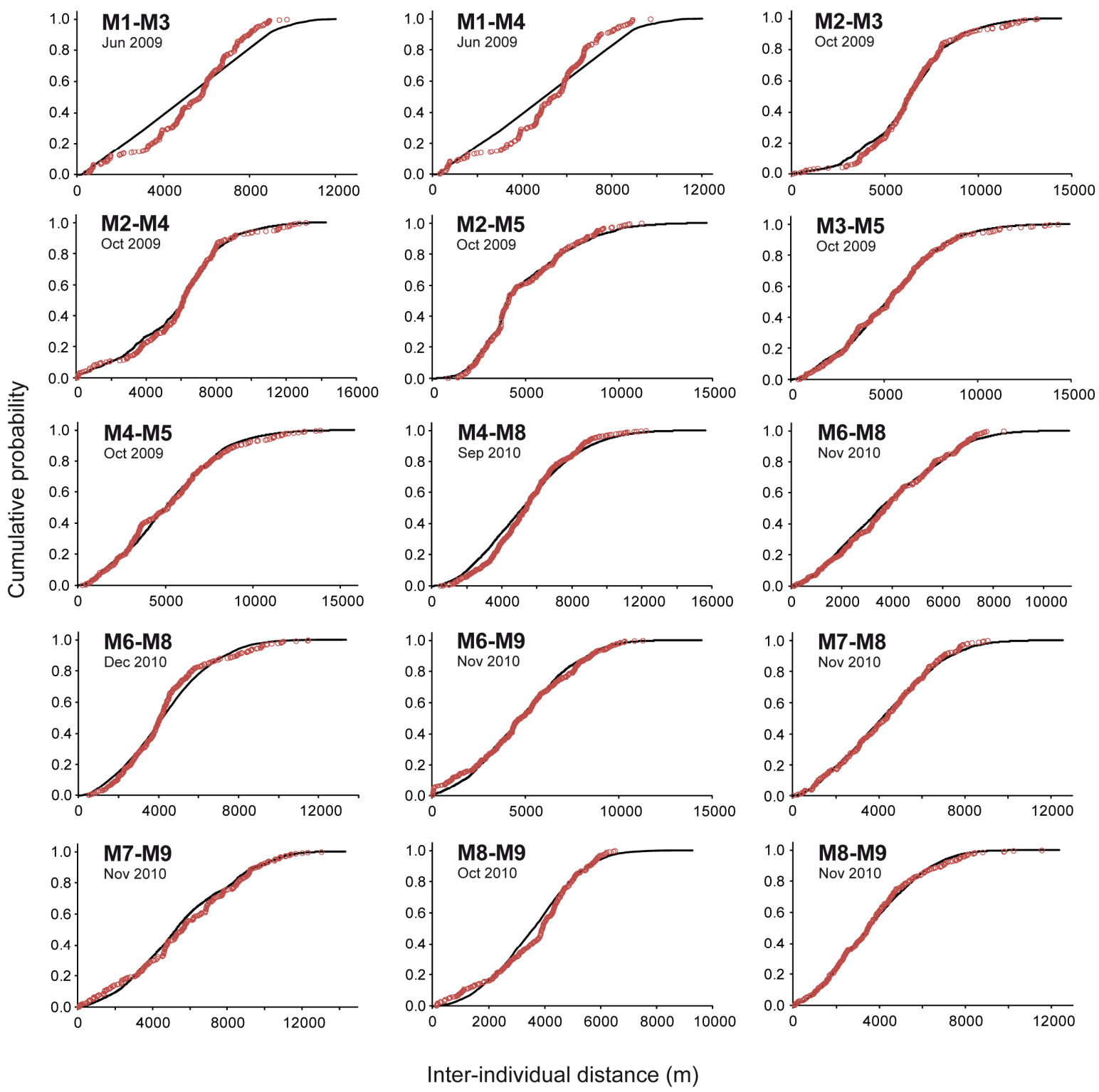

F. A3 Cumulative probabilities of observed (red circles) and expected (black line) inter-individual distances for simultaneously tracked male-male dyads sorted by ID. Expected values were calculated according to Doncaster (1990) from all possible $n^{2}$ distances between $n$ positions of both individuals. 

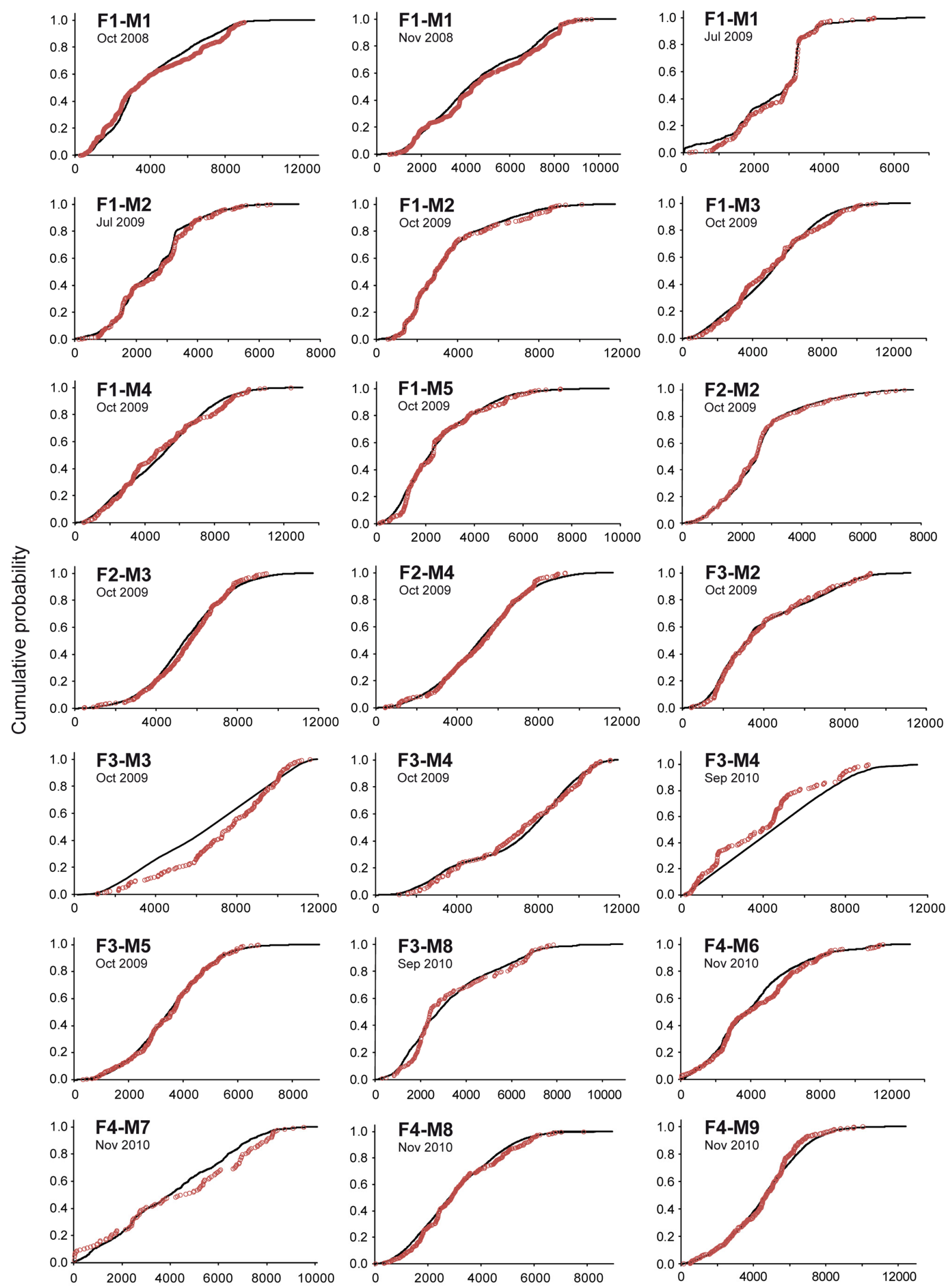

Inter-individual distance $(\mathrm{m})$

Fig. A4 Cumulative probabilities of observed (red circles) and expected (black line) inter-individual distances for simultaneously tracked female-male dyads sorted by ID of the female. Expected values were calculated according to Doncaster (1990) from all possible $n^{2}$ distances between $n$ positions of both individuals. 
Appendix II: Tables 
Table S1 Pairwise relatedness (TrioML) of the sampled fosa population. Tests for sibship of littermates were performed for dyads of same age estimate using the software COLONY (Wang 2008).

\begin{tabular}{|c|c|c|c|c|c|c|c|c|c|c|c|c|c|c|c|c|c|c|c|c|c|c|c|c|}
\hline Identity & $\mathrm{CF}^{1}$ & CF3 & $\mathrm{CF}^{2}{ }^{2}$ & $\mathrm{CF}^{2}$ & $\mathrm{CF}^{\mathrm{J}}$ & CF8 & CF10 & CF11 & CF13 & $\mathrm{CF} 15^{1}$ & CF16 & CF $18^{3}$ & CF19 & CF $20^{4}$ & CF $21^{4}$ & CF $22^{3}$ & $\mathrm{CF} 24^{1,5}$ & CF $25^{1,5}$ & CF26 & CF $27^{6}$ & CF28 & CF29 & CF30 & CF $31^{6}$ \\
\hline \multicolumn{25}{|l|}{$\mathrm{CF}^{1}{ }^{1}$} \\
\hline CF3 & 0.08 & & & & & & & & & & & & & & & & & & & & & & & \\
\hline $\mathrm{CF} 4^{2}$ & 0.16 & 0.00 & & & & & & & & & & & & & & & & & & & & & & \\
\hline $\mathrm{CF}^{2}$ & 0.00 & 0.03 & $0.43^{\mathrm{HS}}$ & & & & & & & & & & & & & & & & & & & & & \\
\hline $\mathrm{CF}^{\mathrm{J}}$ & 0.67 & 0.00 & 0.00 & 0.00 & & & & & & & & & & & & & & & & & & & & \\
\hline CF8 & 0.00 & 0.10 & 0.13 & 0.00 & 0.10 & & & & & & & & & & & & & & & & & & & \\
\hline CF10 & 0.11 & 0.00 & 0.03 & 0.00 & 0.00 & 0.13 & & & & & & & & & & & & & & & & & & \\
\hline CF11 & 0.00 & 0.00 & 0.05 & 0.00 & 0.00 & 0.00 & 0.04 & & & & & & & & & & & & & & & & & \\
\hline CF13 & 0.00 & 0.07 & 0.06 & 0.17 & 0.00 & 0.09 & 0.06 & 0.01 & & & & & & & & & & & & & & & & \\
\hline CF $15^{1}$ & $0.72^{\mathrm{FS}}$ & 0.00 & 0.00 & 0.00 & 0.99 & 0.32 & 0.10 & 0.00 & 0.03 & & & & & & & & & & & & & & & \\
\hline CF16 & 0.00 & 0.19 & 0.03 & 0.04 & 0.00 & 0.09 & 0.01 & 0.16 & 0.00 & 0.00 & & & & & & & & & & & & & & \\
\hline CF $18^{3}$ & 0.00 & 0.05 & 0.00 & 0.00 & 0.10 & 0.37 & 0.02 & 0.00 & 0.00 & 0.13 & 0.04 & & & & & & & & & & & & & \\
\hline CF19 & 0.06 & 0.20 & 0.03 & 0.00 & 0.00 & 0.00 & 0.00 & 0.31 & 0.00 & 0.00 & 0.23 & 0.02 & & & & & & & & & & & & \\
\hline $\mathrm{CF} 20^{4}$ & 0.00 & 0.04 & 0.00 & 0.00 & 0.00 & 0.04 & 0.18 & 0.00 & 0.02 & 0.00 & 0.00 & 0.11 & 0.00 & & & & & & & & & & & \\
\hline $\mathrm{CF} 21^{4}$ & 0.05 & 0.04 & 0.00 & 0.09 & 0.09 & 0.00 & 0.06 & 0.00 & 0.17 & 0.01 & 0.05 & 0.02 & 0.00 & 0.00 & & & & & & & & & & \\
\hline $\mathrm{CF} 22^{3}$ & 0.00 & 0.00 & 0.00 & 0.00 & 0.00 & 0.06 & 0.00 & 0.07 & 0.02 & 0.00 & 0.02 & $0.40^{\mathrm{FS}}$ & 0.02 & 0.00 & 0.04 & & & & & & & & & \\
\hline $\mathrm{CF} 24^{1,5}$ & 0.00 & 0.11 & 0.00 & 0.00 & 0.00 & 0.13 & 0.07 & 0.31 & 0.09 & 0.12 & 0.08 & 0.02 & 0.49 & 0.04 & 0.21 & 0.13 & & & & & & & & \\
\hline $\mathrm{CF} 25^{\mathrm{J}, 5}$ & 0.00 & 0.06 & 0.04 & 0.09 & 0.00 & 0.00 & 0.04 & 0.02 & 0.00 & 0.00 & 0.03 & 0.00 & 0.23 & 0.22 & 0.04 & 0.10 & 0.07 & & & & & & & \\
\hline CF26 & 0.04 & 0.00 & 0.12 & 0.08 & 0.06 & 0.07 & 0.15 & 0.12 & 0.07 & 0.00 & 0.28 & 0.02 & 0.00 & 0.08 & 0.00 & 0.00 & 0.00 & 0.00 & & & & & & \\
\hline $\mathrm{CF} 27^{6}$ & 0.00 & 0.00 & 0.02 & 0.00 & 0.04 & 0.00 & 0.00 & 0.04 & 0.08 & 0.23 & 0.00 & 0.02 & 0.00 & 0.37 & 0.00 & 0.00 & 0.05 & 0.00 & 0.00 & & & & & \\
\hline CF28 & 0.06 & 0.06 & 0.00 & 0.00 & 0.00 & 0.22 & 0.04 & 0.14 & 0.04 & 0.00 & 0.00 & 0.11 & 0.05 & 0.20 & 0.00 & 0.00 & 0.00 & 0.00 & 0.20 & 0.05 & & & & \\
\hline CF29 & 0.12 & 0.21 & 0.01 & 0.04 & 0.07 & 0.01 & 0.02 & 0.06 & 0.00 & 0.04 & 0.06 & 0.00 & 0.36 & 0.00 & 0.04 & 0.00 & 0.28 & 0.41 & 0.04 & 0.01 & 0.04 & & & \\
\hline CF30 & 0.00 & 0.06 & 0.28 & 0.19 & 0.01 & 0.00 & 0.04 & 0.38 & 0.00 & 0.05 & 0.28 & 0.00 & 0.27 & 0.00 & 0.09 & 0.04 & 0.21 & 0.52 & 0.05 & 0.00 & 0.06 & 0.20 & & \\
\hline $\mathrm{CF} 31^{6}$ & 0.00 & 0.08 & 0.00 & 0.00 & 0.00 & 0.00 & 0.00 & 0.20 & 0.00 & 0.01 & 0.00 & 0.04 & 0.00 & 0.19 & 0.00 & 0.08 & 0.00 & 0.00 & 0.00 & $0.52^{\mathrm{HS}}$ & 0.05 & 0.13 & 0.00 & \\
\hline CF $34^{J}$ & 0.05 & 0.22 & 0.00 & 0.00 & 0.00 & 0.00 & 0.00 & 0.23 & 0.00 & 0.00 & 0.00 & 0.03 & 0.05 & 0.23 & 0.00 & 0.09 & 0.00 & 0.12 & 0.13 & 0.11 & 0.29 & 0.04 & 0.05 & 0.20 \\
\hline
\end{tabular}

${ }^{1-6}$ male associations (numbers depict respective associates)

juveniles

${ }^{\mathrm{FS}}$ full-siblings $(p>0.8)$ of same age estimate

${ }^{H s}$ paternal half-siblings $(p=1.0)$ of same age estimate 
Table S2 Details on the microsatellite markers used in this study. If not otherwise listed, laboratory protocols were adapted to Vogler et al. (2009). Ranges are given for the number of amplifications run when numbers varied between individuals. Repeatability is given for homozygotes ( $H Z)$ as the proportion of homozygotes confirmed as such.

\begin{tabular}{|c|c|c|c|c|c|c|}
\hline Locus & $\begin{array}{c}\text { Annealing } \\
\text { temperature }\left({ }^{\circ} \mathrm{C}\right)\end{array}$ & $\begin{array}{c}\text { No. } \\
\text { alleles }\end{array}$ & $\begin{array}{l}\mathrm{HZ} \\
\text { rate }\end{array}$ & $\begin{array}{c}\text { No. } \\
\text { amplifications }\end{array}$ & $\begin{array}{c}\text { No. repeated HZ } \\
\text { amplifications }\end{array}$ & Repeatability \\
\hline 41HDZ1 & 61 & 3 & 0.42 & $1-4$ & $2-3$ & 1.0 \\
\hline 41HDZ67 & 55 & 6 & 0.15 & $1-4$ & 2 & 1.0 \\
\hline 41HDZ71 & 55 & 6 & 0.21 & $1-3$ & $1-2$ & 1.0 \\
\hline 41HDZ74 & 63 & 5 & 0.33 & $1-4$ & $1-2$ & 1.0 \\
\hline 41HDZ78 & 62 & 5 & 0.21 & $1-4$ & $2-3$ & 1.0 \\
\hline 41HDZ88 & 61 & 4 & 0.36 & $1-3$ & $1-2$ & 1.0 \\
\hline 41HDZ90 & 62 & 7 & 0.27 & $1-3$ & $1-2$ & 1.0 \\
\hline 41HDZ105 & 55 & 9 & 0.12 & $1-3$ & 1 & 1.0 \\
\hline 41HDZ112 & 55 & 6 & 0.27 & $1-4$ & $1-3$ & 1.0 \\
\hline 41HDZ122 & 57 & 3 & 0.27 & $1-3$ & $1-2$ & 1.0 \\
\hline 41HDZ217 & 58 & 7 & 0.06 & $1-4$ & 2 & 1.0 \\
\hline 41HDZ261 & 54 & 3 & 0.45 & $1-4$ & $2-3$ & 1.0 \\
\hline 41HDZ592 & 54 & 3 & 0.58 & $1-3$ & $1-2$ & 1.0 \\
\hline 41HDZ626 & 53 & 4 & 0.42 & $1-2$ & 1 & 1.0 \\
\hline 41HDZ633 & 53 & 6 & 0.21 & $1-3$ & $1-2$ & 1.0 \\
\hline 41HDZ960 & 57 & 5 & 0.21 & $1-4$ & $1-2$ & 1.0 \\
\hline
\end{tabular}


Appendix III: Tables

Table A1 Model outputs.

(a) Determinants of copulation length (LMM)*

\begin{tabular}{lrrrrr}
\hline & Estimate & SE & df & $t$ & \multicolumn{1}{c}{$P$} \\
\hline Intercept & $\mathbf{3 . 0 0}$ & $\mathbf{0 . 2 3}$ & $\mathbf{8}$ & $\mathbf{1 3 . 2 6 2}$ & $<\mathbf{0 . 0 0 0 1}$ \\
Male body mass 7-9 & 0.02 & 0.24 & 8 & 0.103 & 0.9181 \\
Male body mass $\geq \mathbf{9}$ & $\mathbf{0 . 5 3}$ & $\mathbf{0 . 2 4}$ & $\mathbf{8}$ & $\mathbf{2 . 1 7 3}$ & $\mathbf{0 . 0 3 0 8}$ \\
Termination by rival male $^{\text {Aggression received per approach }}{ }^{2}$ & -0.07 & 0.20 & 8 & -0.326 & 0.7451 \\
\hline
\end{tabular}

(b) Determinants of male monopolisation of mating time ${ }^{\mathrm{z}}(\mathrm{LMM})^{*}$

\begin{tabular}{lrrrrr}
\hline & Estimate & SE & df & $t$ & \multicolumn{1}{c}{$P$} \\
\hline Intercept & -1.45 & 0.21 & 8 & -7.007 & $<0.0001$ \\
Male body mass 7-9 & 0.39 & 0.20 & 8 & 1.997 & 0.0494 \\
Male body mass $\geq 9$ & 0.42 & 0.19 & 8 & 2.250 & 0.0274 \\
Nights mating & 0.55 & 0.09 & 8 & 5.950 & $<0.0001$ \\
Presence during female peak activity & 0.53 & 0.20 & 8 & 2.664 & 0.0095 \\
\hline
\end{tabular}

(c) Determinants of male monopolisation of peak mating time ${ }^{z}(\mathrm{LMM})^{*}$

\begin{tabular}{lrccc}
\hline & Estimate & SE & $t$ & $P$ \\
\hline Intercept & -0.09 & 0.22 & -0.418 & 0.0052 \\
Male body mass 7-9 & 0.70 & 0.30 & 2.323 & 0.6087 \\
Male body mass $\geq 9$ & 0.80 & 0.28 & 2.872 & 0.0039 \\
Aggression received per approach $^{2}$ & -0.37 & 0.12 & -2.976 & 0.2853 \\
\hline
\end{tabular}

(d) Determinants of female aggression ${ }^{2}$ against males (LMM)*

\begin{tabular}{|c|c|c|c|c|c|}
\hline & Estimate & SE & $d f$ & $t$ & $P$ \\
\hline Intercept & -0.42 & 0.11 & 11 & -3.830 & 0.0002 \\
\hline Male body mass 7-9 & 0.04 & 0.13 & 11 & 0.282 & 0.7784 \\
\hline Male body mass $\geq 9$ & 0.53 & 0.12 & 11 & 4.603 & $<0.0001$ \\
\hline No. approaches ${ }^{z}$ & 0.18 & 0.11 & 11 & 1.699 & 0.0909 \\
\hline Female peak activity & 0.02 & 0.13 & 11 & 0.194 & 0.8467 \\
\hline Post female activity & 0.29 & 0.12 & 11 & 2.453 & 0.0151 \\
\hline Male body mass 7-9: no. approaches ${ }^{2}$ & 0.08 & 0.14 & 11 & 0.538 & 0.5915 \\
\hline Male body mass $\geq 9$ : no. approaches ${ }^{2}$ & 0.77 & 0.13 & 11 & 5.972 & $<0.0001$ \\
\hline
\end{tabular}

(e) Determinants of likelihood to receive solicitations (GLMM, binomial regression)*

\begin{tabular}{lrccc}
\hline & Estimate & $S E$ & $z$ & $P$ \\
\hline Intercept & $\mathbf{- 2 . 7 8}$ & $\mathbf{0 . 8 0}$ & $\mathbf{- 3 . 4 7 2}$ & $\mathbf{0 . 0 0 0 5}$ \\
Male body mass $\leq \mathbf{7}$ & $\mathbf{1 . 9 7}$ & $\mathbf{0 . 6 5}$ & $\mathbf{3 . 0 1 4}$ & $\mathbf{0 . 0 0 2 6}$ \\
Male body mass 7-9 & $\mathbf{1 . 3 9}$ & $\mathbf{0 . 6 7}$ & $\mathbf{2 . 0 8 0}$ & $\mathbf{0 . 0 3 7 6}$ \\
Pre period & -0.09 & 0.69 & -0.132 & 0.8947 \\
Post period & 0.71 & 0.62 & 1.155 & 0.2479 \\
\hline
\end{tabular}

\footnotetext{
*Statistically significant predictors are depicted in bold.
}

92 


\section{Appendix III: Figures}

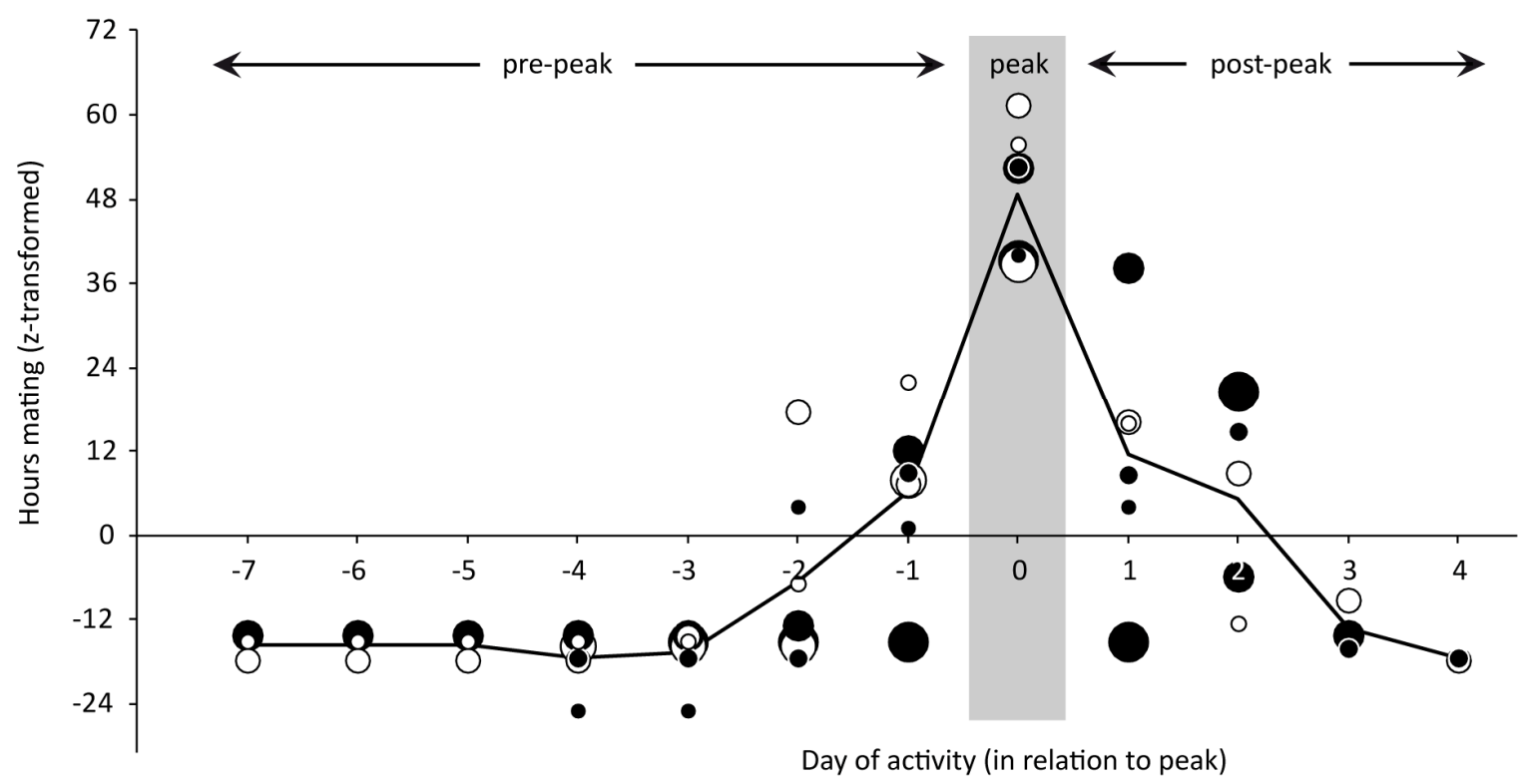

Fig. A1 Development of female mating activity over time. Mating time (in hours) was z-transformed to achieve comparable scale across individuals. Peak in absolute and relative mating activity is shaded in grey. Plotted are the following female-years in order of decreasing circle size (alternating black and white): F1-2007, F2, F1-2008, F3-2008, F3-2009, F4, F5.

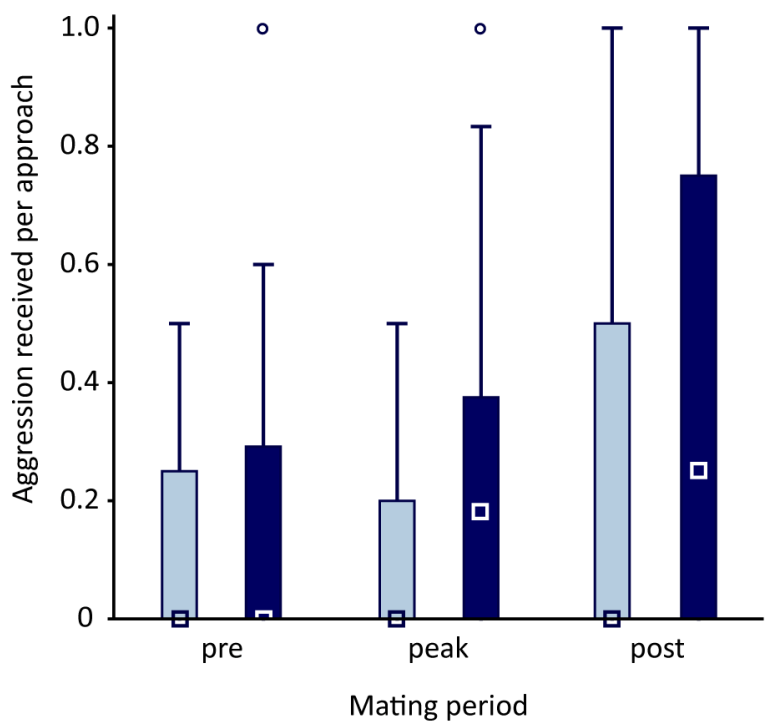

Fig. A2 Relative aggression received from the female by males of different body mass. Males which did not differ from females in body mass and size are shown in light blue, heavier males (> $7 \mathrm{~kg}$ ) are shown in dark blue. Plotted are medians, quartiles (boxes) and range (whiskers) with separated outliers (circles). 


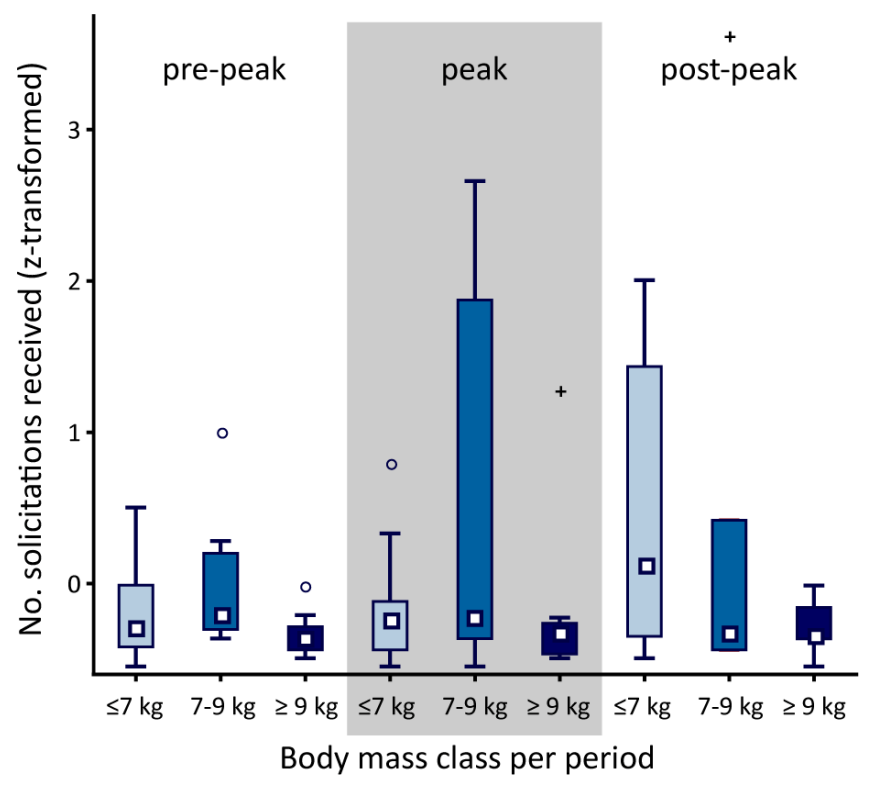

Fig. A3 Solicitations received by males of different body mass during periods of varying female mating activity. Peak mating activity is shaded in grey. Plotted are medians, quartiles (boxes) and range (whiskers) with separated outliers (circles) and extremes (crosses). 
F1

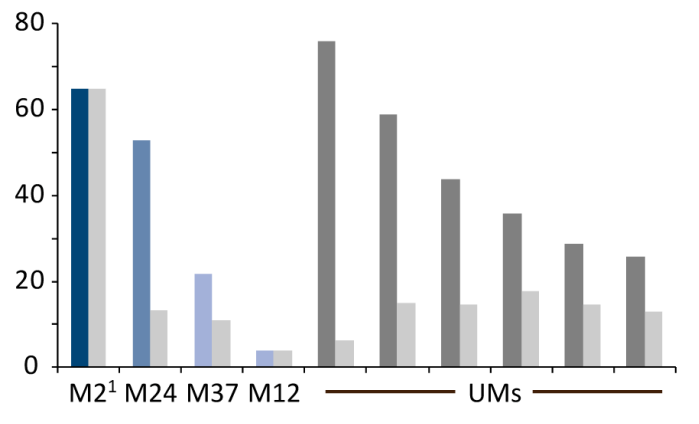

F3

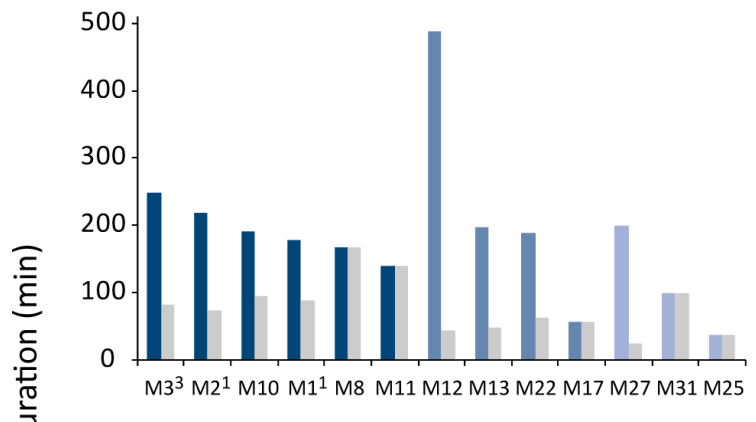

F3

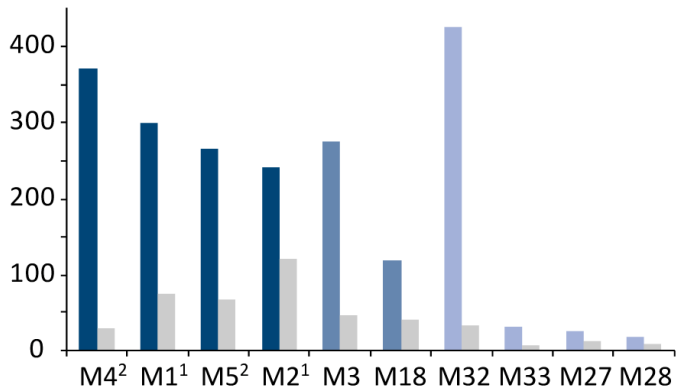

F5

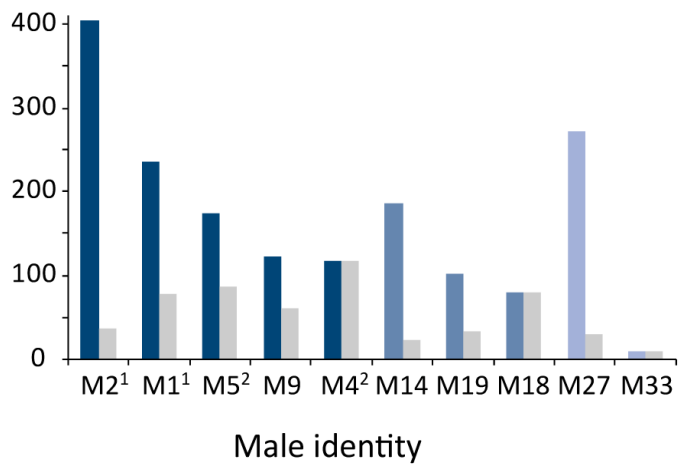

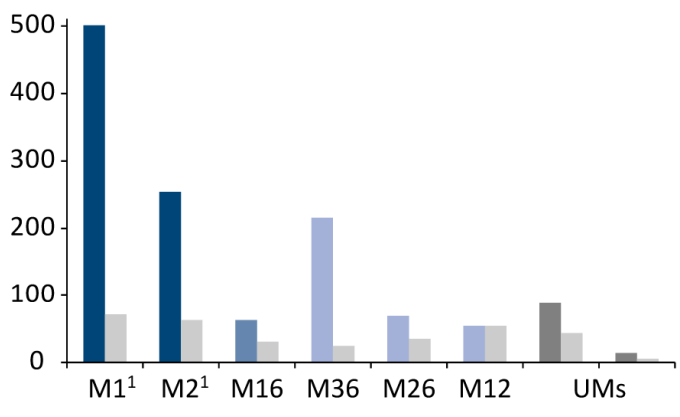

F1

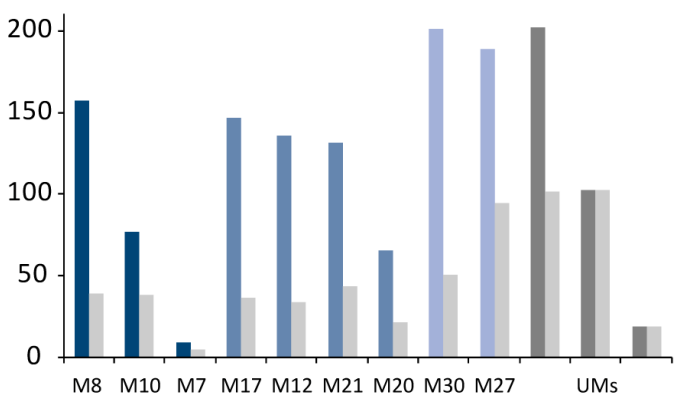

2008

F4

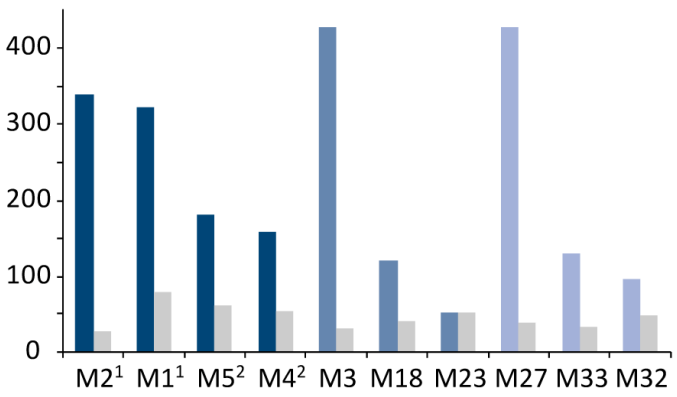

2009

2009

Fig. A4 Individual total (coloured) and average (light grey) monopolisation success per male (M1-M33), female (F1-F5) and year (2007-2009). Males of the heaviest body mass class ( $\geq 9 \mathrm{~kg}$ ) are plotted in dark blue, medium mass males (7-9 kg) in blue and lightest males ( $\leq 7 \mathrm{~kg}$ ) in light blue. Unidentified males ('UMs') with unknown body mass are depicted in dark grey. Superscript numbers denote members of respective male associations. 


\section{Acknowledgments}

I thank my supervisor Peter Kappeler for offering me the unique opportunity to study fosas in Kirindy Forest and his investment in this project as well as for probably the most rapid e-mail responses in the world and for his unwearing efforts to correct my "Denglish". I also thank my co-supervisor Eckhard "Ecki" Heymann for being an inspiring teacher during my studies and for his regular feedback on my work. I am further grateful to the most competent, reliable and knowledgeable field assistant Rémy from Ampataka who not only gave me an indispensable hand in fosa trapping but who also admirably helped me to survive endless nights under fosa mating trees by bravely replacing me in the early morning. Misaotra betsaka! I think, the two of us have learned a lot from each other and I wonder whether the lessons I learned from Rémy were more valuable. Rémy and me, we also enjoyed helpful support from Nelson "Bary" Rabarijaona, Tianasoa "Tina" Andrianjanahary and over the years by all other members of the DPZ field assistance team in Kirindy. Especially Bary had a lot of extra work with the transport and installation of the fosa traps and the installation and surveillance of the stationary GPS base stations, misaotra be! Since these base stations had to be installed on top of trees, our team's most skilled climber Jean-Pierre "JiPa" Tolojanahary was also essentially helpful in the surveillance of the devices. The DPZ camp manager Léonard Razafimanantsoa, Rodin Rasoloarison, Heike Klensang and Peter Kappeler made this study logistically and administratively possible, and I would like to thank Léon in particular for good times in Kirindy and sharing his "carnivore passion". I would also like to thank our amazing kitchen team in Kirindy (Adrien L. N. Rafanjanirinamana, Tatiana "Taty" Luciano and Fanja) for more than just their exemplary cooking and baking efforts but also for carrying out the only part of my field work I was unable to do by myself, namely the many chicken slaughters. The team of the CNFEREF (most notably Cyril, Gregy, Soly, Irène and Martial) was very helpful in detecting fosa mating activity and largely contributed to make my stay in Kirindy sunshiny and unforgettable. The same is of course true for all members of the DPZ field assistance, including MaJeBaTi, Samy, Eliane and Fano in Morondava, and my research colleagues who spent both philosophical and giggly times with me in the field. In this respect, I would like to specifically thank Melanie, Elise, Moritz "Moe", Anna, Anni, Susanne, Sandra and Emma for memorable Kirindy nights. I am grateful to the same colleagues as well as to Conny, Chacka, Henning, Christina, Ulli, Deike and Anja for good times in Göttingen. Anything I have ever understood about statistics (which is admittedly little) I have learned from Conny and Melanie. Melanie also conducted the stable isotope analyses for chapter 3 of this thesis and introduced me to the theory behind it. Christina Oberdieck was a patient help in the laboratory and extracted a subset of DNA replicates for genetic analyses in chapter 3. I am very grateful to Christina for healing me from my lab-o-phobia and for easy-going teamwork in the lab. I would also like to explicitly thank Henning for his general readiness to help with all kinds of computer issues and for regular laughter in the office.

This thesis was made possible in its current form by kind approval and support by the Département de Biologie Animale, Université d'Antananarivo, the Commission Tripartite and the CAFF of the Direction des Eaux et Forêts, the CNFEREF Morondava, the Bundesamt für Naturschutz and the Deutsches Primatenzentrum. Financial support was provided by the Deutsche Forschungsgemeinschaft (DFG, KA 1082/17-1), and additional financial and logistic support was provided by the Fossa Fonds of Zoo Duisburg, NHK and BBC.

My most special thanks go to the three persons who made all this possible from its very beginning on: my parents Heinz-Hermann Lührs and Charlie Lührs and my dearest friend Melanie. My 
parents not only influenced my interest in nature and conservation but they also supported my education continuously despite reasonable doubt concerning my decision to become a biologist. My parents' and all my family's and friends' pride and trust in me made up a substantial part of my undiscourageable motivation. Last but not least, I want to thank Melanie for her constant and benign support in good and in bad times of this thesis and in my life. Melanie had a major influence on my research because she was the best teacher I could imagine and sacrificed a substantial part of her private life to enriching discussions about science. Without you, Melanie, this thesis would have never been possible. Thank you for helping me make a dream come true and for everything there was, there is and there is to come. 


\section{Summary}

Mammalian mating systems are closely related to the social organisation of a species, which in turn is determined by sex-specific selection pressures with respect to access to limited resources. In previous studies of solitary carnivores, mating systems have often been described based on social organisation or molecular evidence alone, due to difficulties of observing mating behaviour in farranging species with low population densities. In the present study, I combined spatial data collected via modern GPS technology with detailed behavioural and genetic data on a solitary carnivore, the fosa (Cryptoprocta ferox). The fosa is a Madagascar mongoose (Eupleridae) of medium size (6-11 kg body mass), which exhibits a unique mating system involving prolonged polyandrous mating activity on traditional mating trees. The main aim of this thesis was to illuminate determinants of this unusual system with a specific focus on the underlying sex-specific reproductive strategies and thereby contributing new insights into our general understanding of the incentives of female polyandry, the operation of pre-copulatory female choice and male competitive tactics as well as the evolution and diversity of mammalian mating systems. Moreover, anecdotal evidence indicated the existence of male associations along with solitary males and females and cooperative hunting behaviour of these male associations. Therefore, a specific focus of this thesis was to investigate the occurrence, patterns and consequences of this rare phenomenon in mammals. By focussing on the interplay of the species' social organisation with male associations and sex-specific mating strategies, I further aimed to draw conclusions on factors driving the evolution of the fosa's social system as a whole.

From 2007 to 2010, I trapped, anaesthetised, sampled and took measurements of 34 fosas (25 males, 9 females) in Kirindy Forest/CNFEREF, Madagascar. Nine males and four females could be partially tracked simultaneously by means of GPS tags embedded in collars, which provided detailed insight into movement patterns, ranging area and degree of sociality of these individuals. To investigate correlates and consequences of male association, I combined body acceleration data obtained from accelerometry-sensors in collars with spatial information of simultaneous tracking and stable isotope analyses of hair samples to indirectly detect the occurrence of cooperative hunting among associates. Furthermore, I used genetic analyses based on 16 variable microsatellite markers to determine relatedness patterns in the population and specifically the degree of relatedness among associated males. During the seasonal mating periods of four successive years, I followed six oestrous females during their complete mating activity, collecting 540 hours of continuous observation including information on 316 copulations on four different mating trees. These data allowed elucidating determinants of male mating success, the degree of polyandry and patterns of female pre-copulatory choice.

This combination of multiple methodological approaches yielded several major results. First, females ranged solitarily and showed indications of territoriality. Males had three times larger ranges $\left(\varnothing 53.1 \mathrm{~km}^{2}\right)$ than females $\left(\varnothing 17.8 \mathrm{~km}^{2}\right)$ and spatially overlapped extensively with females and males. Second, whereas some males ranged solitarily, 10 of 22 adult males trapped were organised in temporally stable associations that were most often composed of littermates (four out of five adult dyads). Third, associated males differed in several characteristics from solitary males; they were (1) $13 \%$ larger and $38 \%$ heavier at comparable age, (2) hunted cooperatively, (3) used larger prey types more often (diurnal lemurs Propithecus verreauxi verreauxi and Eulemur rufifrons), and (4) had higher mating success. Associated males neither defended territories nor exclusive excess to 
oestrous females. Instead, their physical superiority appeared to be of advantage in the termination of matings of rival males. Fourth, females dominated males regardless of their physical dissimilarity and actively sought polyandrous matings. Fifth, females indirectly chose physically superior, i.e. associated males, by enhancing male-male contest and temporally restricted intervention in its outcome. Hence, associated males gained two-fold benefit with respect to male and female mating strategies.

Overall, these results allow four major conclusions concerning the fosa's social organisation and mating system. First, the species' basic social organisation can be characterised as solitary but a high proportion of males forms spatially and temporally synchronised social units. Second, associated males achieve higher body mass and size than solitary individuals, which is most likely fuelled by effective cooperative hunting. Third, male body mass and thereby a male's degree of sociality are major determinants of male mating success. Fourth, concerning the mating system of the fosa, convenience polyandry can be excluded as most likely driver in the system. Instead, this mating system appears to be ultimately explained by a combination of benefits from polyandry and the consequences of different subsistence strategies. This interplay of male sociality and female preference for superior competitors provides an important reference for future socio-ecological research. 


\section{Zusammenfassung}

Die Diversität der Sozialsysteme lässt sich auf die Interaktion von geschlechtsspezifischen Fortpflanzungsstrategien und sozialer Organisation zurückführen, welche ihrerseits durch ökologische Faktoren bestimmt sind. Innerhalb der Säugetiere haben die Raubtiere (Ordnung Carnivora) eine Vielzahl an verschiedenen Sozialsystemen entwickelt. Arten dieser Ordnung sind deshalb besonders geeignet, die Determinanten von Sozialsystemen zu untersuchen. Große Streifgebiete, geringe Populationsdichte und eine vorherrschend solitäre Lebensart haben jedoch bisher direkte detaillierte Untersuchungen erschwert. In der vorliegenden Arbeit habe ich deshalb das Sozialsystem einer solitären Raubtierart, der Fossa (Cryptoprocta ferox), untersucht, welche in der Isolation Madagaskars ein unter Säugetieren einzigartiges Paarungssystem sowie eine seltene Form sozialer Organisation entwickelt hat. Fossas gehören zur endemischen Familie der MadagaskarMangusten (Eupleridae) und werden 6-11 kg schwer. Ihr Paarungssystem zeichnet sich durch auffällig gesteigerte weibliche Promiskuität aus, welche auf traditionellen Paarungsbäumen zu beobachten ist. Das Hauptziel der vorliegenden Arbeit war es, die diesem System zugrundeliegenden Fortpflanzungsstrategien zu verstehen. Dazu habe ich mich auf die mögliche Motivation weiblicher Polyandrie, Muster prä-kopulatorischer Weibchenwahl sowie die Mechanismen von Konkurrenz unter Männchen fokussiert. Bezüglich der sozialen Organisation der Fossa war es ein weiteres Ziel dieser Arbeit, Muster, Determinanten und Konsequenzen von anekdotisch beschriebenen Männchen-Assoziationen empirisch zu untersuchen und damit Rückschlüsse auf die diesem seltenen Phänomen zugrundeliegende evolutionäre Faktoren ziehen zu können.

Die Datenaufnahme erfolgte in fünf mehrmonatigen Feldaufenthalten zwischen 2007 und 2010 in Kirindy/CNFEREF, Madagaskar. Dort habe ich 34 Fossas (25 Männchen, 9 Weibchen) gefangen, betäubt, vermessen und markiert und ihnen Haar- und Gewebeproben entnommen. Neun Männchen und vier Weibchen wurden mit GPS-Halsbändern ausgestattet, welche zum Teil simultan Informationen über Bewegungsmuster, Streifgebietsgröße und Geselligkeit der betreffenden Individuen lieferten. Die Kombination dieser räumlichen Daten mit gleichzeitig gemessener Information zur Beschleunigung des Halsbandes am Tier sowie Nahrungsanalysen anhand stabiler Isotope aus Haarproben erlaubten es erstmals, kooperative Jagd unter assoziierten Männchen indirekt zu quantifizieren. Anhand von 16 polymorphen Mikrosatellitenmarkern bestimmte ich außerdem die verwandtschaftlichen Beziehungen innerhalb der Studienpopulation mit besonderem Fokus auf die Verwandtschaft assoziierter Männchen. Um Paarungsstrategien von Männchen und Weibchen im Detail zu untersuchen, habe ich kontinuierlich die Paarungsaktivität von sechs Weibchen an vier verschiedenen Paarungsbäumen verfolgt und in über 540 Stunden 316 Kopulationen beobachten können. Diese Beobachtungen erlaubten detaillierte Aufschlüsse über die Determinanten des Paarungserfolgs der Männchen, den Grad der Polyandrie sowie über die Mechanismen prä-kopulatorischer Weibchenwahl.

Bezüglich der sozialen Organisation der Fossa zeigt die vorliegende Arbeit, dass Weibchen streng solitär sind und Anzeichen für Territorialität zeigen. Die Streifgebiete von Männchen $(\varnothing 53,1$ $\left.\mathrm{km}^{2}\right)$ sind etwa dreimal so groß wie die der Weibchen $\left(\varnothing 17,8 \mathrm{~km}^{2}\right)$ und weisen ausgeprägte interund intrasexuelle räumliche Überlappung auf. Während manche Männchen ebenfalls solitär leben, bildet etwa die Hälfte der adulten Männchen in der untersuchten Population (10 von 22) zeitlich und räumlich stabile Assoziationen. Diese sozialen Einheiten bestehen aus bis zu drei Tieren, die vorwiegend Wurfgeschwistern sind (4 von 5 Assoziationen). Assoziierte Männchen weisen weiterhin 
bedeutende Unterschiede zu solitären Männchen in Morphologie und Verhalten auf. Im Gegensatz zu solitären Männchen werden sie (1) 13\% größer und 38\% schwerer, (2) jagen kooperativ, (3) jagen vorwiegend große Beutetiere (tagaktive Lemuren Propithecus verreauxi verreauxi und Eulemur rufifrons) und (4) haben größeren Paarungserfolg. Assoziierte Männchen scheinen jedoch kein Territorium zu verteidigen und können den Zugang zu Weibchen nicht monopolisieren. Stattdessen scheint die physische Überlegenheit dieser Männchen besonders bei der Störung der Paarungen anderer Männchen von Vorteil zu sein. Weiterhin hat diese Arbeit gezeigt, dass Weibchen trotz ausgeprägtem Sexualdimorphismus in der Körpergröße im Paarungskontext über alle Männchen dominant sind. Das Paarungsverhalten der Weibchen deutete auf indirekte Präferenz der Weibchen für schwerere und damit assoziierte Männchen hin. Assoziierte Fossa-Männchen sind also sowohl in Hinblick auf Konkurrenz unter Männchen als auch bei der Weibchenwahl bevorteilt.

Insgesamt erlaubt die vorliegende Arbeit vier grundlegende Schlussfolgerungen bezüglich des Sozialsystems der Fossa. (1) Die soziale Organisation der Fossa ist grundlegend solitär mit fakultativer Sozialität unter Männchen. (2) Assoziierte Männchen sind den solitär organisierten Artgenossen körperlich überlegen, was vermutlich auf deren kooperative Jagd zurückzuführen ist. (3) Das Gewicht und damit die Sozialität eines Männchens bestimmt dessen Paarungserfolg. (4) Polyandrie bei Fossas ist nicht das Ergebnis sexueller Repression durch Männchen, sondern scheint vielmehr von dem Interesse der Weibchen an Mehrfachverpaarungen bestimmt zu sein. Eine ultimate Erklärung dieses einzigartigen Paarungssystems scheint also in einer Kombination aus indirekten Vorteilen der Polyandrie und den Folgen männlicher Jagdstrategien begründet zu sein. Die detaillierte Beschreibung der spezifischen Wechselwirkung zwischen Männchen-Sozialität und indirekter Weibchenwahl bei Fossas erweitert damit unser Verständnis über die sozioökologischen Determinanten von Sozialsystemen. 
